\title{
PEERING IN: IMPROVING EXISTING BUILDINGS WITH COLORFUL INCREMENTS
}

\author{
A Thesis \\ presented to \\ the Faculty of California Polytechnic State University, \\ San Luis Obispo
}

\author{
In Partial Fulfillment \\ of the Requirements for the Degree \\ Master of Science in Architecture
}

by

Dáire Heneghan

March 2016 
(C) 2016

Dáire Heneghan

ALL RIGHTS RESERVED 


\section{COMMITTEE MEMBERSHIP}

TITLE:

Peering In: Improving Existing Buildings

with Colorful Increments

AUTHOR:

Dáire Heneghan

DATE SUBMITTED:

March 2016

COMMITTEE CHAIR: $\quad$ Elbert Speidel, MS

Lecturer of Construction Management

COMMITTEE MEMBER: Sandra Stannard, MS

Professor of Architecture

COMMITTEE MEMBER: Clare J. Olsen, MS

Assistant Professor of Architecture 


\section{ABSTRACT \\ Peering In: Improving Existing Buildings with Colorful Increments \\ Dáire Heneghan}

Existing office buildings’ embodied energy, history and culture offer something a newly constructed building cannot. On the other hand, new office buildings' adoption of new technologies and building philosophies offer a range of sustainable efficiencies previously unavailable. Combining these efficiencies with elements that embrace human diversity and wellbeing offer the opportunity to not only mend our existing buildings' deteriorating physical bodies but aid in creating workplaces that promote good physical and mental health.

This project provides recommendation on how an existing high-rise commercial building can incorporate a number of incremental improvements that continually evolve to meet rapidly changing market demands. This design approach allows for ease of installation and modification to meet the needs of the tenants and the building owner.

Keywords: Diversity, Incremental, Sustainable, Prefabrication, Adaptive 


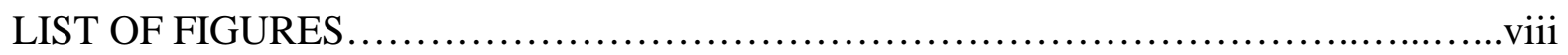

\section{CHAPTER}

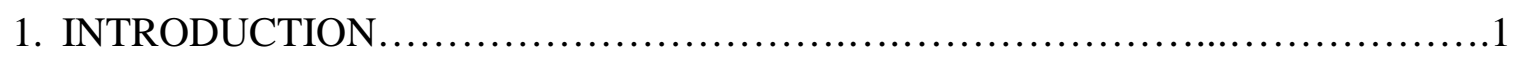

1.1. Problem Statement........................................................ 4

1.2. Obstacles to High Rise Reuse................................................ 5

1.3. Justification for the Study ................................................

2. PRECEDENT STUDIES .................................................... 12

2.1. Adaptive Reuse / Retrofit Facades.............................................12

2.1.1. 680 Folsom Street, San Francisco................................12

2.1.2. 690 Folsom Street, San Francisco......................................16

2.1.3. 185 Post Street, San Francisco......................................21

2.1.4. 100 Van Ness Street, San Francisco.................................23

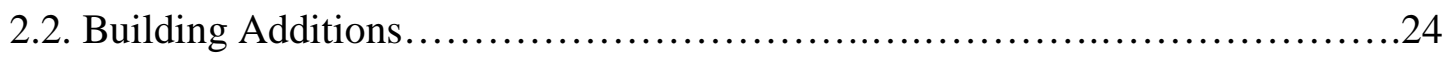

2.2.1. Hands, San Jose and Spectators, Miami..............................24

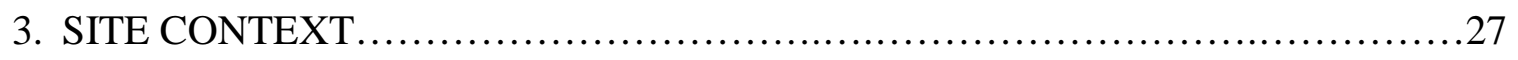

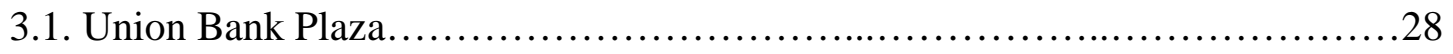

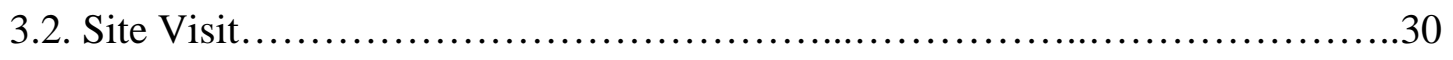

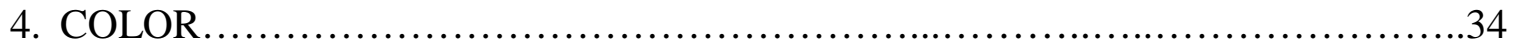

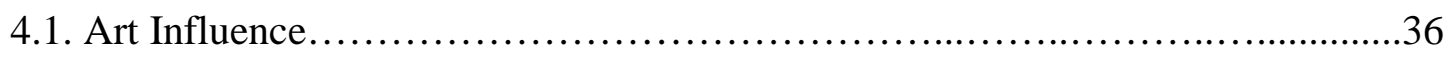

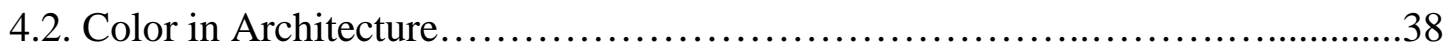


5. Materials.

5.1. Material Selection.................................................49

5.1.1. Minerals and Concrete.........................................49

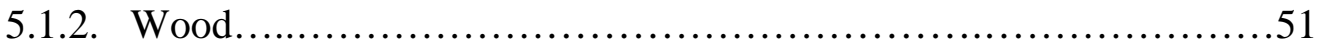

5.1.3. Glass and Plastic...........................................52

5.1.4. Metal............................................................ 54

5.2. Finishes........................................................ 57

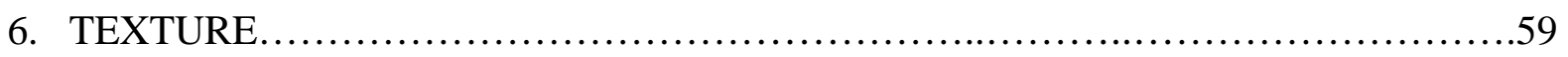

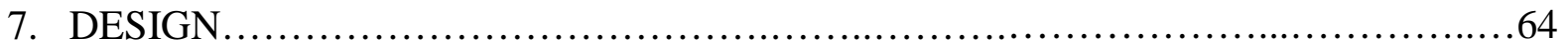

7.1. Integrated Building Envelopes........................................64

7.2. Design Details...................................................68

7.3. Construction.........................................................69

8. CONCLUSION................................................................. 71

8.1. Stakeholders...................................................... 71

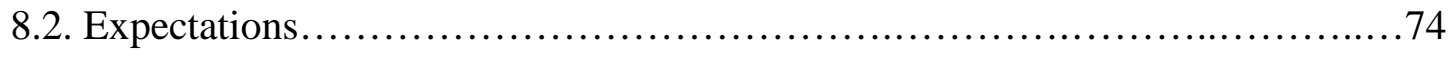

8.3. Design Difficulties................................................. 76

8.4. Building in an Already Built Environment................................77

8.5. Successful Execution............................................... 77

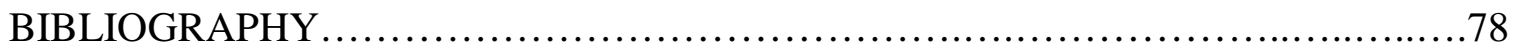

\section{APPENDICES}

A - Peering In Drawings - Sheet 1 to Sheet 11. 
B - Peering In Drawings - Beach House - Sheet 8 to Sheet $9 \ldots \ldots \ldots \ldots \ldots \ldots \ldots \ldots \ldots \ldots . . . . . . \ldots 5$

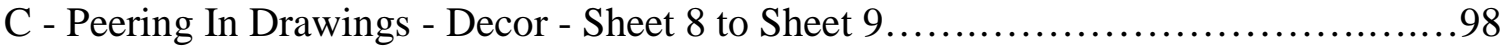

D - Peering In Construction Schedule............................................ 101 


\section{LIST OF FIGURES}

Figure Page

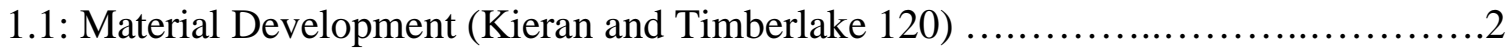

1.2: Abandonment of Traditional Office Space (Gensler, 2012) .......................

1.3: Incremental Upgrades Savings (Gensler, 2012)...............................

1.4: Nancy Wolf's Lost City (Franck 92)......................................11

2.1: 680/690 Folsom Before Renovations (Socketsite, 2015)........................12

2.2: 680 Folsom Building Improvements (ULI, 2015)............................13

2.3: 680/690 Folsom Street Rendering after Renovation (ULI, 2015).................16

2.4: 690 Folsom Street Building at Night (Bloszies, 2015) ........................17

2.5: 690 Folsom Street Day and Night East Elevation (Bloszies, 2015).................18

2.6: 690 Folsom Street Evening East Elevation (Heneghan, 2014).....................18

2.7: 690 Folsom Street Parametric Design Refinement (Bloszies, 2015) ...............19

2.8: 690 Folsom Street Screen Wall Window Feature (Bloszies, 2015).................20

2.9: 690 Folsom Street Construction Details (Bloszies, 2015)......................20

2.10: 185 Post Historical Photo (Architectural Record, 2015)..........................22

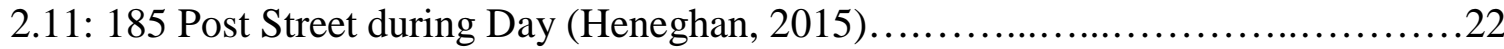

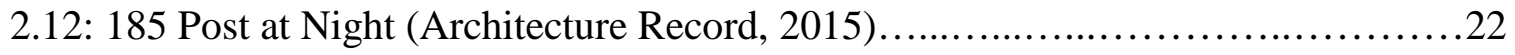

2.13: Progression of Civic Centers Commons Renovation

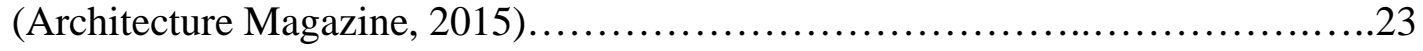

2.14: Civic Centers Commons Crane Attachment (Heneghan, 2015)..................24

2.15: Civic Centers Commons Curtain Wall Aluminum Frame (Heneghan, 2015).......24 
2.16: Hands from a Distance, San Jose International Airport (SEGD, 2015)............25

2.17: Hands near the Garage, San Jose International Airport (Heneghan, 2015)...........26

2.18: Hands within the Garage, San Jose International Airport (Heneghan, 2015)........26

2.19: Spectators, Miami Florida (Moeller, 2015) ..................................26

3.1: NoHo Art District LA (inspirationfeed, 2015)...............................27

3.2: Union Bank Plaza - Front Entry (Heneghan, 2014) ..........................28

3.3: Union Bank Plaza - Front Elevation (Heneghan, 2014)...........................28

3.4: Union Bank Plaza during Construction (Los Angeles Times, 2015)................29

3.5: Union Bank Plaza - Floor Plan 1 (Heneghan, 2014).............................30

3.6: Union Bank Plaza - Floor Plan 2 (Heneghan, 2014)...........................31

3.7: Union Bank Plaza - Glazing Termination Detail (Heneghan, 2014)..................31

3.8: Union Bank Plaza - Safety Cable Tie Off (Heneghan, 2014).......................32

4.1: Joli, Los Angeles (MacGregor, 2015).................................... 35

4.2: Smile South Central, Los Angeles (Shadow Monster Bear, 2015)..................36

4.3: Mural at 420 Boyd Street, LA (Castro et al, 2015).............................

4.4: Sunrise by Claude Monet (Art Factory, 2015)..............................37

4.5: Dull Gray Victorians (Lenclos 81)........................................38

4.6: Colorful Venice Beach (Discover Los Angeles, 2015)........................40

4.7: Pink, Yellow, and Blue Indian Facades (Lenclos 259).........................41

4.8: Yellow, Blue, Pink, and Green Algerian Facades (Lenclos 189)..................41

4.9: Blue-Green and Orange Facades in Guatemala (Lenclos 102)......................42 
4.10: Turquoise and Yellow Facades in Guatemala (Lenclos 101)....................42

4.11: Yellow and Violet Façade (Lenclos 31) ......................................42

4.12: Berlin Police and Fire Station Extension (Sauerbuch Hutton, 2015)...............43

4.13: Color Palette (Design Seeds, 2014).....................................44

4.14: Orange, Yellow and Turquoise (Leibowitz, 2014)..........................45

4.15: Turquoise, Red, and Orange (Hooper, 2015)...............................45

4.16: Orange and Turquoise (Upton, 2015)..................................45

4.17: Purple, Yellow and Blue (Erin Ashley Art, 2015) ..........................46

4.18: Blue, Violet and Orange (Knauff, 2015) ...............................46

4.19: Office Space Window Shades (MechoSystems, 2015)........................46

5.1: Exterior of Nembro Library Expansion, Italy (Ceramic Architectures, 2015)..........50

5.2: Interior of Nembro Library Expansion, Italy (Ceramic Architectures, 2015).........50

5.3: Salk Institute, San Diego (Heneghan, 2015)................................51

5.4: La Defense, Netherlands (UNStudio, 2015) ..............................52

5.5: Nelson-Atkins Museum of Art Extension, Missouri (Steven Holl, 2015) ..............53

5.6: Sarphatistraat Offices, Netherlands (ArchDaily, 2015).........................54

5.7: Nestlé Chile S.A. Cor-Ten Steel Skin (ArchDaily, 2015).........................55

5.8: Construction Benefits of Aluminum (The Aluminum Association, 2015)............56

6.1: Iron Fire Escape in San Francisco (Lenclos, 77) ...............................59

6.2: Walkway at One Workplace Headquarters (Comtemporist, 2015)................60

6.3: 355 11th Street Perforation (ArchDaily, 2015)..............................60 
6.4: Converted 355 11th Street, San Francisco (ArchDaily, 2015) ........................60

6.5: Proposed 355 11th Street Conversion, San Francisco (ArchDaily, 2015)...............61

6.6: Roskilde Incinerator Perforated Aluminum Façade (Dezeen Magazine, 2015).......61

6.7: Campus Netwerk Exterior Façade (Dezeen Magazine, 2015)...........................62

6.8: Experiments in Porosity (Ponoko, 2015).........................................62

6.9: Vanke City Center Sales Gallery Project (ArchDaily, 2015)........................63

7.1: Integrated Façade (Knaack et al 36)..............................................66

7.2: Hot Black Roof versus Cool White Roof (AutoDesk, 2015)..........................67 


\section{Introduction}

Post World War II economic expansion, referred to as the Golden Age of Capitalism, was a period of economic prosperity during the mid-twentieth century that resulted in the rapid development of commercial high rise buildings in United States metropolitan areas. The G.I. Bill’s financial support of educational programs for veterans acted as a catalyst to this urban expansion through the provision of a well-educated workforce. These educated veterans moved to cities in search of higher paying jobs.

Significant events that occurred during the twentieth century in the United States which led to the rise of commercial buildings included: increased value of land in major United States cities driven by land scarcity and substantial commercial growth (Beckmann and Bowles 200), a sweeping revolution in architectural design that rejected the use of historic styles including the adoption of the rationalist thinking of Louis Sullivan who promoted a hierarchy of form following function (Sykes 110), widespread acceptance in the United States of the structural frame method that allowed buildings to reach new heights through a faster, stronger and more cost effective construction methods (Rostron 26, Murray 12), the use and continuous refinement of steel as the material of choice for structural frames which is lighter and stronger than its nineteenth century predecessor iron (Foulks 139), a shift in structural design procedures from the rules-of-thumb method that designed based upon experience to a scientific testing method that helped determining more accurate member sizes (Beckmann and Bowles 31), the appearance of the automatic passenger elevator in the 1930s transformed less sought after upper floors to the most desired spaces due to ease of access and views (Weston 104), and the rapid explosion of new building materials available for use as outlined by Figure 1.1. 


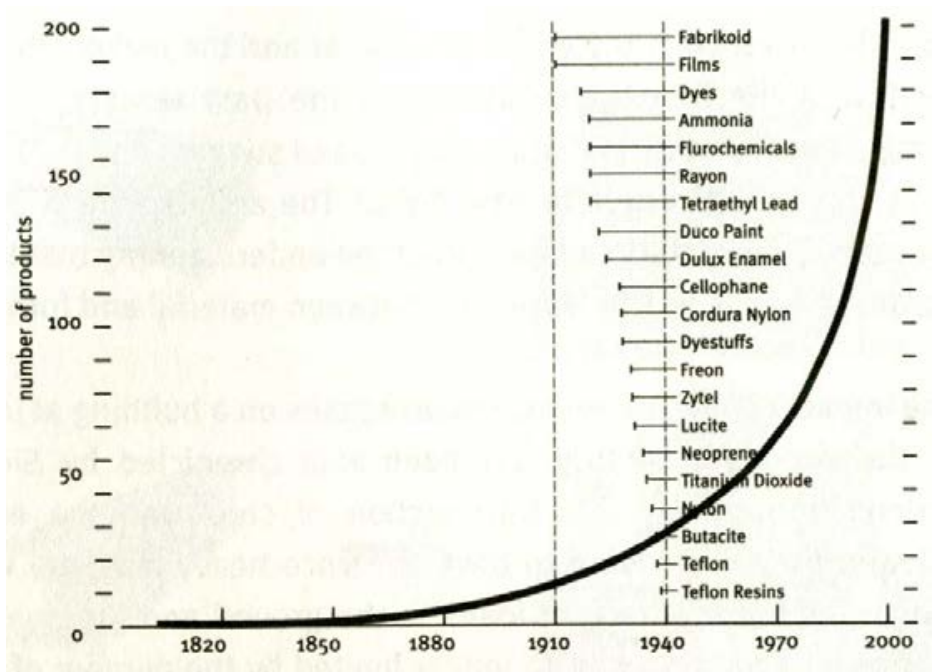

Figure 1.1: Material Development (Kieran and Timberlake 120)

These events aided in the creation and refinement of the curtain wall. The curtain wall system redistribution the primary structure’s weight away from the exterior envelop. This redistribution of weight allows for more dynamic lightweight cladding systems to be employed for building facades. Ludwig Mies van der Rohe called this "Skin and Bones” architecture (Weston 99). While a number of these developments where occurring around the world, no other country had the same level of ambition to push the boundaries of the commercial building as the United States. The group of architects that became known as the Chicago School are an example of those in North America who fostered the acceptance of the new structural frame through an era of experimentation in the 1880s and 1890s.

The towering high-rise office buildings, that defined this mid-twentieth century era of expansion, are now falling into disrepair as the programmatic requirements of the traditional commercial space have fallen out of favor. Key factors including digital advancement and globalization have led to this the deterioration of the high rise commercial typology. 
The digital age is transforming work life and its supporting architecture. The widespread availability of the internet supported by network infrastructure improvements, affordability of computers and other mobile devices are allowing employees to complete tasks from remote locations. Telecommuting employees reduce office space overhead and help increase levels of production due to a rise in quality of life for employees who are not confined to a desk and office cubicle for eight or more hours a day. Figure 1.2 displays this abandonment of the traditional office at an accelerated rate since the 1970s.

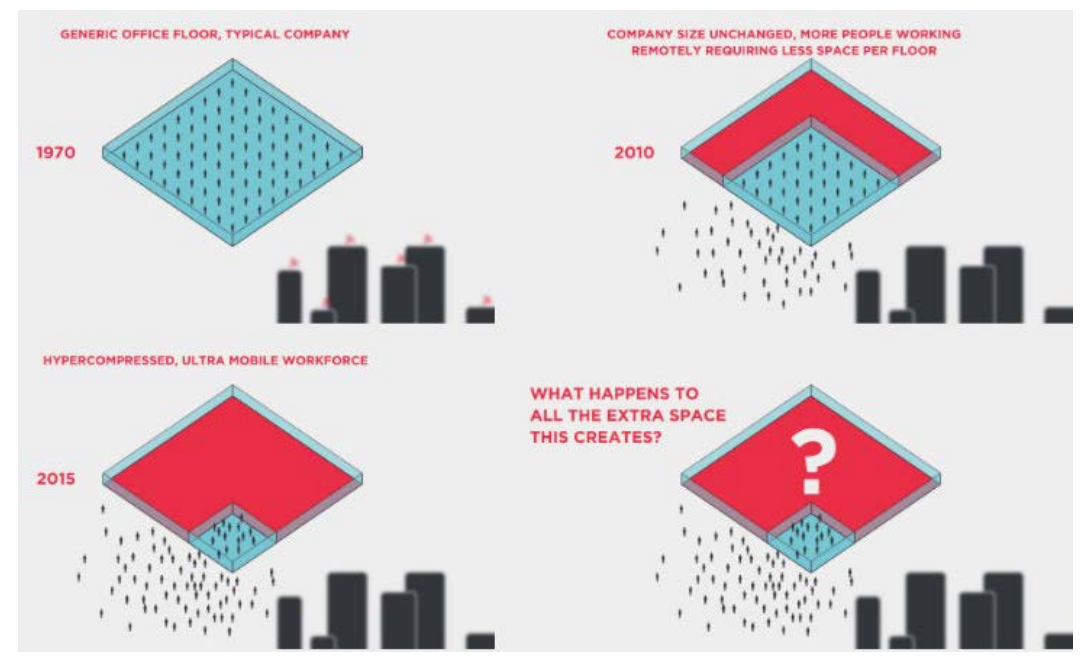

Figure 1.2: Abandonment of Traditional Office Space (Gensler, 2012)

This mobility has allowed the majority of employees who used to work within generic office cubicles for the duration of the day to escape the confines of the traditional office space. No longer are they confined to a life of mediocracy where only the few and fortunate were provided with larger perimeter offices. This hierarchy and confinement has called the traditional office space into question, offering adaptive reuse projects the opportunity to bring spatial, technological and social needs into consideration for all (Martin, 2014). Jones Lange LaSalle stated on their website (JLL, 2015) that a Wall Street Journal article published on the sixth of July 2015 stated that even though the office market has recovered to its prerecession employment levels it is slow to reach the market peak of 
2007. Analysts attribute this slow growth to the fact that employers are pushing for denser space and doing away with private offices and large cubicles associated with the more tradition office space.

Globalization has aided in the creation of a world economy that is evolving with greater speed than ever before. Ease of access of information through the use of the internet and a reduction of trade barriers by organizations like, the World Trade Organization, have been central to this evolution. Commercial businesses in the United States are continuing to be innovative and are adapting to meet the needs of new market trends. The willingness to change with the times is echoed by the growth in demand for commercial real estate in the United States marketplace since the Great Recession. Jones Lang LaSalle’s online Office Property Clock tool reflects this market growth. In Los Angeles the growing tenant demand for office space and improving local economy is reducing vacancy rates and pushing rental values up for landlords (JLL, 2015).

\subsection{Problem Statement}

Converting traditional mid-twentieth century commercial buildings through the practice of adaptive reuse can preserve the cultural and historic importance of icons, while being less costly and time intensive than demolishing whole existing high-rises as displayed by Figure 1.3. Furthermore, smaller incremental improvements to an existing mid-century high-rise building reduce upfront costs, reduce the potential risk of rejection of the new space, and allow the space to be built faster to meet new market demands. 


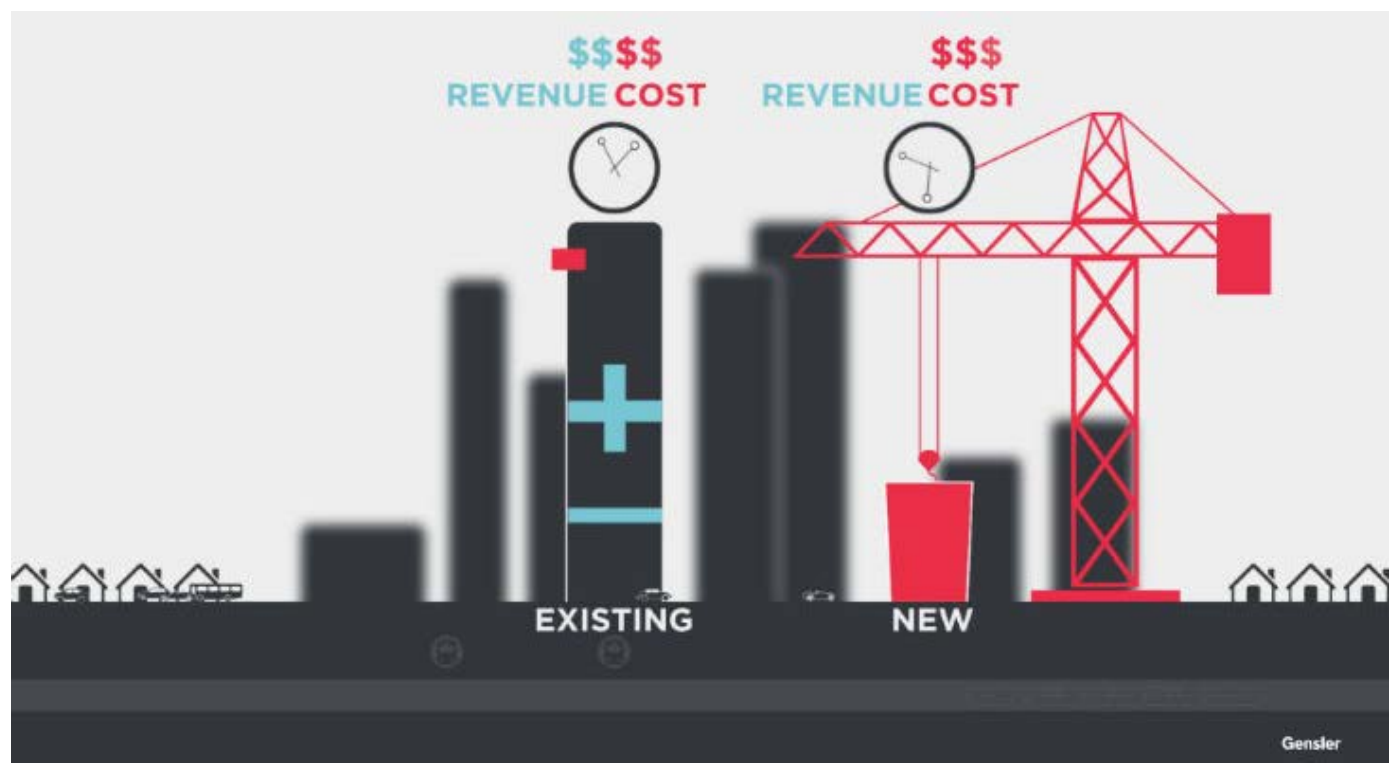

Figure 1.3: Incremental Upgrades Savings (Gensler, 2012)

This thesis project, called Peering In, focuses on developing a modular building system that can be installed easily in increments, improves building energy performance, is cost effective, and adaptable but most importantly enhances the quality of the space for users within.

The building selected for the focus of this project is Union Bank Plaza located downtown in the City of Los Angeles. This building possesses a number of the typical characteristics of the mid-century office building that are falling out of favor. The building's facade was the perfect element to focus the project on since its conversion would not only allow all the goals noted above to be achieved but it would create an external beauty. Adapting the facade would help redefine the building to the outside world as not being the typical office building, while improving the quality of the space for its occupants.

\subsection{Obstacles to High Rise Reuse}

The motto "Reduce. Reuse. Recycle." is central to the sustainable building movement in the United States. Lack of intent to follow these core principles in previous 
years and in less developed countries has proven destructive. The design and construction of forthcoming projects play a critical role in the fight to preserve our environment. Therefore, projects that reuse existing structures offer greater merit, since they are less wasteful then newly constructed projects. Greater degrees of complexity in design and construction combined with a cultural norm of throwing away versus reducing, reusing and recycling are hampering adaptive reuse projects. There are numerous potential risks involved with building reuse projects in Los Angeles with respect to existing condition of a premises including:

- Removal of hazardous material, including asbestos

- Restoration of deteriorating waterproofing membranes or building envelops

- Seismically upgrading existing building structures for life safety

- Replacing or integrating with outdated mechanical, electrical and plumbing systems; especially as they relate to meeting the capacity requirements of new more demanding 2013 Title 24 energy conservation requirements

- Accessing design and construction documentation from the initial build and follow-up renovations, including maintenance work documentation

- The risk of discovering unforeseen obstacles not documented or existing code deficits not corrected

- Lack of maintenance leading to the wear and tear of building components

Refining the Union Bank Plaza project design to meet key requirements set out by the California Building Code, The City of Los Angeles Department of Building and Safety requirements as well as building owner regulation will be a huge challenge. Private and public sector professionals that would be involved in designing and building such a project 
would be tested to tackle questions that go beyond the standard tenant improvement project. These standard tenant improvement projects focus on converting interior office space while leaving the exterior building envelop intact. This study's main goal differs since it aims to develop incremental improvements that primarily impact the façade of the building, which in turn will tie into the overall building context. Tenant improvement projects are typically interior upgrades made by a tenant who plans to lease an office or industrial space, while a building owner referred to as the landlord is typically responsible for core building upgrades and exterior improvements. Creating a well-rounded solution that meets the requirements of the building owner, tenant and Los Angeles Building Department is a risk that many developers may steer away from until others have proven that the risk is justified through successful precedents. Peering In aims to lead the way in the development of an incremental façade improvement system for other projects to follow.

It will be a huge challenge to modify the Union Bank Plaza's facade in a sustainable cost-effective fashion to meet client's needs while meeting the intent of the proposed design. The success of the project will be greatly dependent on the practice of incremental improvements. Smaller more realistic tenant improvement projects that are portions of the overall proposed design can be undertaken through the process of phased construction. This approach will reduce the upfront cost and risk associated with rejection of these unique types of upgrades while leaving space for design refinement for future phases once user feedback is obtained.

\subsection{Justification for the Study}

The initial focus of this study was to design a connection that would allow a prefabricated façade system to be connected to an existing commercial building's primary 
structure during a renovation. The issue of connecting prefabricated façade sections to an existing structure is not only an issue for the Union Bank Plaza, but is a prevalent concern for a large number of adaptive reuse projects, since providing customizable prefabricated components that negotiate varying existing conditions is a huge challenge. The 680 Folsom Street precedent study indicated that this issue of connection is being overcome through the alteration of facade connections based upon field investigation and testing, as outlined in the interview conducted with design team members who worked on the 680 Folsom Street renovation (Boswell and Takada, 2014).

Further research led to the discovery of the range of building functions that are influenced by its façade and the potential this project has to impact multiple building functions positively through the integration of a new screen wall system with the existing building's facade. The functions of the building envelop are vast; including acting as the barrier that controls ventilation and natural light that enters the space, protecting its occupancy from the outside weather, and sets the tone of the space for those that view the building from its exterior, while providing views of the outside world for its occupancy. These elements are central to the building's energy use since heating, cooling and lighting of a space are all large consumers of electricity and are impacted by the interaction between interior and exterior space. The building envelop was used to bear a large portion of a building's weight, but the development of the curtain wall over the last century has allowed a building's primary structure to be supported from within (Brookes and Mejis 147). The development of the curtain wall has led to the creation of a dynamic envelop that can focus its attention on creating a more habitable interior environment. 
Sustainability, mobility of workers, and speed to market are obviously important elements to the success of modern commercial buildouts. While Peering In's design recognizes these factors as central to the success of the overall project, this project also considers tying new world cultural in with the old as critical to the project's success. The Boston architect, Graham Gund recognized the importance of integrating new buildings in with the old by stating, "A city should be a mix of old and new; the new should be used to stitch together the old, to create spaces that bring people together” (Diamonstein 20). The addition of perforated screen walls and interconnecting floors can help achieve this goal of merging cultures by breaking up the uniformity for occupants and passersby.

The Union Bank Plaza building's design has clearly been influenced by the International Style that was developed in the 1920s and 1930s. This architectural style is associated with the striping away of ornamentation and decoration, open interior space, and light plane surfaces (Britannica, 2014). The critics of this style call it inhuman and sterile. Critical Regionalism was coined by Alexander Tzonis in 1981 in the essay The Grid and the Pathway as an architectural style that aimed to find balance between the International Style that focused on a universal modernist style and Regionalism that aimed to immerse a design in local vernacular elements (Canizaro 140).

The rich local mixed demographic and Los Angeles's worldwide exposure, thanks largely to its massive creative industry, calls for personable displays to be intertwined into the existing uniform building design. Such a feat could be accomplished in a cost effective manner by integrating colorful new screen walls into the face of the existing building envelope that embrace local culture. These screens will attract the curious while breaking 
up the repetitiveness of the interior space for its occupants. These elements will also function as reducers of building solar gain and glare.

The ultimate acceptance of the proposed project by a developer will be driven by the acceptance of this new design approach by people who would be willing to pay a premium to lease the space. Greater opportunity exists in attracting occupancies into these mid-twentieth century commercial building at a higher premium if visual cues of the new life within can be provided to passersby. The common practice of preserving an entire building's façade while converting its interior is known as Facadism. This practice restricts not only the visual cues offered by replacing select sections of façade, but it limits the opportunities a new space has within the building to benefit from a new integrated façade. A large number of older buildings that have their façade’s preserved do not possess the same opportunities as the mid-twentieth century commercial building, since they are greatly dependent on their exterior loadbearing walls. The Union Bank Plaza like many other mid-twentieth century commercial buildings have loadbearing columns, beams and slabs along the buildings perimeter that allow for a dynamic curtain wall system to used. The façade has opportunities to span in front of, infill, or to be set back from these supporting elements.

Nancy Wolf's drawing Lost City (Figure 1.6) visually argues the point that something of great importance is being lost if older buildings are just replace by new ones. Adapting buildings will extend the lifespan of our existing stock, which will help protect the rich heritage that is rooted in a vast range of architectural styles from different periods. This approach of adaption offers greater historic and cultural context that will inspire a more diverse future. 


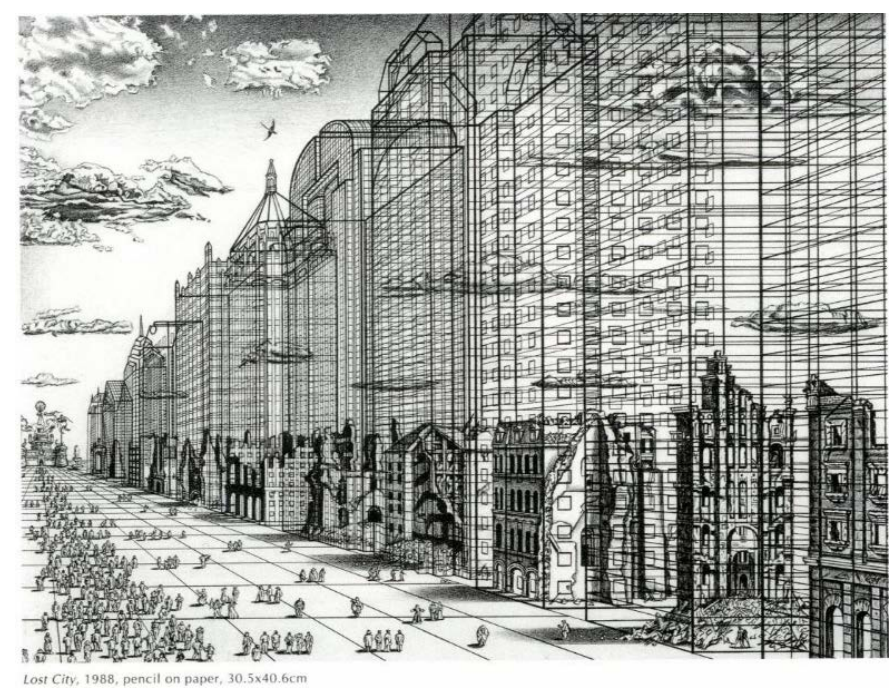

Figure 1.4: Nancy Wolf's Lost City (Franck 92)

The Union Bank Plaza building was the ideal choice for the Peering In project; it once was an icon since it stood as the tallest building in Los Angeles in 1968, it is easily accessible from San Luis Obispo for a site visit, and it has numerous similarities in function to high-rise commercial buildings built throughout the United States during the mid-twenty century. 


\section{Precedent Studies}

Numerous precedents were studied to aid in the creation of a design that works for the proposed application. Each precedent was visited with the exception of Spectators in Miami. Numerous designers were interviewed to help the author not only learn more about the precedents but to gain insist into how the success of these projects can aid the Peering In design. Quality publications accessed through the Cal Poly library and via the internet allowed for further insight into building designs both national and international. The review of these other projects are interlaced into further chapters on texture, material and color.

\subsection{Adaptive Reuse / Retrofit Facades}

There are numerous existing buildings that have fallen out of favor due to poor preference and lack of demand for the traditional function. The revival of four commercial buildings in San Francisco through the undertaking of large renovations is outlined in this section. 680 Folsom, 690 Folsom, 185 Post and 100 Van Ness were all visited to gain a greater understanding of the surrounding areas’ context.

\subsubsection{Folsom Street, San Francisco}

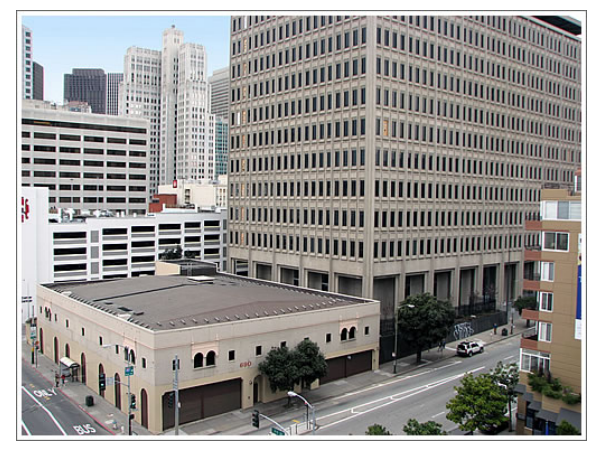

Figure 2.1: 680/690 Folsom Before Renovations (Socketsite, 2015)

680 Folsom originally was a 12-story heavyset concrete clad office building that was built in 1964 (Figure 2.1). It housed a corporate office for Pacific Bell but in 2007 the 
building became obsolete. The building required a facelift and major interior makeover that included asbestos removal and a structural upgrade.

Boston Properties purchased the property in 2008 and invested in a bold makeover that started by demolishing all except for the existing steel frame. The replacement of the concrete facade with a glass curtain wall, addition of horizontals, and the addition of an extra two floors were the largest visible changes made to the building exterior. Inside a new building core was built to make the structure more seismically sound. These improvements were complete in early 2014 and are noted on Figure 2.2. Figure 2.3 provides a rendering of the optimized building.

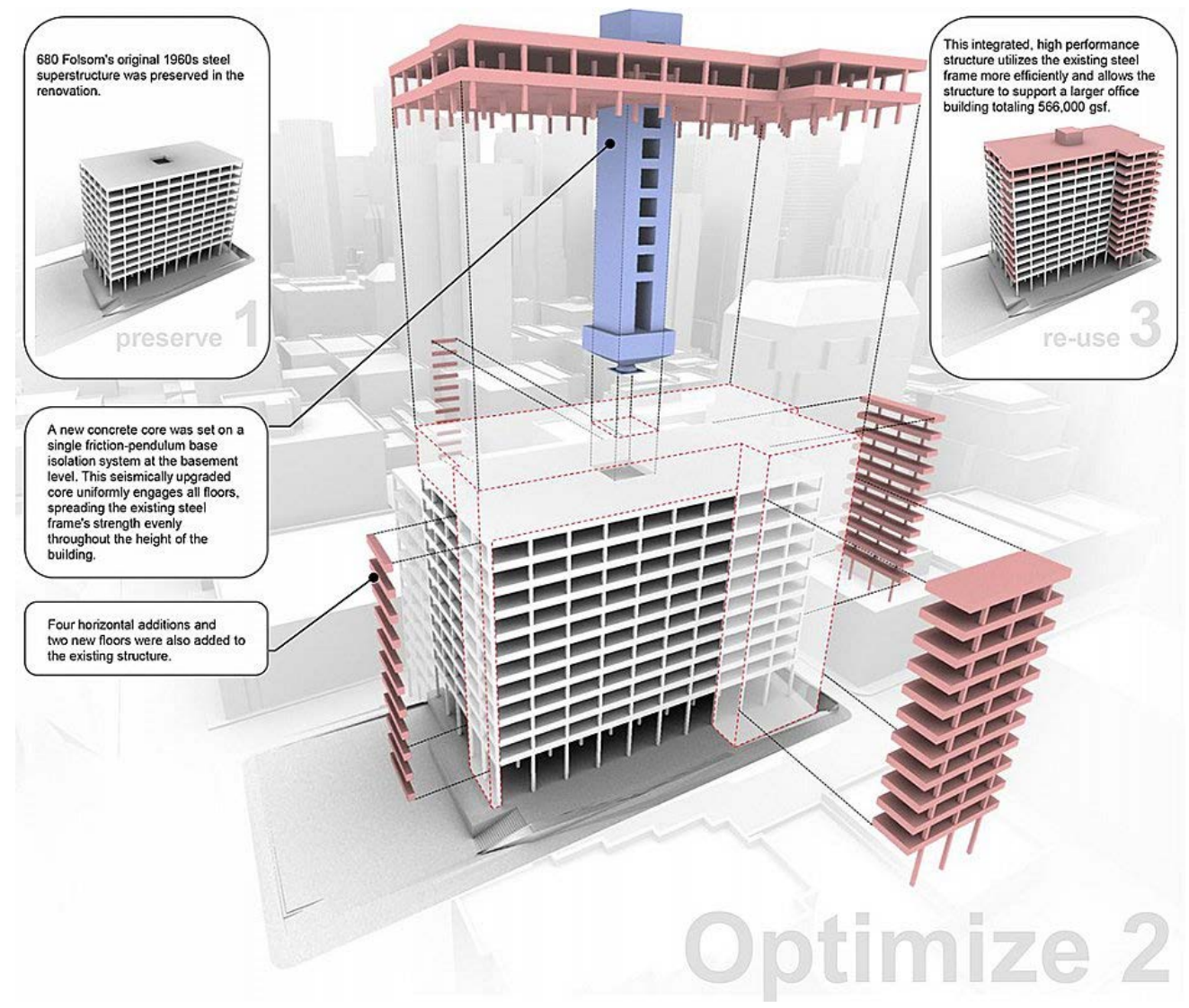

Figure 2.2: 680 Folsom Building Improvements (ULI, 2015) 
An interview was conducted with the world-renowned architecture and engineering design firm Skidmore, Owings \& Merrill LLP (SOM) on the second of May 2014. SOM oversaw the architectural design of the 680 Folsom Street conversion project. The interview was with SOM's Technical Director Keith Boswell and SOM's Technical Designer Yoko Takada who oversaw the building design. The interview between the author, Keith and Yoko is paraphrased below.

Question: Were there unique challenges that you faced in designing a facade that replaced the existing 1960's concrete shell that you typically do not face when designing a new building?

Response: Retaining a large portion of the existing building and reusing it to attach the new curtain wall system was a distinct challenge. Once the existing concrete facade was removed, investigation into the existing condition of the slab was conducted. This investigation enabled designers to develop appropriate methods and locations for curtain wall attachments. The deterioration of the existing structure and greater consideration for wind and seismic loads demanded extensive field testing (Boswell, 2014).

Question: Does the existing slab have a steel component that was welded to for curtain wall connections or was a renovation required were bolting and epoxying of steel plates to the edge of each slab required?

Response: Curtain wall anchors were welded to existing steel angles along the edge of the slab. A lot of testing was conducted to determine the loads that the existing structure could support at points along the slab edge. This investigation aided in the determination of the required anchorage (Boswell, 2014). 
Question: The typical curtain wall units installed are 6'-0" x 15'-0" in dimension. Where do these units break in relation to the slab edge since 15'-0" seems too tall for bottom and top connections for a single floor and too short to span two floors?

Response: Vertical framing members use gravity connections that are located around 1'-0" down from the top of units. Two top connection hold the majority of the gravity load for each unit. At the bottom of units, there is an interlocking detail that helps counteract the lateral load of wind. This detail runs continuous along the bottom horizontal connection plane (Takada, 2014).

Question: Were there a number of alternate facade design ideas considered during project design? If so, what were some of the pros and cons of these alternates?

Response: Creating a contemporary space for occupants and passersby was a primarily design goal. This lead to a design that leaned towards an aluminum system. Using a curtain wall system that took advantage of the modern advances and higher quality associated with prefabrication supported this intent (Boswell, 2014).

Question: Were multiple curtain wall systems used for the facade design?

Response: The majority of the building has a facade made up of curtain wall 6'-0" x 15'-0" units but some areas used a 6'-0" x 20"-0" unitized system. The use of a standardized system helped cut costs and reduced the number of alternate weatherproofing details (Takada, 2014).

Question: Where there any special conditions regarding waterproofing?

Response: A great deal of care was provided when detailing the transition between the curtain wall and the roof. For both new and renovated buildings, water intrusion at this joint is a common issue. A flashing system was used at this joint to bridge the gap between 
systems while a secondary roof coping system was used to reinforce the primary system. Jogs in the building facade created greater complexity in waterproofing details. Therefore, special attention was paid to the transition between the enclosure and the ground level (Boswell, 2014).

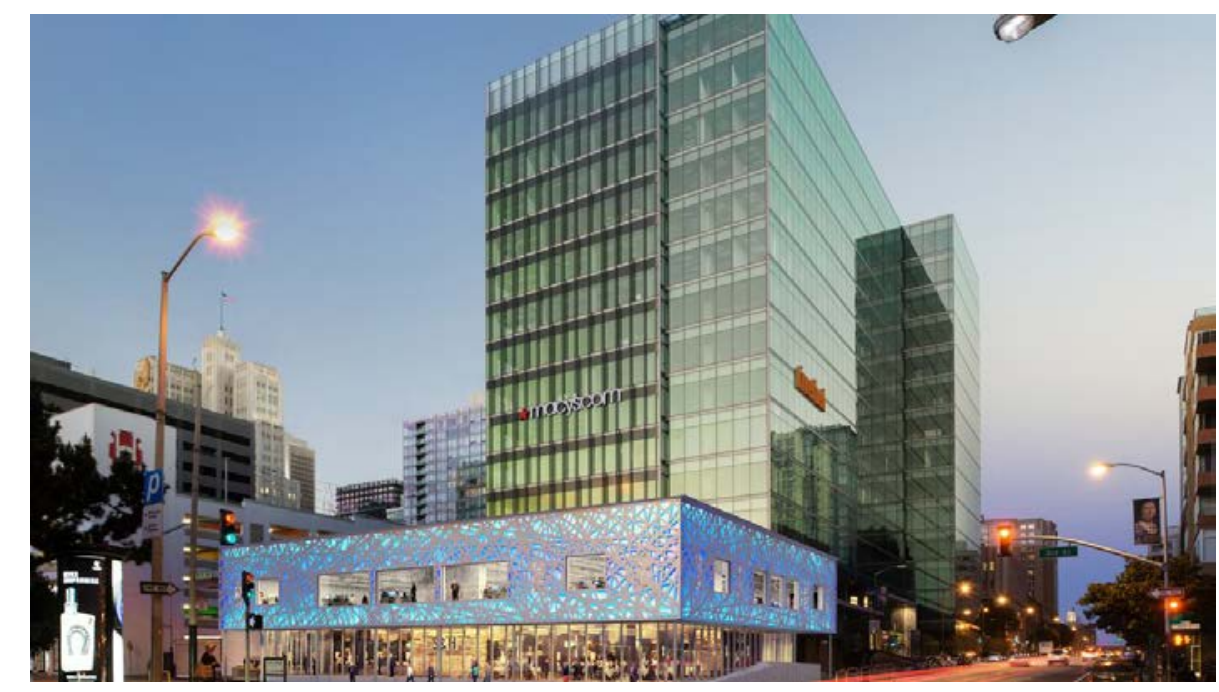

Figure 2.3: 680/690 Folsom Street Rendering after Renovation (ULI, 2015)

\subsubsection{Folsom Street, San Francisco}

When Charles F. Bloszies's office was contacted by the author of this project to gather insist into its design, not only did Charles Bloszies offer to meet with the author on the twenty-ninth of May 2015 but he invited firm Associate Allie Roberson to the meeting. Allie was heavily involved in the creation of the parametric screen design. Bloszies and Roberson provided further insight into the 690 Folsom Street design and offered recommendations into how the author could successfully design a screen wall system for the Peering In project. This project proves that adding a screen wall system to the exterior of standard stucco finished wall can be powerful. 




Figure 2.4: 690 Folsom Street Building at Night (Bloszies, 2015)

The smaller 690 Folsom Street structure in the foreground of Figure 2.1 was an abandoned park garage that was built in 1926. It was repurposed to not only serve as a commercial space but to act as a beacon (Figure 2.4) within the South of Market district for the owner of the newly renovated 680 Folsom Street tower. This was achieved primarily through the incorporation of a striking backlit metal screen. Modern digital tools allowed the architectural firm Charles F. Bloszies to create a uniquely intricate metal screen pattern through the use of the Rhino plug-in Grasshopper. This software drove computer numerically controlled (CNC) machines to create the screen that drapes the second floor of the building. The LED lighting element enriches the screen at night with colors that change bi-weekly and for special events. Furthermore, the lower floor's glass façade and slender steel columns give the structure a feeling of weightlessness (Bloszies, 2015). 

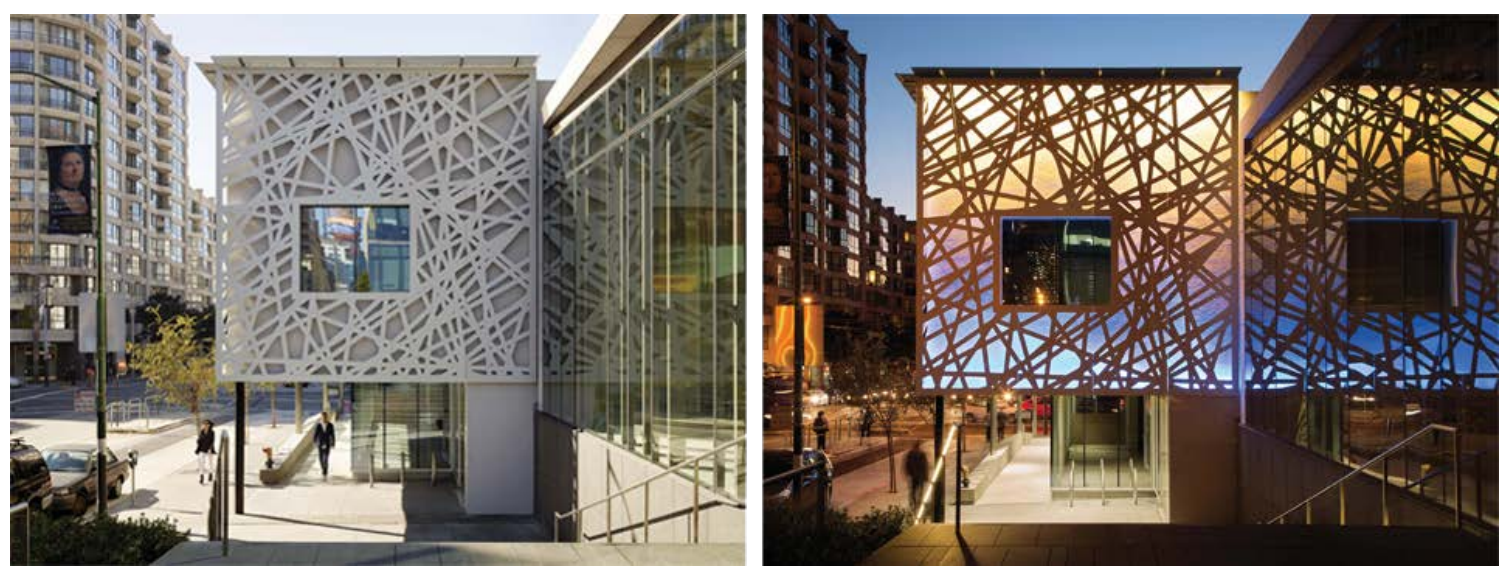

Figure 2.5: 690 Folsom Street Day and Night East Elevation (Bloszies, 2015)

Figure 2.5 shows how the building's east facade transforms from a subtle white palette during the day to a vibrant colorful nighttime display. The author captured the transformation of the façade one evening shortly after the lighting was turned on when the sun began to set at displayed by Figure 2.6. This photo highlights the fact that elimination of sunlight amplifies the nighttime display by reducing natural light pollution.

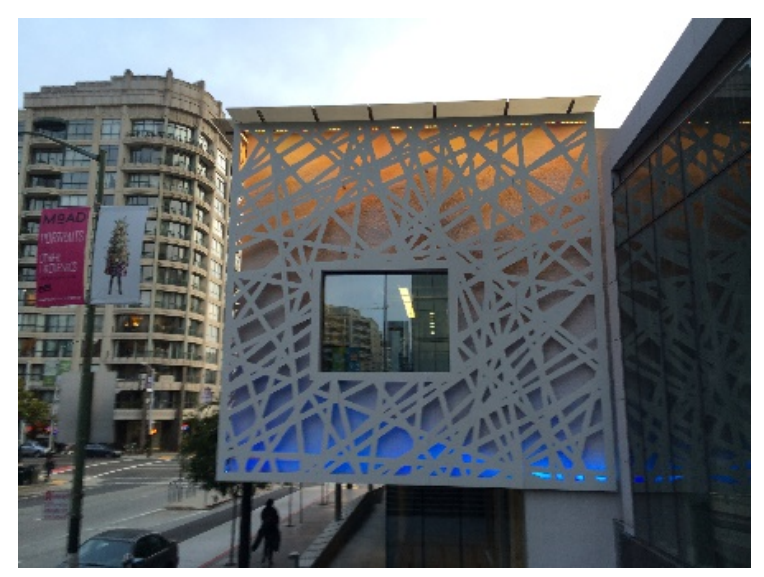

Figure 2.6: 690 Folsom Street Evening East Elevation (Heneghan, 2014)

Modern digital tools are used frequently to create parametric building models but rarely do this parametric models become a reality. The parameters that led to the creation of the complex screen geometry have been reinforced by adding elements to the system. 
These added members helped eliminate large undesirable openings and helped mitigate structural and manufacturer problems (Figure 2.7).

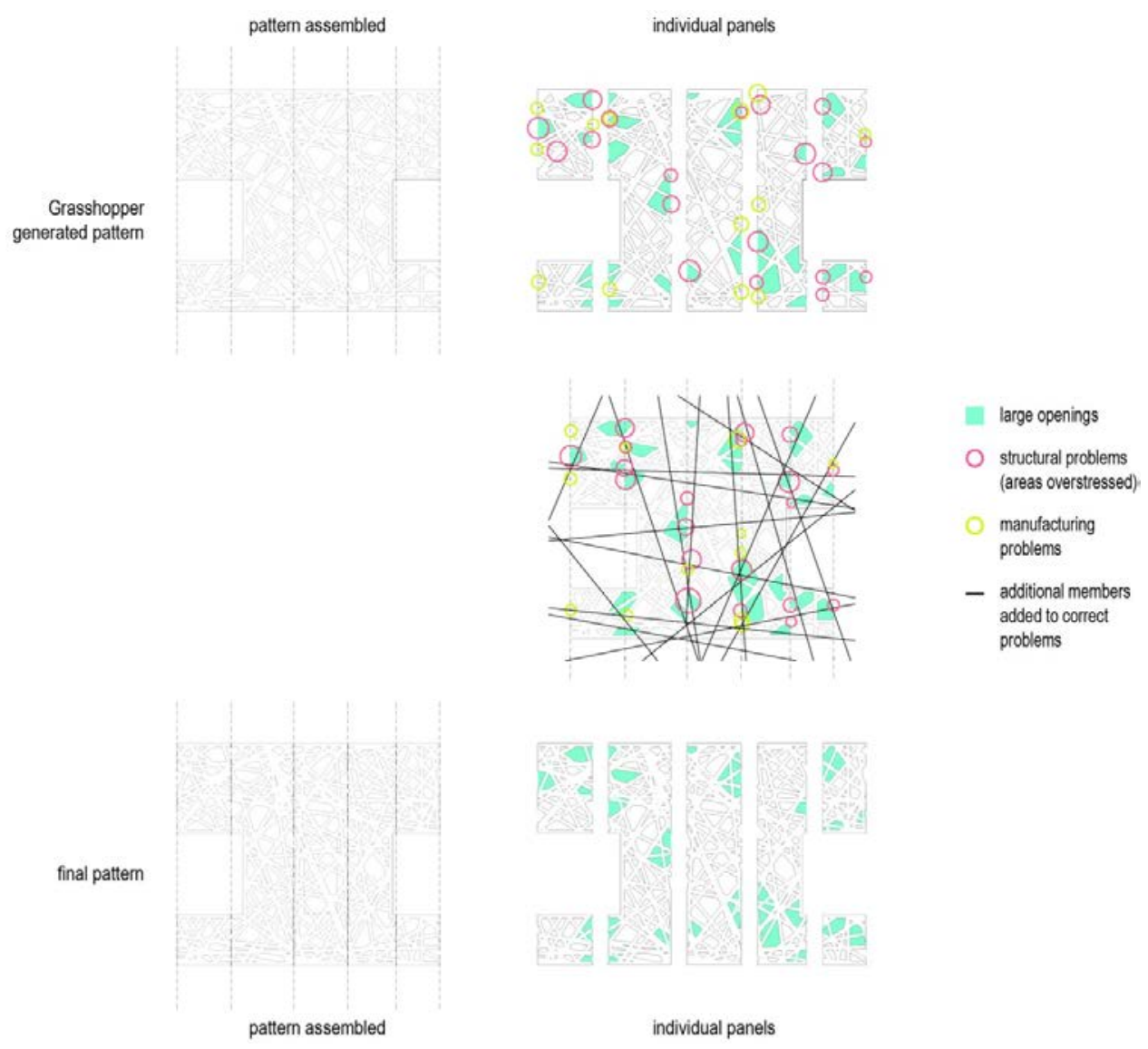

Figure 2.7: 690 Folsom Street Parametric Design Refinement (Bloszies, 2015)

In a number of cases windows are partially covered by the metal screen. This practice not only helps maintain the architect's design intent of limiting large openings in the screen but creates unique sculpture expressions for building occupants when viewing the outside world (Figure 2.8). 


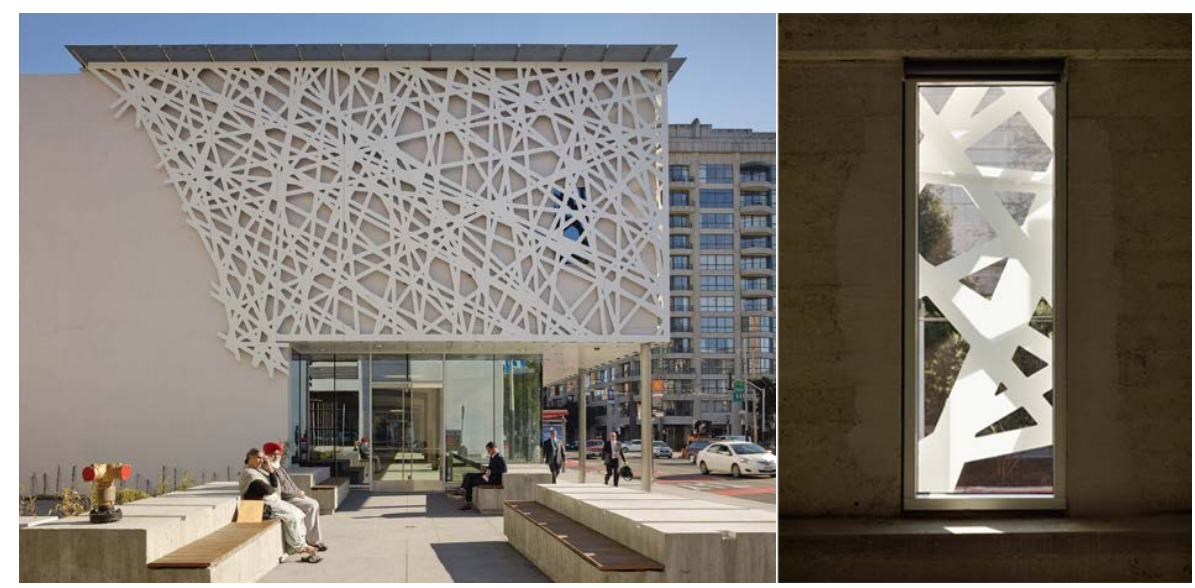

Figure 2.8: 690 Folsom Street Screen Wall Window Feature (Bloszies, 2015)

A construction detail that attached the new screen system to the face of the 690 Folsom Street building required a great attention as displayed by Figure 2.9's cut section. A metal plate that is fastened into the top of the concrete wall allows panels to hang from a distance off the edge of the building to allow space for a light to be positioned between the screen and building's load bearing wall. An intermediate pin connection helps limit vibration of the screen due to wind and potential seismic activity. While the bottom restraint provides a seamless transition between the bottom of the screen and the adjacent building arcade soffit.
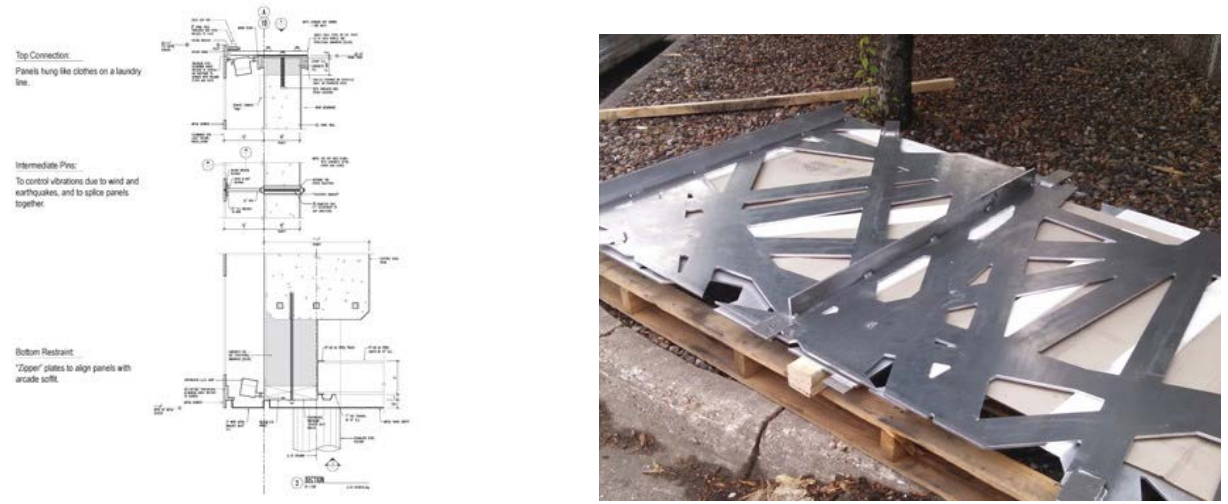

Figure 2.9: 690 Folsom Street Construction Details (Bloszies, 2015) 
Figure 2.9 also displays a photo of a screen section prior to its install. The screen section is reinforced by stiffness that rise off the back of the panel displayed. The screen needs to be fabricated as smaller sections due to manufacturing equipment limits, as well as ease of transportation and installation of panels. Charles Bloszies and Allie Roberson provided insight into the construction details used for the panels, as well as the material and finish selected. 5'-0" is a typical off the shelf screen section size and typically larger panel section have longer fabrication times and costs associated. The screen was made from 3/8" aluminum due to a number of facts including the economy of this type of metal, its light weight and its compatibility with a desired finish. A number of finishes were considered for the panels including anodizing but due to the difficulty of controlling consistency in color of this finish, it was decided to finish the panels by using an automotive paint finish similar to that used for BMW vehicles. (Bloszies and Roberson, 2015)

\subsubsection{Post Street, San Francisco}

This six story 1908 (Figure 2.10) San Francisco retail icon is preserved through an interior and an exterior makeover as seen on Figure 2.11. The original masonry façade transpose its openings onto the newly added glass curtain wall that is held nine inches off the now white epoxy painted masonry structure. This cavity acts as a thermal and acoustical barrier that promotes passive ventilation through the process of the stack effect. New added translucent glass panels encapsulate lighting that illuminate the building's fenestration at night as seen on Figure 2.12 (Band + Allen, 2015).

Touching the existing structure as lightly as possible was the goal of designers Brand + Allen Architects. This was achieved by encasing the existing building in glass as a museum does to protect precious artifacts. The white epoxy paint helps bind and stabilize 
the original beaten red brick walls, while a lightly braced curtain wall system holds curtain wall panels, smaller than six by twelve feet in dimension, off the brick wall with rods that pass through the brick walls. (Architectural Record, 2015)

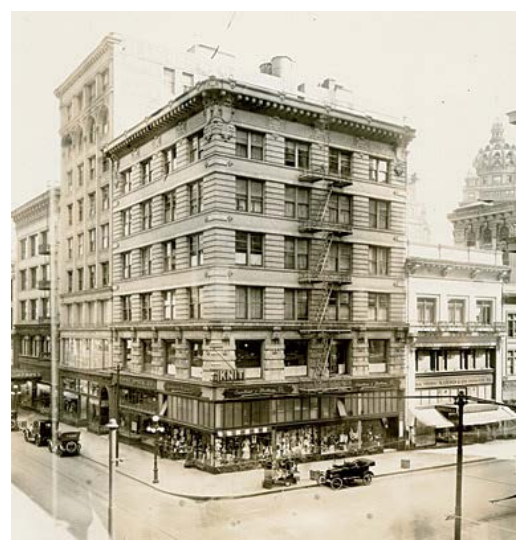

Figure 2.10: 185 Post Historical Photo (Architectural Record, 2015)

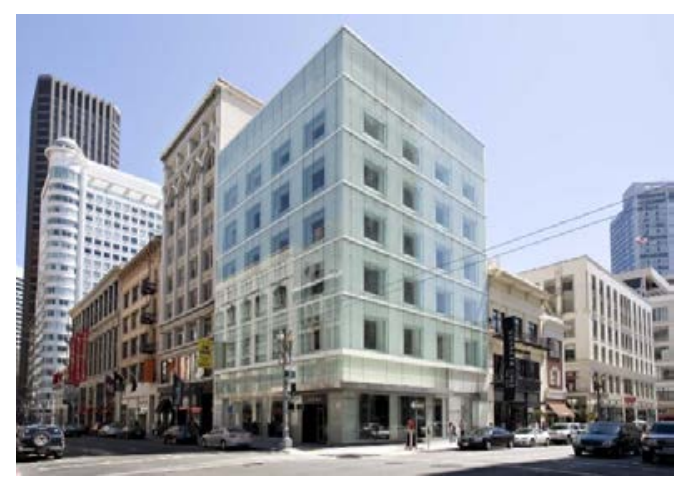

Figure 2.11: 185 Post Street during Day (Heneghan, 2015)

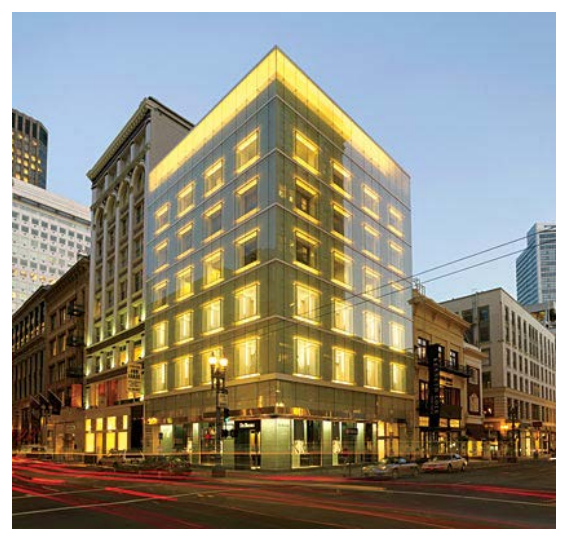

Figure 2.12: 185 Post at Night (Architecture Record, 2015) 


\subsubsection{Van Ness Street, San Francisco}

The adaptive reuse of this existing former AAA 29-story building from an office building into 399 luxury rental apartments called Civic Center Commons will be completed this year. The precast concrete façade has been replaced with a unitized curtain wall system. Figure 2.13 reflects the progression of the project façade replacement starting with the removal of the original concrete façade. Once the concrete façade was stripped away from the top down, the building was then draped to prevent loose debris from falling on to the street below, and finished by adding a new unitized curtain wall that was installed from the bottom up. A similar logistic plan will need to be planned out for Peering In when installing exterior screen walls to make sure installers and visitors to the building remain safe.

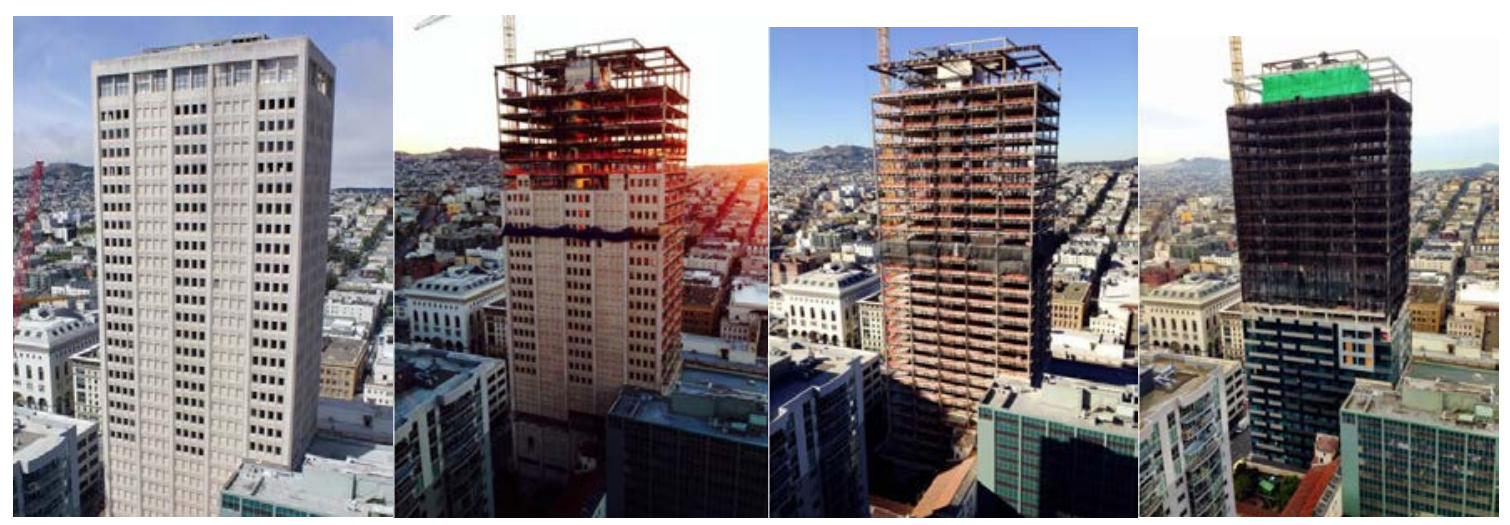

Figure 2.13: Progression of Civic Centers Commons Renovation

(Architecture Magazine, 2015)

A visit to the site during construction revived a unique crane setup of cantilevering the base off the sidewalk to provide clearance for pedestrians to pass. This crane setup did not only avoid blocking the footpath but by being held tight to the building's face (Figure 2.14) it did not obstruct any of the traffic lanes in this busy downtown area. In addition, as seen on Figure 2.15, it appeared that an aluminum frame was built to connect the curtain wall to the supporting steel structure. 


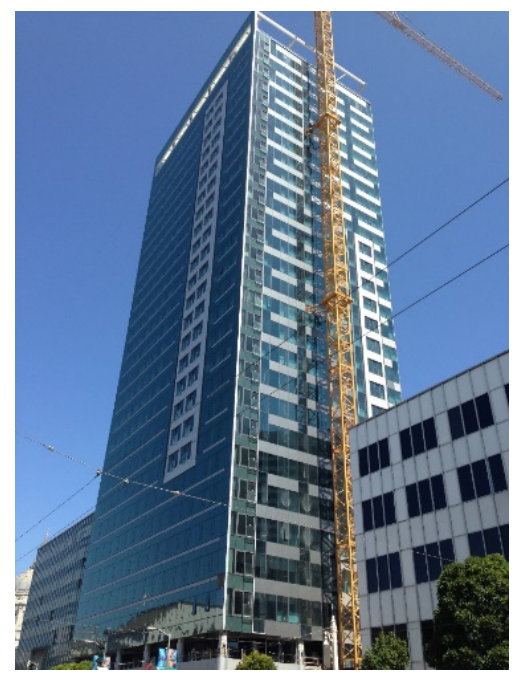

Figure 2.14: Civic Centers Commons Crane Attachment (Heneghan, 2015)

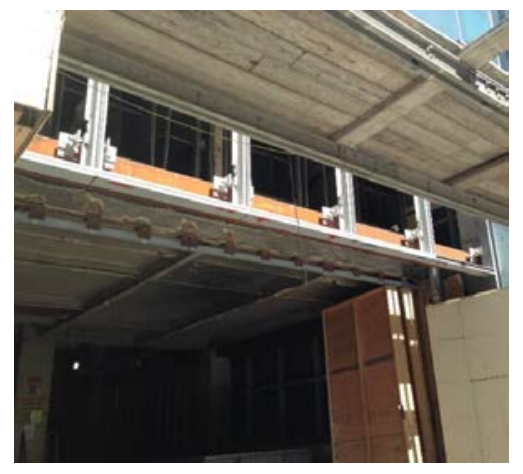

Figure 2.15: Civic Centers Commons Curtain Wall Aluminum Frame (Heneghan, 2015)

\subsection{Building Additions}

This section highlights precedents that have undergone a smaller modification than the adaptive reuse projects outlined in Section 2.1. Since the Peering In project's screen elements are an addition to an existing building that do not replacing an existing system, it is important to highlight other projects that have successfully achieved a similar goal.

\subsubsection{Hands, San Jose and Spectators, Miami}

The facade of the Terminal B Consolidated Rental Car Garage at the San Jose International Airport is covered by the public art display called Hands (Figure 2.16). This project was visited by the author to develop a deeper understanding for this unique project 
that aims at adding a human quantity to a cold concrete structure. This work aims at incorporating the form of local residents' hands into the façade of the garage that faces the 87 Freeway and airport. This display was designed by Christian Moeller as part of his “Bitwalls” body of work that uses "high-tech mapping techniques and plotting technologies [to embed images into existing facades]”(SEGD, 2015).

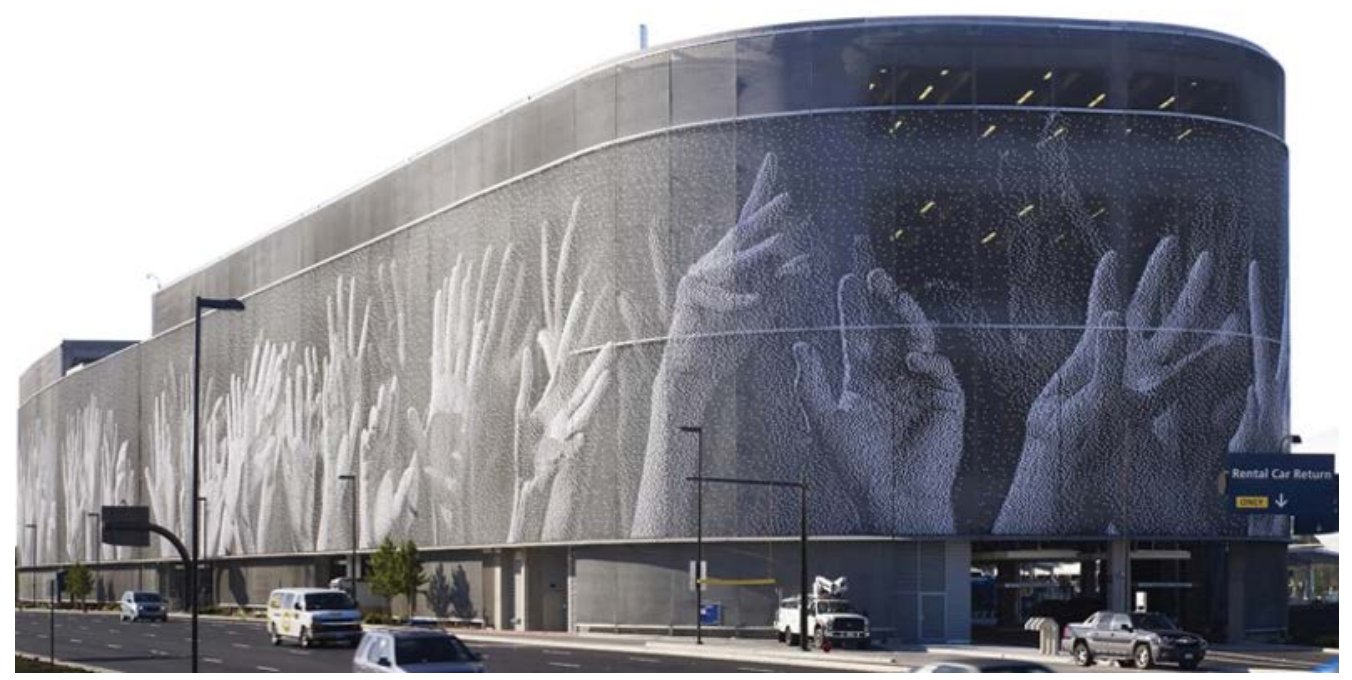

Figure 2.16: Hands from a Distance, San Jose International Airport (SEGD, 2015)

The display of hands is clear at a distance but as a person draws closer to the image it is less apparent as seen on Figure 2.17 and Figure 2.18. These two figures outline the facts that the chain link fence outer layer serves as the canvas for the image while the tighter woven inner layer provides a backdrop. Over 350,000 injection-molded vinyl chips were snapped into place over a three month period to make up the image. (SEGD, 2015) 


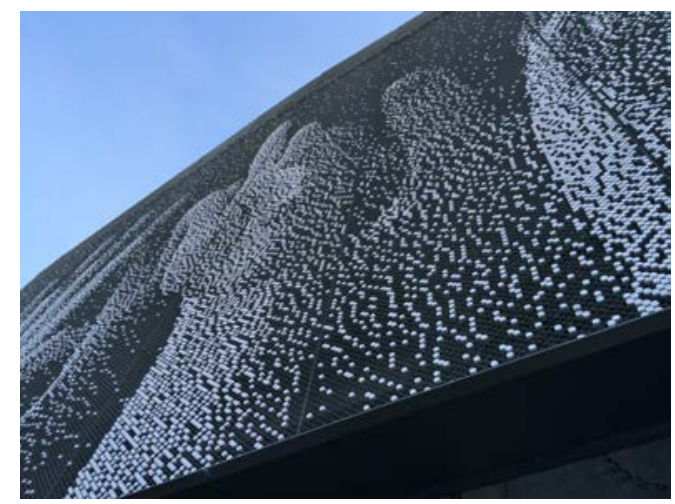

Figure 2.17: Hands near the Garage, San Jose International Airport (Heneghan, 2015)

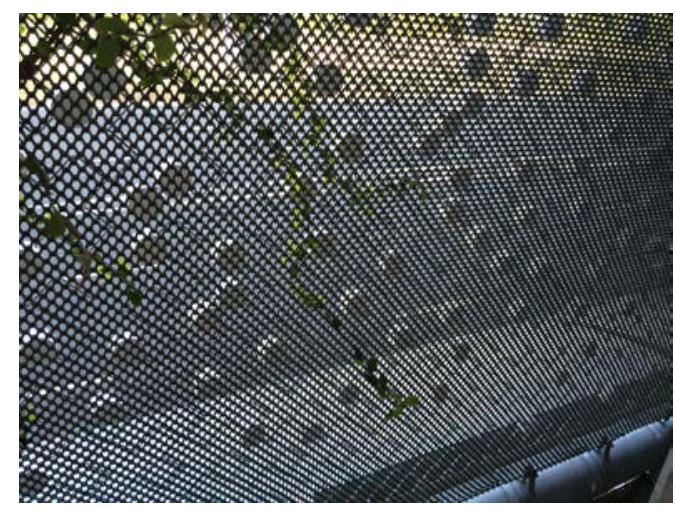

Figure 2.18: Hands within the Garage, San Jose International Airport (Heneghan, 2015)

Spectators (Figure 2.19) is another public art display that was created by Christian Moeller in Miami, Florida 2012. Injection molded vinyl chips create a portrait of immigrant children watching a baseball game from behind a chain-link fence from Little Havana. This image pushes its observers to question immigration policies that impact our society.

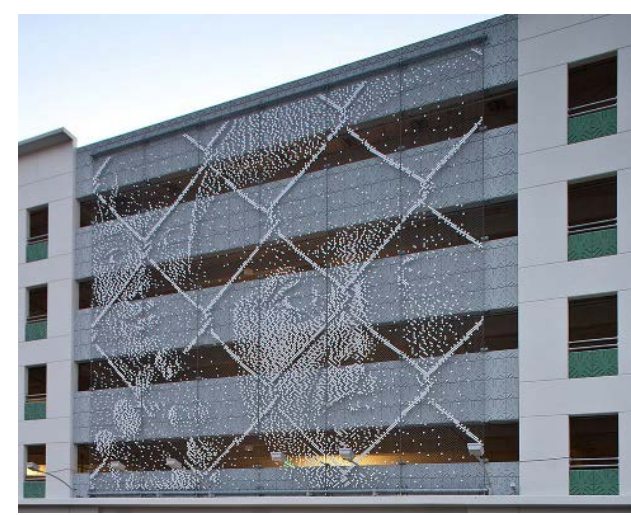

Figure 2.19: Spectators, Miami Florida (Moeller, 2015) 


\section{Site Context}

The proposed building modification is for the Union Bank Plaza, which is located in the heart of The City of Los Angeles. Not only is this city the Entertainment Capital of the World but it is estimated that one in every six Los Angeles city residents works in a creative industry. The city has the highest museums per capita than any other city with over 841 museums and art galleries (Forbes, 2015).

This is a clear reflection of the importance the arts has to this community has resulted in The City of Los Angeles Department of Cultural Affairs creating a Cultural Master Plan. This plan lays out strategies that aim to strengthen L.A.'s through creativity, diversity, and synergy (Mayor’s Office of Economic Development, 2015).

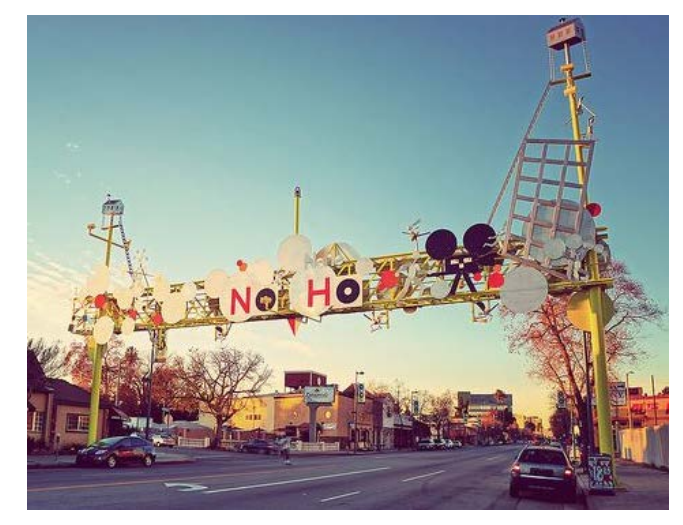

Figure 3.1: NoHo Art District LA (inspirationfeed, 2015)

The NoHo Arts District in North Hollywood is an example of one effort by the community to support the Arts. Its establishment in 1992 by local business owners with the support of the Los Angeles Department of Cultural Affairs has promoted the success and growth of its modern theaters, galleries, shops and cafes. The entrance to this district is highlighted by a busy colorful frame (Figure 3.1). The importance of colorful public art beyond theater is also evident through am ample display of murals located throughout the City of Los Angeles (Figure 4.1 through Figure 4.3). 


\subsection{Union Bank Plaza}

The building that is to be modified for this project is the Union Bank Plaza building (Figure 3.2). This building is a classic modernist building that was built between 1965 and 1968 in the Bunker Hill development area. The modern architecture style is reflected by its clean repetitive floors and facade design. When built, this building with forty levels was the tallest building in LA at 515 feet (Figure 3.3). Each floor is roughly 15,624 square feet (Gensler, 2012).

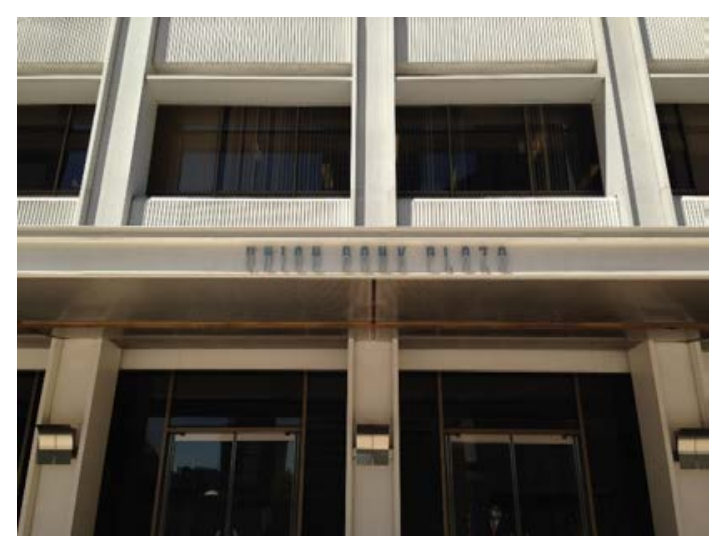

Figure 3.2: Union Bank Plaza - Front Entry (Heneghan, 2014)

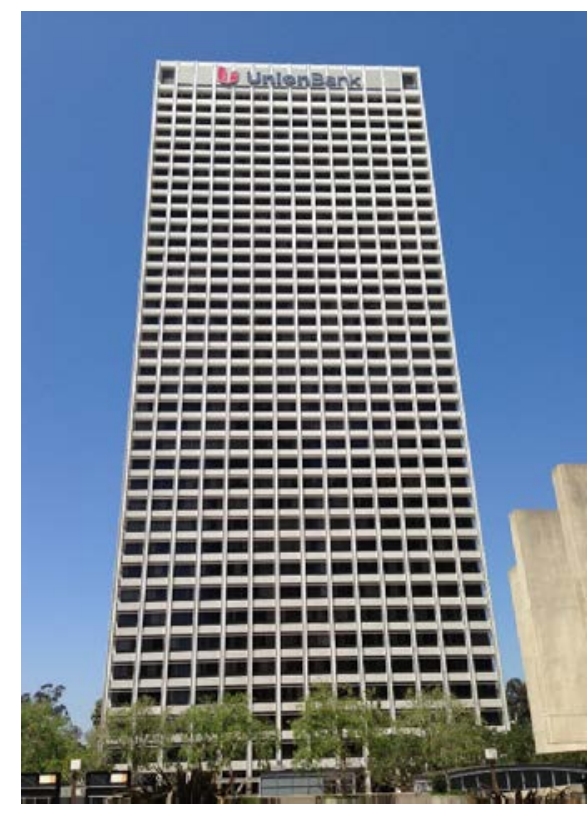

Figure 3.3: Union Bank Plaza - Front Elevation (Heneghan, 2014) 
This building is one of the oldest skyscrapers in Los Angeles and during its construction an era of local Victorian housing was coming to an end to make space for the new City of Los Angeles business district. Figure 3.4 taken during the time of construction of the Union Bank Plaza in the late 1960s shows former Victorian houses in the foreground.

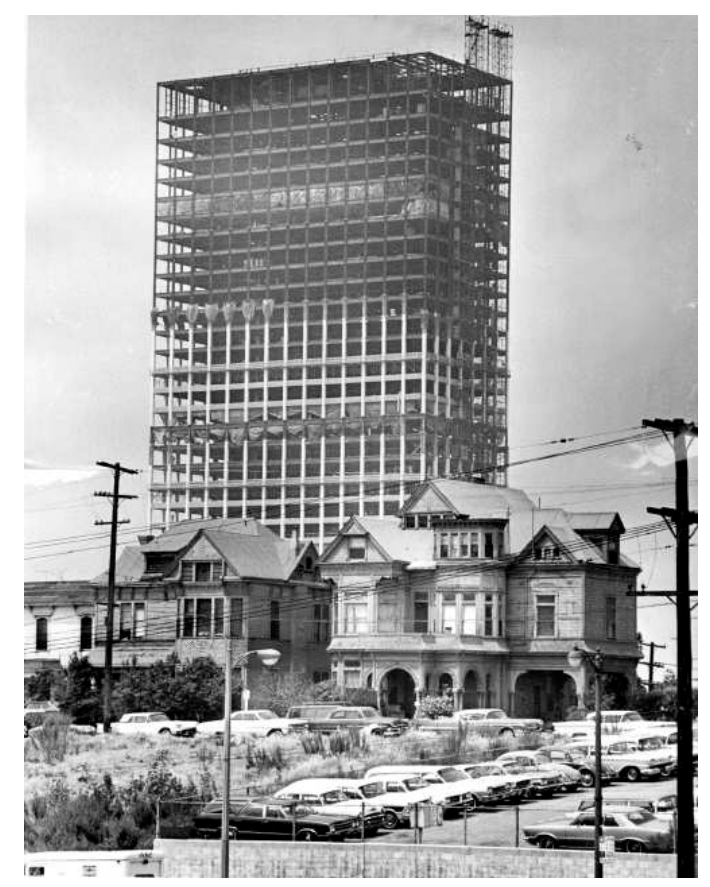

Figure 3.4: Union Bank Plaza during Construction (Los Angeles Times, 2015)

A building renovation between 1992 and 1994 included an addition of a 20,000 square foot retail structure and facade renovation. The building's name was changed from Union Bank Tower to Union Bank Plaza after the renovation (Hertz Group, 2015).

The existing façade design helps reduce glare and heat gain through the incorporation of solar glass and stepping the glazing system back from the perimeter by a few feet. Slab edges combined with horizontal louvers reduce direct sunlight from striking the glazing system. (AC Martin, 2015) 


\subsection{Site Visit}

John E. McAniff the Managing Director at Jones Lang LaSalle provided access to Union Bank Plaza building for a site observation to take place on 7 April 2014. The thirtyfirst level was vacant at the time and visited while in the company of Mr. McAniff. The open floor plan, as seen on Figure 3.5 and Figure 3.6, shows that the building structural supporting systems is a fireproofed steel frame that provides future tenants ample open space to work with due to steel's ability to span great lengths. A fireproofed pan deck slab system offers more lateral support. More than likely this deck can be modified easily to allow for a number of openings between floors to be made as long as primary members are not cut as long as additional small perimeter beams are added around new openings. Beams span out past the exterior glazing units to perimeter columns that run down the face of the building on all four sides, as seen on Figure 3.7.

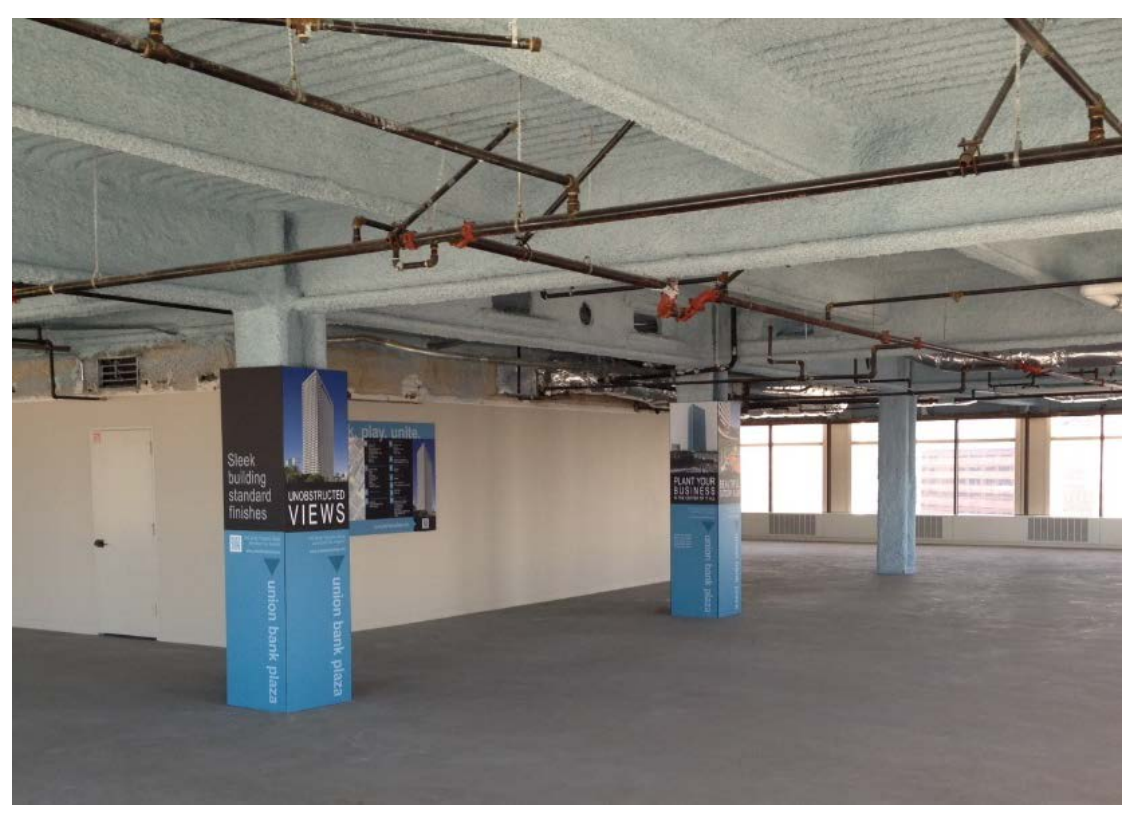

Figure 3.5: Union Bank Plaza - Floor Plan 1 (Heneghan, 2014) 


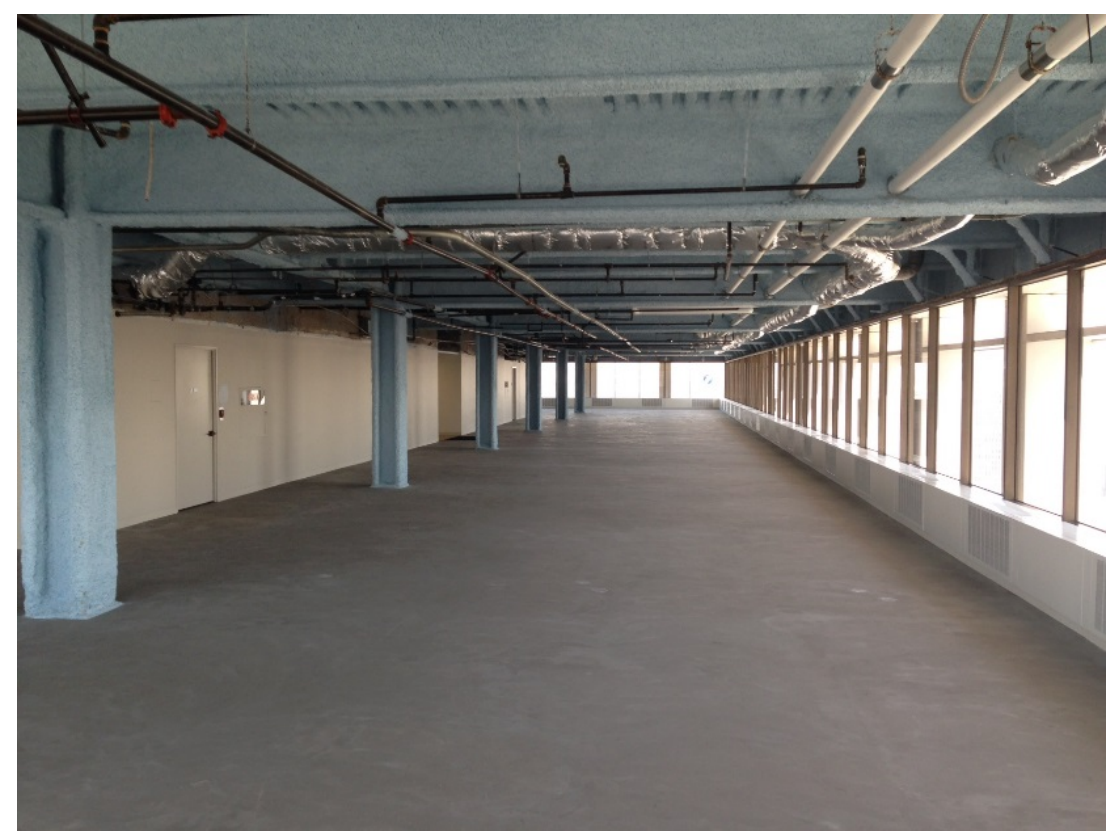

Figure 3.6: Union Bank Plaza - Floor Plan 2 (Heneghan, 2014)

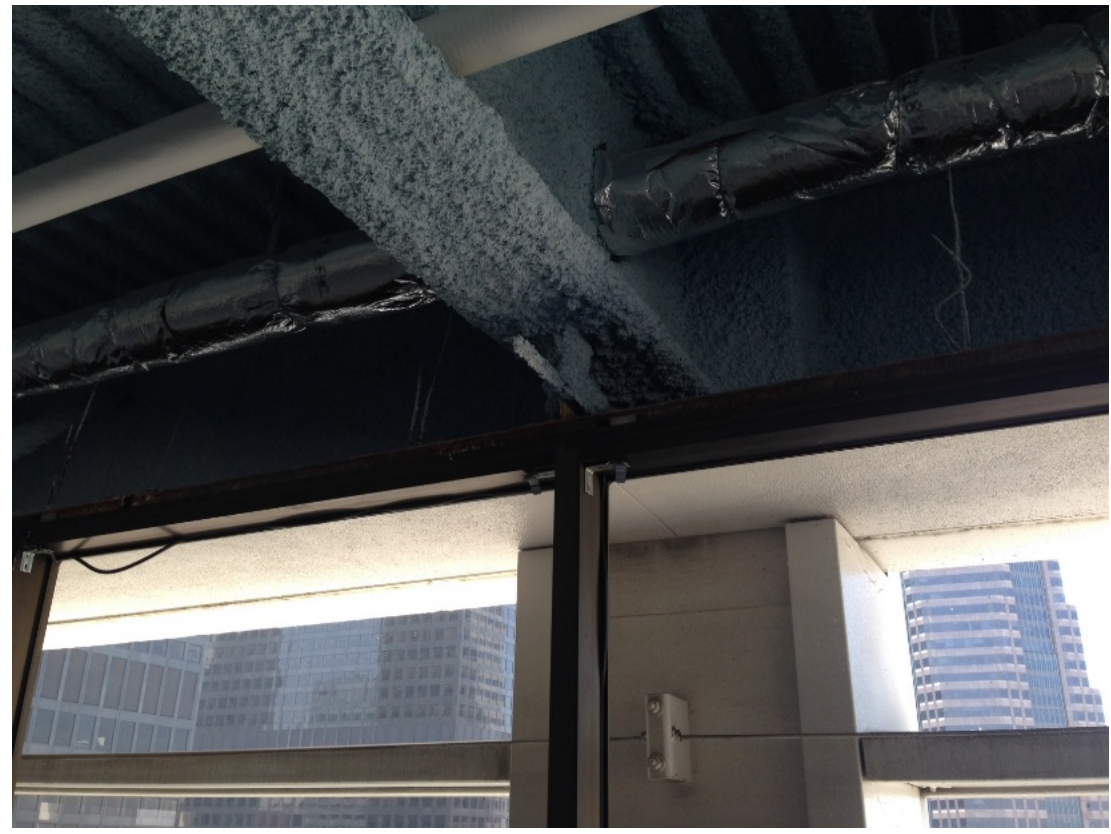

Figure 3.7: Union Bank Plaza - Glazing Termination Detail (Heneghan, 2014)

The exterior glazing system that is held back from the building edge provides space for window washers to walk along while tied off to a steel safety cable that runs around the building perimeter at each level. This metal cable is held a couple of feet down from the 
top of glazing as noted on Figure 3.8. This glazing system was updated in the early 1990s and benefits from its setback since an uninterrupted systems would have allowed for an easier installation, simplification of waterproofing details and a reduction in thermal breaks along the building perimeter. This set back also allows for easier replacement of façade sections or exterior building upgrades to take place, since work can be conducted potential from the slab edge without the need for a crane or scaffold.

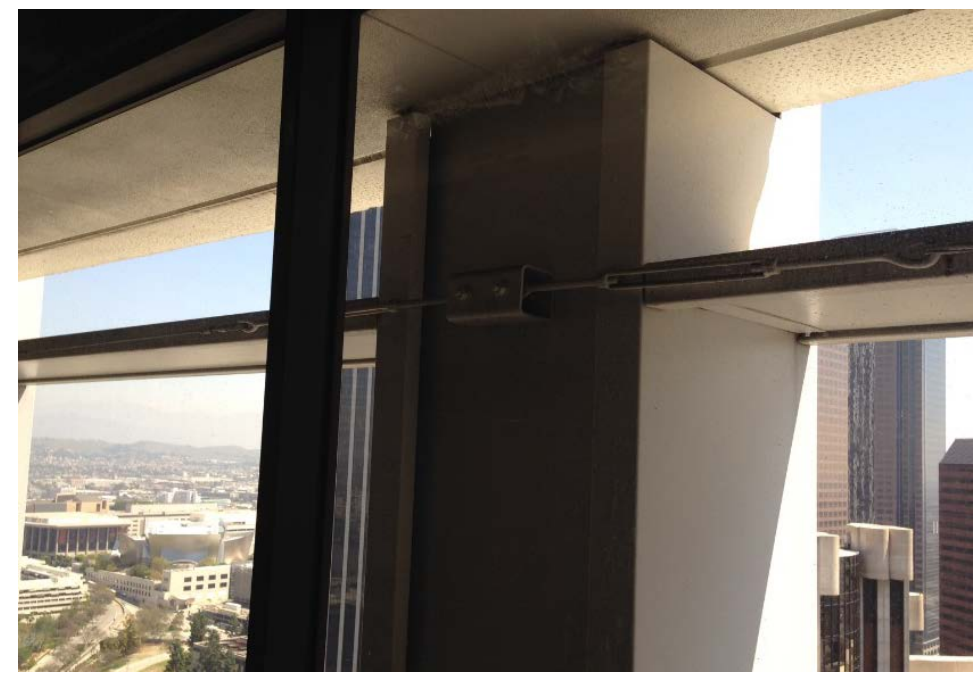

Figure 3.8: Union Bank Plaza - Safety Cable Tie-off (Heneghan, 2014)

Beam and column locations where noted during the visit with approximate accuracy to aid in determining where structural members need to be kept intact when the building is upgraded. A large cost to structurally retrofit the building would be required if primary structural members would need to be moved to allow for upgrades. Considering the location of these members in the developed of the design was critically since moving such members would deem the project as cost prohibitive.

This site visit combined with the literature collected during the visit were essential in the development of an understanding of the existing building conditions that led to the creation of a set of Revit building model. Reference the appendices for these project models 
to see how the overall design evolved through the design process. The Revit models were created with the assumption that the thirty-first floor visited is similar to other building floors with the exception of the ground level and top level. The ground level and top level differs from this typical office floor plan in function and height. The top floor is for mechanical and service equipment use, while the ground floor provides building access. 


\section{Color}

Various meanings apply to specific colors based upon social and cultural context. Colors move us emotionally through their associated meanings while their surrounding setting creates an environment where a color never stands alone or appears the same (McLachlan 9). Background and adjacent colors, as well as light conditions are major factors in creating this complex framing of a color. Exposure to a color in an internal versus external condition is another important factor in determining a color's impact. Senses are heighted when you are immersed in color in an internal space while external exposure is a more detached experience (McLachlan 11).

Determining the best set of colors to be used for this project is a challenge due to a range of parameters including a diverse local culture, working with the existing building's palette of colors, and changing natural and artificial light conditions. Furthermore, the subjective nature of color preference not only differs amongst people but changes with one's state of mind. While it is not possible to appeal to everybody's taste simultaneously, there is clearly an underlying palette of colors that is acceptable amongst popular culture.

Color is a central element to the Peering In design due to its connection to a locally diverse community. Los Angeles is a melting pot of ethnic and cultural diversity. Not only is color vibrant in the Los Angeles area, according to neurologists it is vital for creating an environment that supports both logical and emotional responses that are catalysts to creativity (McLachlan 193). Finding a balance of colors that supports both the rational and emotion parts of the brain effectively is a huge challenge. Since these two sides of the brain are constantly battling with one another. Plato describes this tug of war within the brain like steering two horses which are pulling in opposite directions. 
It is evident that vibrant colors play an important role to the Los Angeles community through an ample display of colorful public art, including a collection of murals painted by native and foreign artists. For example native street artist Miles MacGregor, also known as El Mac, spray-painted the Latina Joli on brick in Los Angeles in 2008 (Figure 4.1). He draws inspiration from the Chicano and Mexican culture he grew up around. Furthermore, he frequently works in collaboration with other artists from different backgrounds including the artist Retna who painted the background that contains Joli's halo that uses contrasting cool blues and warm reds.

The self-taught Los Angeles based female graffiti artist Shadow Monster Bear painted the display of three colorful dogs in South Central (Figure 4.2). While the exciting mural at 420 Boyd Street (Figure 4.3) is the work of Brazilian collaborative Bicicleta Sem Frieo who were commissioned by the building tenant the Legendary Developments, LLC in partnership with The Do Art Foundation and the Los Angeles City Council.

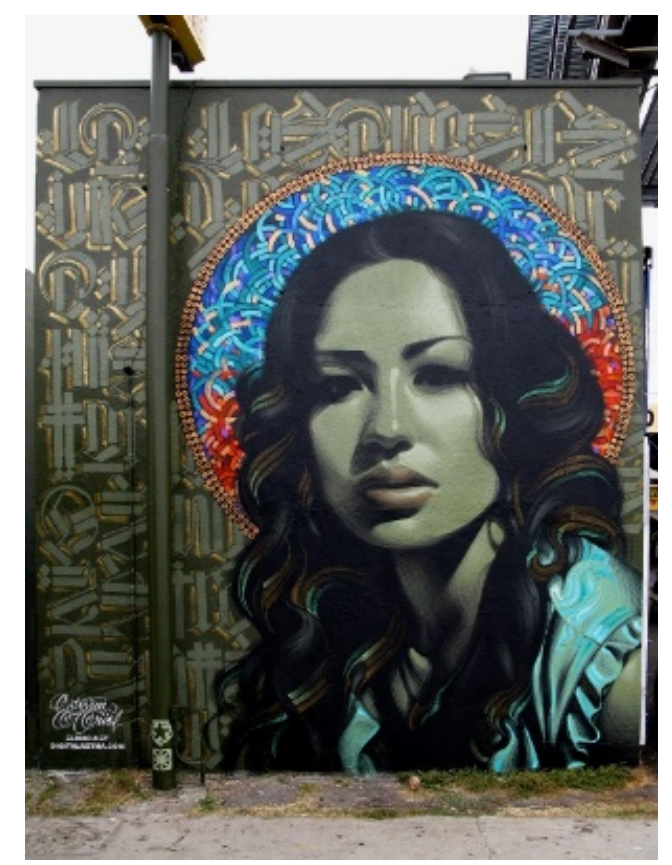

Figure 4.1: Joli, Los Angeles (MacGregor, 2015) 


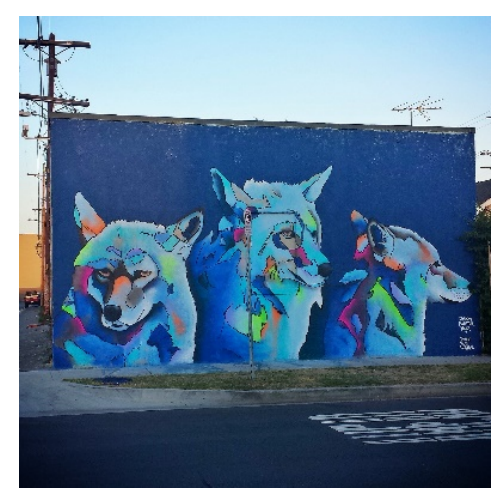

Figure 4.2: Smile South Central, Los Angeles (Shadow Monster Bear, 2015)

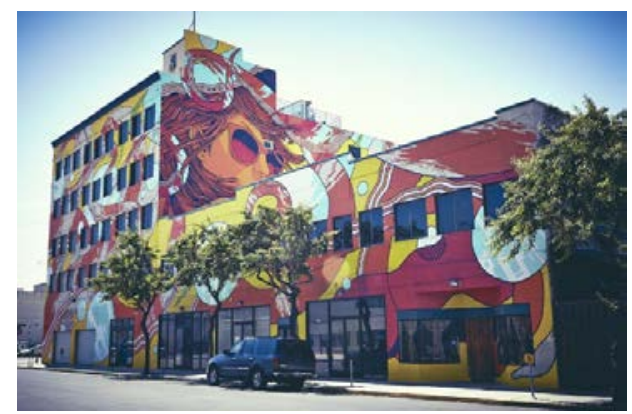

Figure 4.3: Mural at 420 Boyd Street, LA (Castro et al, 2015)

\subsection{Art Influence}

Color is perceived prior to form and dominates the reading of an object. Color can reinforce an object's form or camouflage it by distorting the perception of the surface (McLachlan 12). Even after "light grows dim, colours fade and forms flatten...We may still 'see' colour, but the colour may be purely a memory or an association with an object (McLachlan 91).” Together color and texture define surfaces. They play an integral part in our experience within a space, altering our moods and triggering memories and emotions through our experiences. However the potential of color is frequently left unrealized by architects due to fear of misuse (McLachlan 159). Such a conservative stance helps colorful architecture standout for better or worse due to its scarcity within our communities (McLachlan 137). 
Artists are champions at challenging these conventional boundaries that color has fallen victim to within the architectural realm. In the 1950s and 1960s the Colour Field painters brought to light the importance color plays on an emotional level by painting large areas of color empty of form (McLachlan 3). This approach of freeing color from its associated functions through the expression of color purity has a deeper sense of purpose architects can learn from.

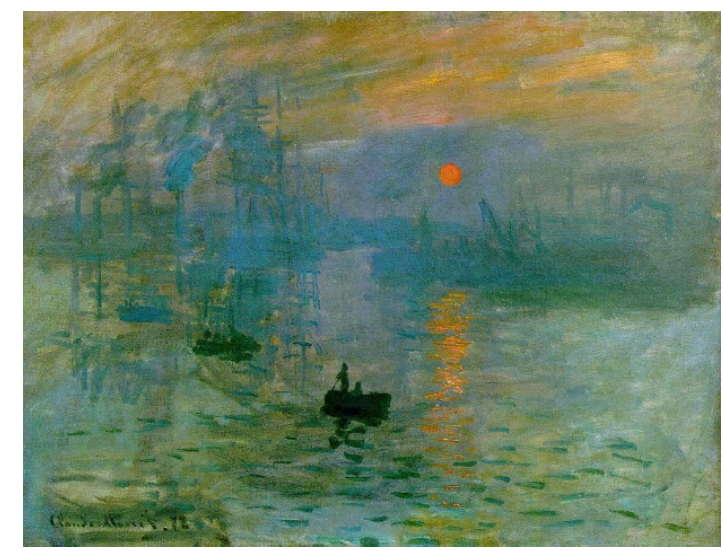

Figure 4.4: Sunrise by Claude Monet (Art Factory, 2015)

Prior to this exploration of color absence form, many sufficient events occurred that challenged the norms of the color palette for artists. Michel Eugene Chevreul's publication The Law of Contrast of Colour inspired the work of great Impressionist painters, notably Claude Monet and Vincent van Gogh by identifying simultaneous contrast, which outlines the effect two different colors have on one another. This line of study indicated that colors opposite on Chevreul's color wheel strengthen the appearance of each when placed beside one another (McLachlan 10). Impressionist painters used the teachings of Chevreul to evoke emotions by not painting figures the colors they are in real life but by using colors that strengthen one another when used together. Monet kick started Impressionism with the work of art Sunrise (Figure 4.4) through the use of gradients of oranges, blues and greens. 


\subsection{Color in Architecture}

While color movements in art were ample, architecture was not absence of similar developments. The San Francisco Colorist Movement was an example of one such movement that that occurred during the mid-twentieth century when the Union Bank Plaza was built down south in the same state. This movement was spawned from the push back on the restriction of emotional expression during War World II, which resulted in Victorians being painted dull gray, similar to that of warships (Figure 4.5). These Victorians experienced a rebirth when painted bright vibrant colors including but not limited to red, yellow, blue, and pink. To this day, the popularity of The Painted Ladies is a testament of the movement's success which was in response to a world that was becoming dehumanized by technology and the standardization of buildings (Lenclos 81).

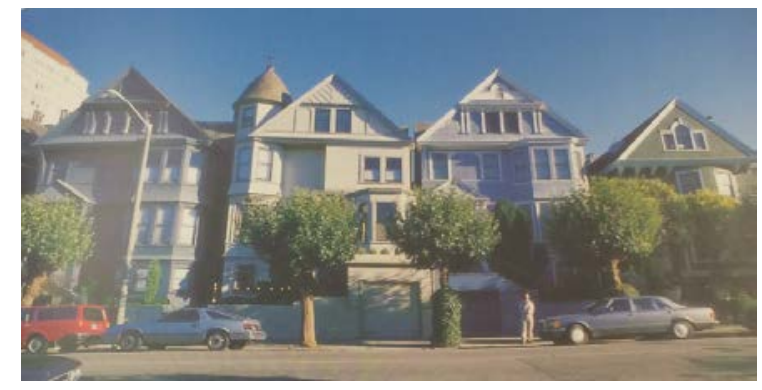

Figure 4.5: Dull Gray Victorians (Lenclos 81)

It is important not to depend purely on the use of color within the field of art but to investigate its effective use in architecture because the function and our degree of exposure to art and architecture differ drastically. Steven Holl acknowledges this level of exposure that we have to architecture by stating "unlike painting, we can turn away from, and music and film we can turn off, architecture surrounds us (McLachlan 87).” Forgoing established color controls can lead to chaotic overstimulation, while over use of such controls can create a sterile monotone environment (McLachlan 186). Holl's modern works try to limit 
the terrifying quality that bright colors can have through his architecture that controls color and light with harmonious palettes.

While color manufactures like Dulux prescribe examples of color pairings that should not be used, it has been determined that such rules should be broke if a certain degree of knowledge has been attained according to the late abstract artist Josef Alber. Alber's belief to push yourself to develop an eye for color by making a special effort to use disliked colors usually leads us to loving them. An example of using clashing colors according to manufacturers' prescription is successfully pulled off by Sauerbruch Hutton architects who developed an understanding for the mixer of oranges and pinks when exploring India (McLachlan 193). Alber's position supports the argument that we must invite emotion and spontaneity into the process of selecting colors for a project since symbolic and cultural languages extend beyond the established science of color (McLachlan 194).

The color theorist Jean-Philippe Lenclos's documentation of exteriors of buildings from around the world is a valuable aid in creating an appropriate palette for this project. His work has been used extensively by city planners to help with the selection of suitable color palettes that work with surrounding context, as well as cultural traditions. Historic architecture has been driven largely by locally available materials and its associated pigments but its applied color usually has a rooted cultural significant (McLachlan 93).

Lenclos uncovers the important role color plays in defining cultural identity of countries and its people on a global scale in his publication Color of the World. The prescriptive International Style the Union Bank Plaza abided by when designed is dangerous since it promotes a universal and uniform culture. Introducing a colorful palette 
of colors into the existing Union Bank Plaza that not only has a local connection but has been used with success in countries where residents and visitors have roots is the goal of research into colors. The colorful palette of blue-green, orange, yellow, pink and violet are not only seen worldwide but in the vibrant areas of Los Angeles City including Venice Beach (Figure 4.6).

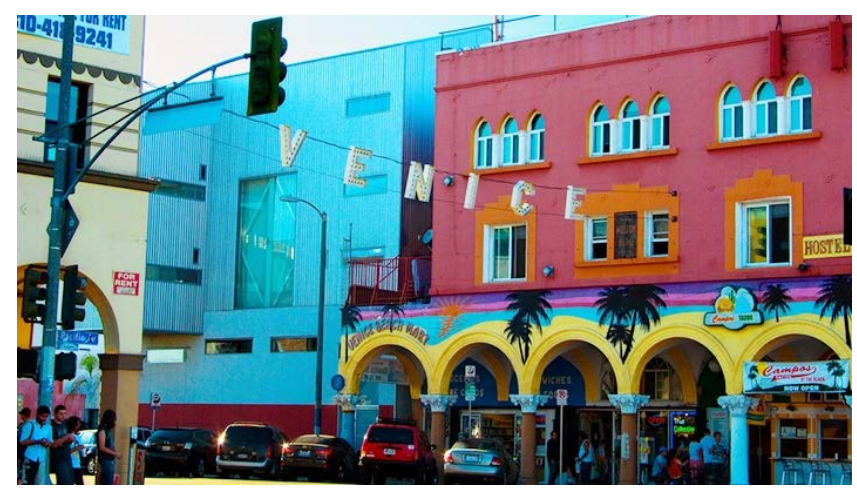

Figure 4.6: Colorful Venice Beach (Discover Los Angeles, 2015)

In Jodhpur, India as represented by watercolors seen on Figure 4.7, pink, yellow and blue are used as primary colors for paint building facades with contrasting doors and shutters. Pink represents the Jaipur and is used within the city center and along major thoroughfares. Yellow represents the Jaisalmer and their buildings are made from yellow sandstone. Blue represents the Jodhpur and is used within the neighborhood where the highest Hindu caste live. (Lenclos 258) A similar palette is used for facades for homes in M’zab in Algeria which include yellow, blue, pink, and green (Figure 4.8).

The frequent use of colors in certain cultures is surprising. In colorful Guatemala the bright contrast of mixing blue-green with orange (Figure 4.9) and yellow (Figure 4.10) into building facades is evident. This attraction to the use of blue-green is rooted in the Guatemalan’s Mayan ancestry. Not only is blue-green associated on the broader scale with everything precious to the Mayans but it was one of the five symbolic pigments to the 
Mayans representing water and fertility. Furthermore, in Chinese cultural blue or green represent the spring season and wood, and in Iran blue-green has a talismanic quality (Lenclos 24).

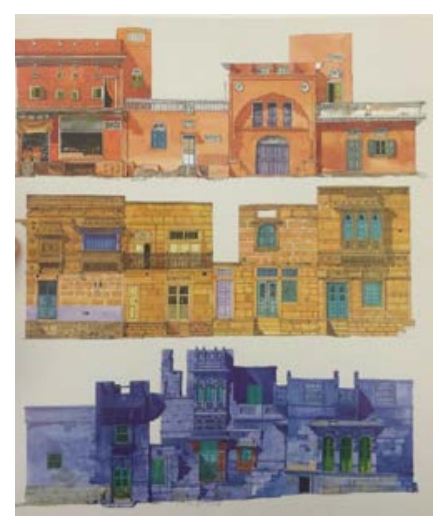

Figure 4.7: Pink, Yellow, and Blue Indian Facades (Lenclos 259)

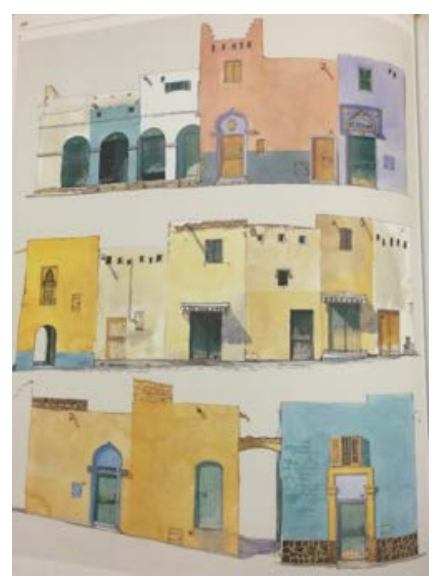

Figure 4.8: Yellow, Blue, Pink, and Green Algerian Facades (Lenclos 189)

Yellow is the lightest, the most luminous, and the most reflective color. It symbolizes wealth, life and light. It is the most prevalent color in Chinese culture and the color of the Emperor. In Portugal (Figure 4.11) yellow is used for facades with violet around fenestrations. This Portuguese palette is echoed in Condado, Brazil and Suzdal, Russia (Lenclos 31). 


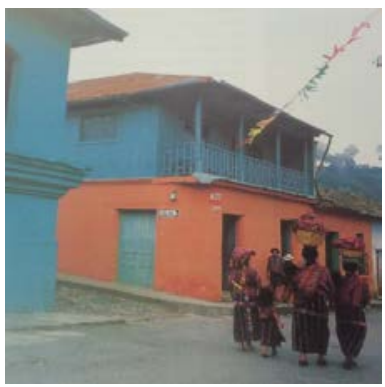

Figure 4.9: Blue-Green and Orange Facades in Guatemala (Lenclos 102)

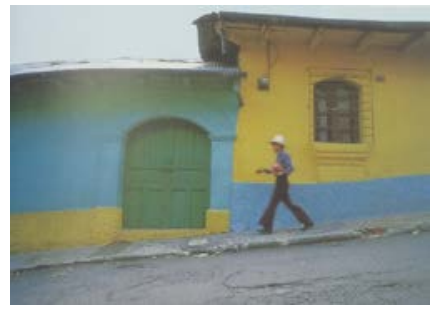

Figure 4.10: Turquoise and Yellow Facades in Guatemala (Lenclos 101)

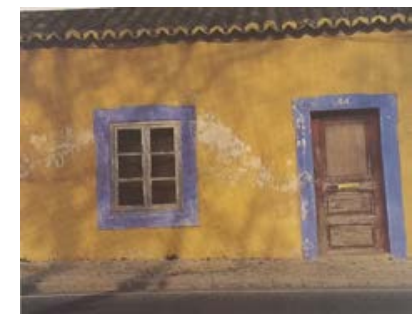

Figure 4.11: Yellow and Violet Façade (Lenclos 31)

The use of warm stimulating colors are more appropriate for circulation or active spaces while cooler calming colors are better suited for spaces that promote relaxation. A dynamic balance that is neither over nor under prescribed creates a more visually appealing space. Opposing colors can create this sense of harmony and are embedded in many modern color systems. This concept of creating balance using opposing colors is outlined by many scholars including Ewald Hering in his 1870 Opponent Colour Theory publication (McLachlan 191).

Research into colors as outlined above has aided in developing a suitable color palette for the proposed architectural renovation that aims to revive the existing building. 
Initially integrating copper screens that were both in its initial reddish brown and its aged bluish green was considered due to its natural contrasting colors and its ability to oxidize versus rusting, which helps limit maintenance of the material. Allowing the installed material to age naturally was also in line with the Brutalist architectural style, which was popular during the construction of the original building. Further research lead to the determination that not only is this material too expensive, its desired shiny reddish brown becomes dull and too muted in many cases after a brief period. Research into its palette was beneficial since it lead to the discovery of the fact that its aged blue-green is held with high regard by many cultures around the world and that it works with orange or pink.

This practice of using contrasting colors is used effectively by the architectural firm Sauerbruch Hutton in their design of a 2004 extension at a Berlin fire and police station (Figure 4.12). Not only are the two colors used opposite on the circle wheel, they represent the red color of the fire department and the green color of the police department. These colors also work to support the contrast of the original 1907 red brick building and its surrounding green mature trees. The extension uses modern glass shingles that contrast with the existing building traditional materials. The design has a more exciting appearance since a liberal approach of intertwining an array of green and red shingles in an irregular pattern is used.

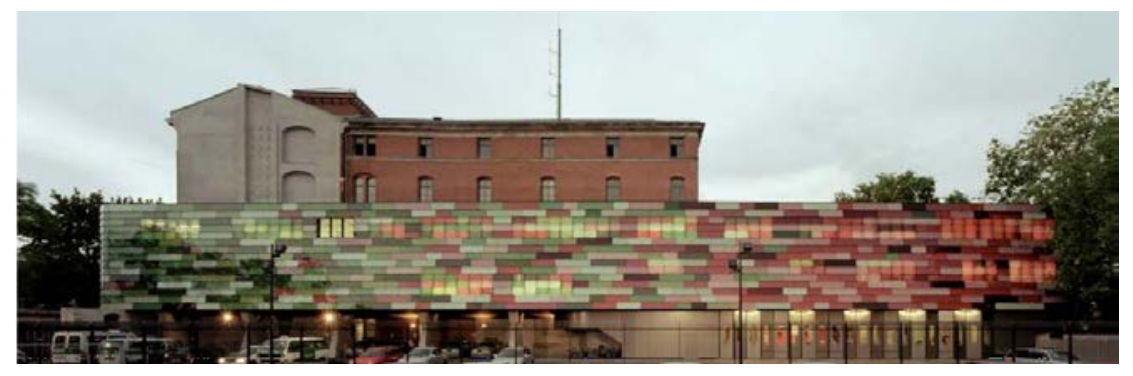

Figure 4.12: Berlin Police and Fire Station Extension (Sauerbuch Hutton, 2015) 


\subsection{Project Color Palette}

Gradations of the colors from Figure 4.13 make up the color palette that is going to be used for this project's newly added screen elements, interconnecting stairs and guardrails. Screen assemblies will use contrasting color sets blue-green / turquoise and orange, as well as yellow and violet for the two perforated panel sets that attach to the stud that supports each screen wall section. In addition to the supporting material above Figures 4.14 through Figure 4.18 clearly display that a combination of colors from the selected palette work well together. Navy blue can be used for the stair and guard rail trim.

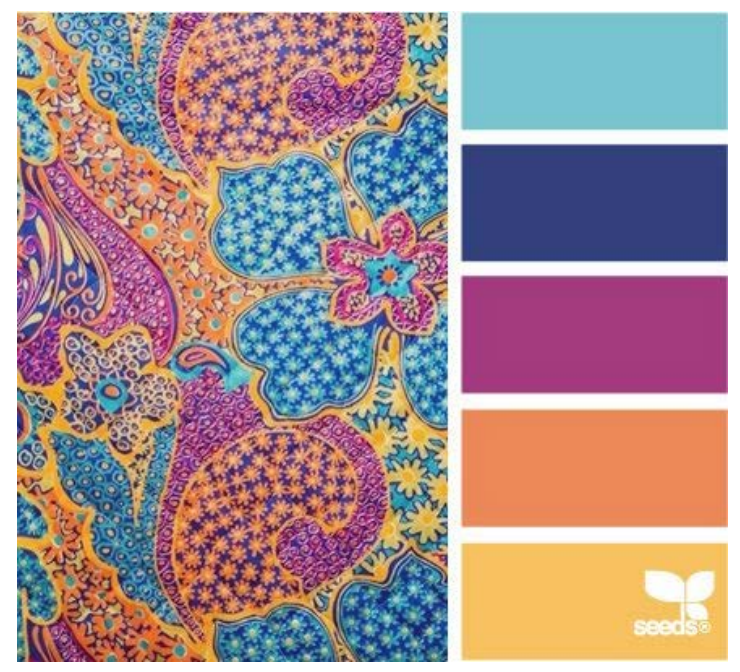

Figure 4.13: Color Palette (Design Seeds, 2014)

The brighter orange and yellow will face outwards while the turquoise and violet will face inwards. The brighter color will attract attention to the building while the cool colors will create a calming interior work environment. The degree of perforation in the screens will be extensive and will allow for both the occupants and passersby to experience a blend of cool and warm colors when looking at a screen wall sections. This will help prevent the warm exterior colors from becoming obnoxious and the interior colors from creating a cold depressing environment. 


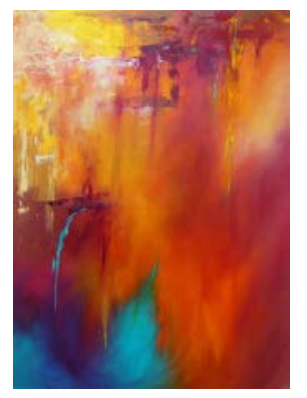

Figure 4.14: Orange, Yellow and Turquoise (Leibowitz, 2014)

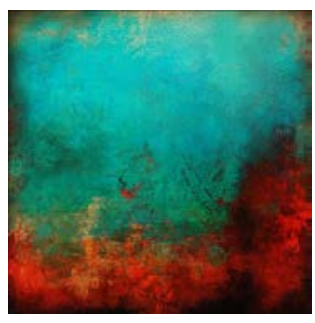

Figure 4.15: Turquoise, Red, and Orange (Hooper, 2015)

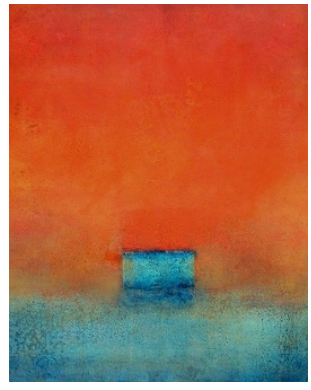

Figure 4.16: Orange and Turquoise (Upton, 2015)

The addition of a select number of new perforated colorful metal screen wall sections to the exterior of the Union Bank Plaza building will attract attention to the building as a whole without the need to drape the whole façade with a screen wall system. While at a distance the impact of these elements will differ since perforation will no longer be discernible and colors begin to merge due to color assimilation (Lancaster 28).

According to color psychologist Angela Wright the correct use of color in office space can increase productivity. A more intense color has greater saturation and can stimulate while low saturated color can soothe (Wright, 2015). The screen wall system 
proposed by the Peering In project has an advantage over colored interior walls since a window shade system that is commonly incorporated into building tenant improvement projects can control the degree of saturation by rolling up and down shades. The bright screen wall colors selected can become more subtle to meet the needs of the tenant based upon the time of day, the event that is taking place within the building and mood of the occupants by adjust the shades. Figure 4.19 is a typical shade system manufactured by MechoSystems that is used in office spaces. Such a shade system could be used to reduce the intensity of the sunlight, screen saturation and heat gain within the space.

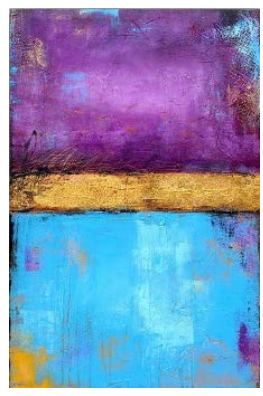

Figure 4.17: Purple, Yellow and Blue (Erin Ashley Art, 2015)

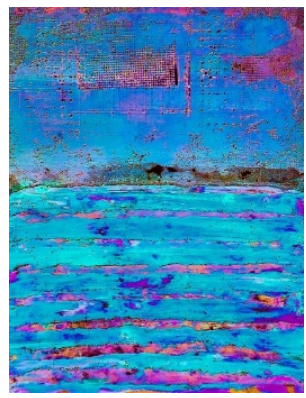

Figure 4.18: Blue, Violet and Orange (Knauff, 2015)

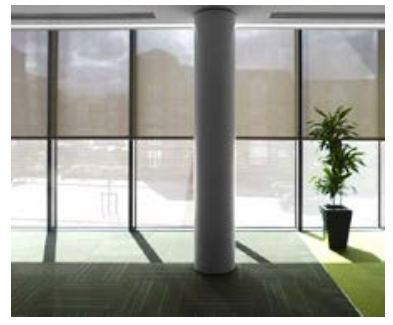

Figure 4.19: Office Space Window Shades (MechoSystems, 2015) 


\section{Materials}

In traditional societies, the choice of materials used for construction was dependent upon a variety of factors not limited to but including the climate, local availability, technical know-how, aesthetic receptiveness, and respect for social and religious tradition (Lenclos 35). One factor that has changed greatly in the past two centuries and has shaped our skyline a great deal is the development of material technologies and their application. Material advancement has been driven by many motivations including economic, social and environmental needs. The rapid explosion of available building materials outlined by Figure 1.1 reflects an array of materials that are now available. While contemporary architecture is almost unimaginable with the absence of the structural frame (Brookes and Meijs 2) since it gave rise to the non-loadbearing curtain wall, this system would have never been a feasible design option without the evolution of its metal material. Improvements in manufacturing processes, an increase in production and changing building demands during the Industrial Revolution lead to the use of iron as a viable building material that allowed for stronger and longer spans to be built. The continued refinement of the material led to the discovery of its alloy steel that transformed our skyline.

A facade can now be more dynamic since the weight of a building can be carried by its frame. This has given rise to the use of a spectrum of materials that can be used to infill around the frame's assembly. As new discoveries are made the facade will continue to evolve. Even though the functionality of the curtain wall has gained greater consideration in the modern day, it is important not to forget that the form still expresses the owner's image to the outside world (Foulks vii). 
According to Blaine Brownell the author of Material Strategies: Innovative Applications in Architecture the most influential architecture implements five strategies that incorporate the artist and scientific significance of material innovation. Brownell names these strategies: "push limits, assimilate, reveal-conceal, surprise, and edit (p 10)."

Pushing existing limits with the goal of avoiding the creation of a predictable design has been considered in this project as it relates to bridging the gap between a building that has little to no ornamentation to one that embraces a rich local artistic culture through the introduction of color and expressive form.

Creating an assimilated design that unifies the new elements in with the existing building plays a role in the design. While the added elements will take advantage of new materials and building technics, the symmetric form of the screen panels and a consideration for symmetry in relation to the whole building scale is in line with the building's existing symmetric body.

Finding a balance between revealing and concealing physical components to decrease the visual distraction they may create was considered in the design. Points of connection are designed to be hidden from the eye, while a smooth material finish helps observers focus their attention on panel form and color as a whole.

By adding vibrant colors and form to the existing plain background the design will surprise by adding personal expression. This approach questions the notion that those working in white-collar jobs within this building and the surrounding business district perform better in conservative environments that lacks expressive form and color. As outlined in Chapter 4.1 architects often shy away from expressive color due to the fear of 
its misuse. This project not only uses standalone vibrant colors but blends contrasting colors to create visual harmony per Chapter 4.

The design has been edited to create a project that has the potential of being executed. The project has evolved throughout the design process to eliminate unnecessary complexity. The refinement of this design has reduced the palette of materials to be used and the degree of customization that is required to form these materials into the desired shapes. This calibration in design is outlined in detail in Chapter 6.2 Project Execution and Chapter 6.3 Evolution.

\subsection{Material Selection}

There are many material types that can be chosen for this project. Commonly used architectural materials can be broken into the categories: mineral, concrete, wood, glass, plastic, and metal. Selecting a material or selection of materials that are lightweight, durable, and strong are the minimum characteristics that must be possessed to create the project's screen walls.

\subsubsection{Minerals and Concrete}

While the collection of materials loam, stone, and ceramics were essential in the creation of our first cities their heavy weight and weakness to seismic activity make them less suitable for the proposed screen wall system. While concrete is more suitable than mineral materials, its weight and minimum thickness make it an impractical material for this project due to fact that installation will require a crane and the form of concrete will restrict too much light from entering the interior space. 


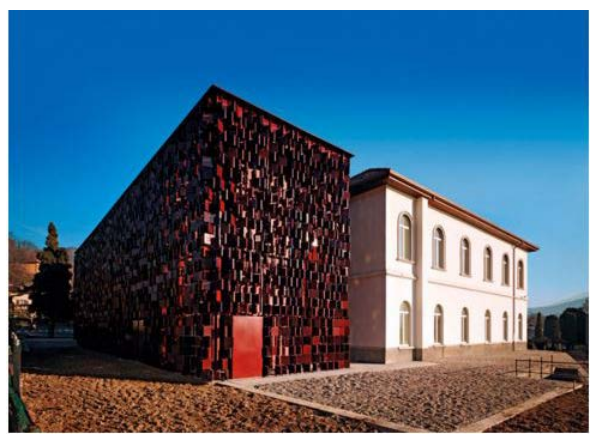

Figure 5.1: Exterior of Nembro Library Expansion, Italy (Ceramic Architectures, 2015)

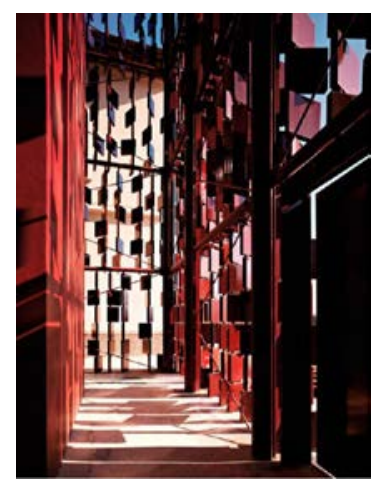

Figure 5.2: Interior of Nembro Library Expansion, Italy (Ceramic Architectures, 2015)

While these materials do not show much promise for the Peering In design the Nembro Library Expansion in Italy is an interesting precedent that shows a creative way of expressing the form of the extension's function (Figure 5.1). Randomly rotated red terracotta tiles that appear to be books turning in the wind run up vertical posts that make up the library extension screen wall system. According to Giuseppe Pezzano, who works with the designing architecture firm Archea Associati, the concept was to create a building that explains its own function in line with the nineteenth century practice of Architecture Parlante associated with architectural theorist Claude-Nicolas Ledoux. The series of contrasts between the new extension and the original building built in 1897 provides a heightened sense of value for both as displayed by Figure 5.1. While the new extension offers an alternate experience to visitors, its existence depends on the main building since the extension can only be accessed through the main library, creating a intertwined 
experience between new and old (Bollack 158). While books rest of shelves on the interior, they also appear to flow down the face of the façade. The sun's light creates a set of dynamic shadows that transpose the façade’s form inside, as displayed by Figure 5.2.

\subsubsection{Wood}

Wood has greater promise for the proposed screen wall system than mineral or concrete materials, since it is less expensive, less brittle, and not as thick. Its natural aesthetic makes it an appealing material but it requires frequent maintenance when exposed to exterior conditions. This material is also combustible, which will more than likely deem it unusable by the building or fire department for the proposed application due to the building's fire rating.

A trip to the Salk Institute in San Diego by the author made it evident that exposed wood ages quickly, especially when not treated. While the rest of the institute's building exterior was in terrific condition the teak wood used as seen on Figure 5.3 had weathered significantly. The designer Louis Kahn used teak wood since it was used in shipbuilding due to its durability. Therefore, even a prescribed wood type weathers badly when exposed. The lighter shaded teak wall section on Figure 5.3 is a recently restored panel that reflects the significance weathering has on the other panels.

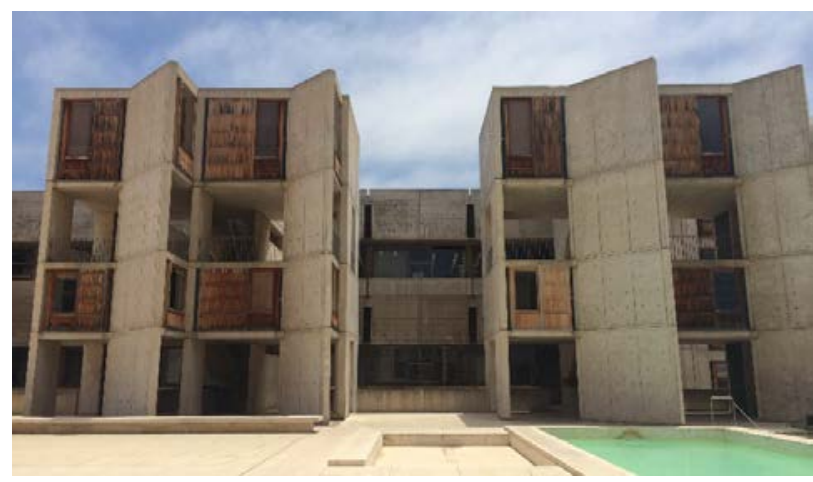

Figure 5.3: Salk Institute, San Diego (Heneghan, 2015) 


\subsubsection{Glass and Plastic}

Glass is typically made transparent allowing for connection between the inside and outside worlds. This material had been used intensively in façade designs by modernist architects up until the present day. Its brittle nature makes full panels susceptible to breakage even if only a small portion of a panel is damaged. Corners and edges are especially vulnerable. Therefore, glass is typically enclosed in a protective frame. Glass's low insulation rating also reduces its ability to limit solar heat gain and heat lose when there is a temperature differential between the interior and exterior environment. This makes it a poor environment and economical choice since its use will increase energy usage to either heat or cool the interior space. While glass has its limitations it has been used in an expressive manner successfully for building façades including the design of La Defense and the addition to the Nelson-Atkins Museum of Art.

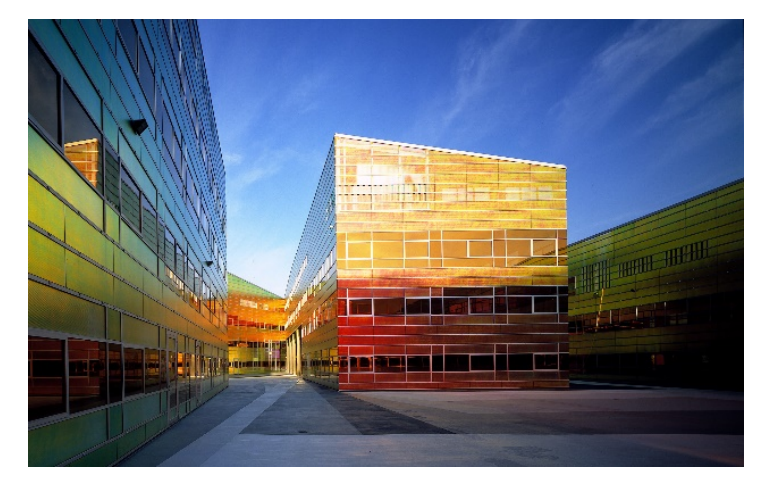

Figure 5.4: La Defense, Netherlands (UNStudio, 2015)

UNStudio’s La Defense building (Figure 5.4) was built in 2004 in Almere, Netherlands. The building's façade is cladded with glass panels that use a multi-colored foil system. This system allows the building to change color as the sun's angle of incidence changes throughout the day. 


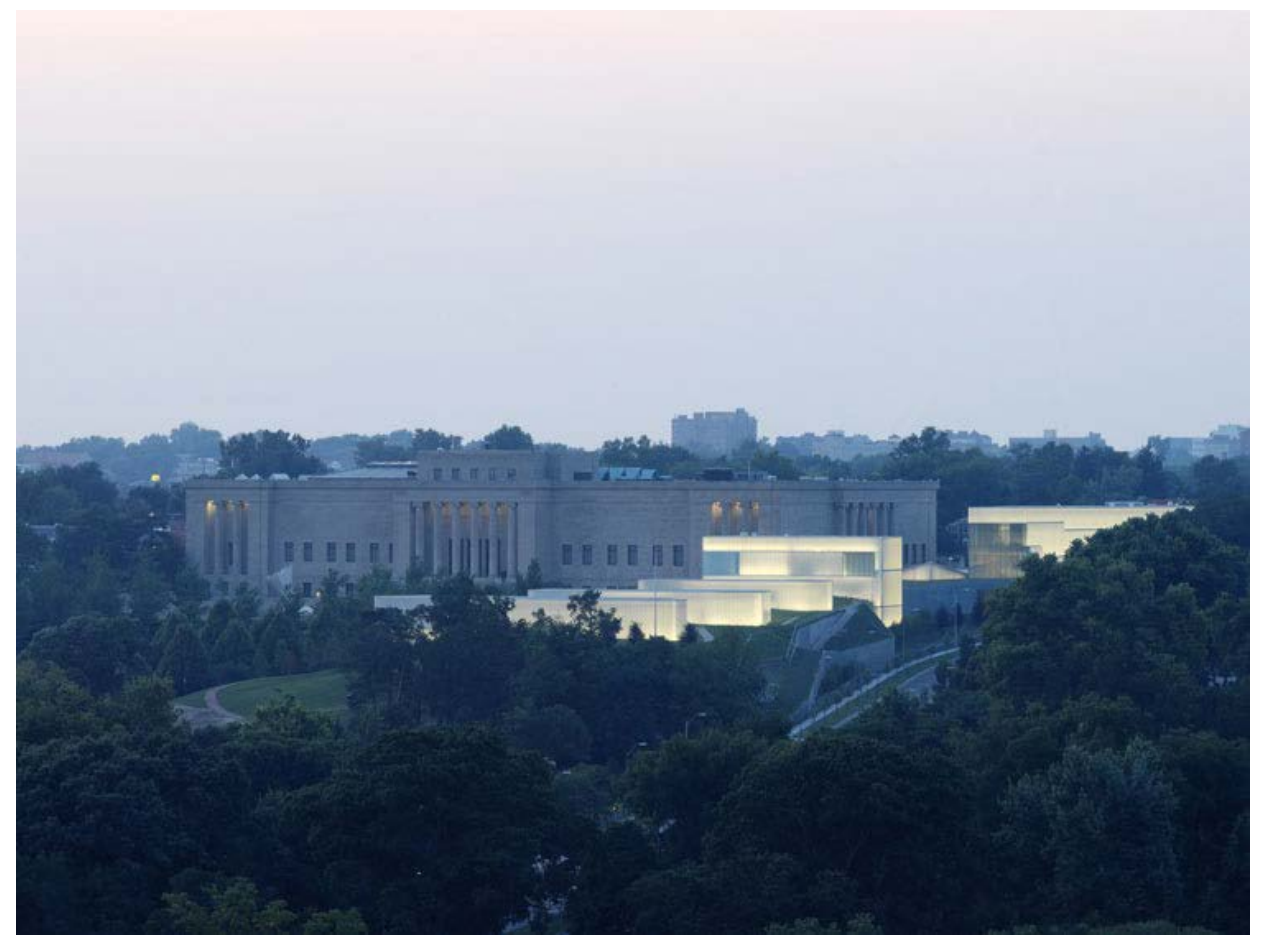

Figure 5.5: Nelson-Atkins Museum of Art Extension, Missouri (Steven Holl, 2015)

The addition to the Nelson-Atkins Museum of Art by designer Steven Holl Architects in Kansas City, Missouri was built in 2007. This design forgoes the typical transparent glass quality for a translucent quality. Instead of allowing the light to shine through the façade, the translucent channel glass system captures the light. This approach transforms the building extension into a radiating lantern at night (Figure 5.5).

Plastic is a modern material that is widely used as a building material and in many cases acts as a substitute for glass as a transparent or translucent material. While plastic materials like carbon fiber reinforced plastic is extremely strong and lightweight its current cost is not economical for the construction of the screen wall system. Other polymer based materials are used extensively in construction including applications such as piping, adhesive, insulation, waterproof members, sinks, and flooring but there are no clear materials that can be used to create an affordable perforated screen wall system. 


\subsubsection{Metal}

Metal's strength and beauty has made it a popular design choice. The area of architectural metals is dedicated to its use as a functional ornamental element. Metal needs to be protected from corrosion and if it acts as a structural member it needs to also be protected from fire. While the majority of metals rust when exposed to exterior conditions some do not including copper and aluminum which oxidize resulting in the creation of a protective patina barrier.

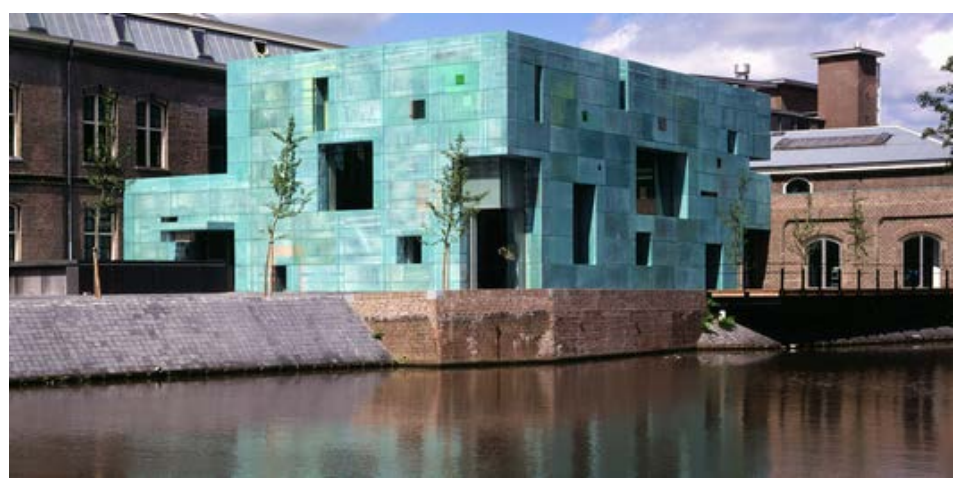

Figure 5.6: Sarphatistraat Offices, Netherlands (ArchDaily, 2015)

Design and built between 1996 and 2000, the Sarphatistraat Office building project by Steven Holl Architects (Figure 5.6) involved the renovation of a U-shaped brick building including a green perforated copper exterior cladding which complementary contrasts the surrounding red brick courtyard and buildings. While the use of oxidized copper is effectively applied to this design by Steven Holl Architects, the use of copper for the Peering In project is cost prohibitive due to the present day high cost of copper. 


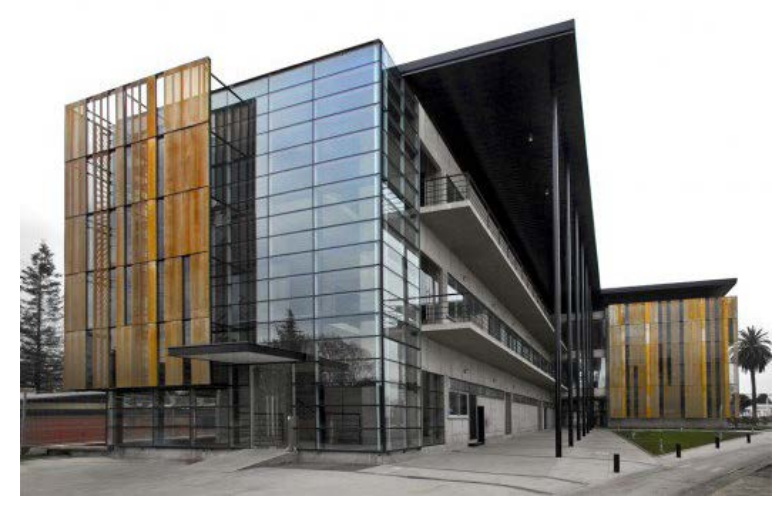

Figure 5.7: Nestlé Chile S.A. Cor-Ten Steel Skin (ArchDaily, 2015)

The design of Nestlé Chile S.A. located in Graneros, Chile incorporates a Cor-Ten steel screen wall as a second skin. Cor-Ten steel is the trademarked name for a steel alloy originally produced by United States Steel. It is a weathering steel that is corrosion resistant and if left uncoated it produces an outer rust colored patina as seen on Figure 5.7. Disadvantages of this material include the fact that the material is not rustproof and when exposed to atmospheric pollutants the rusting process is accelerated. This material also bleeds rust onto surrounding surfaces. These disadvantages make this material unsuitable for the proposed screen wall system even if the desired color of the new screens was to be rust colored.

Aluminum products are corrosion resistant, weatherproof, and have a very high strength-to-weight ratio (Figure 5.8). Its durability helps reduce maintenance costs and its purchase cost is far less than metals like copper.

Aluminum has also been used sustainably in the United States since the early 1900s. A reflection of aluminum's sustainable nature is the fact that nearly 75 percent of the aluminum produced in the United States is still in use due to its high recyclability. This recycled material saves over 90 percent of the energy needed to collect and process raw material. (The Aluminum Association, 2015) 


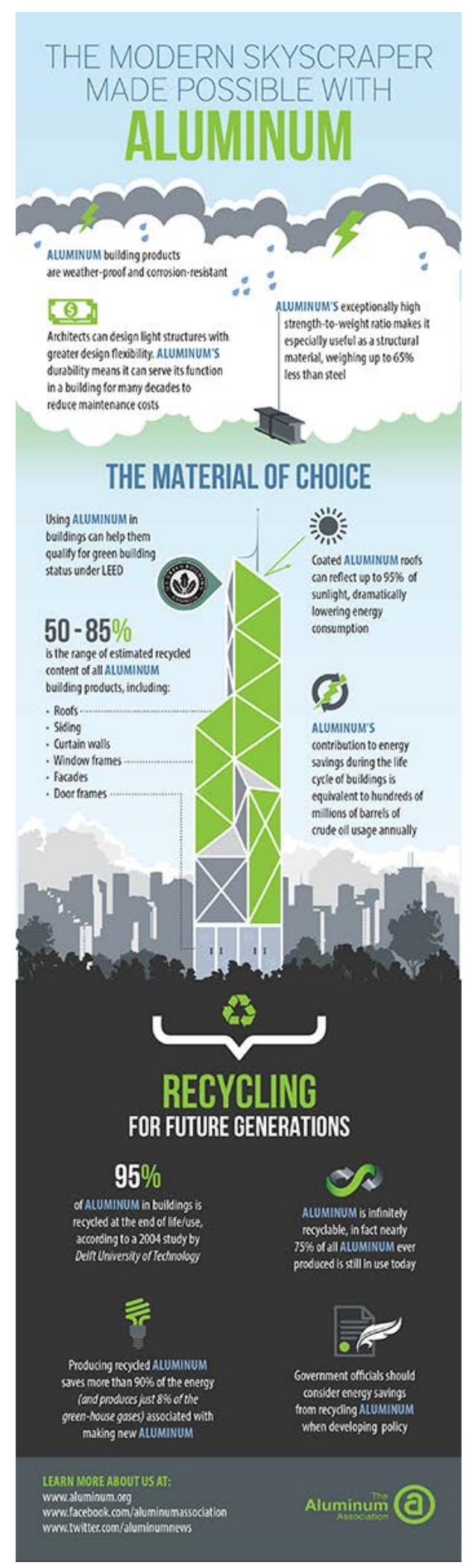

Figure 5.8: Construction Benefits of Aluminum (The Aluminum Association, 2015) 


\subsection{Finishes}

Since aluminum will be the primary material used, determining a suitable finish to achieve the desired look is required. There are multiple finish options to choose from for the aluminum panels used for both interior guardrails and exterior screen walls. For this project three finishes will be decided between including wet coating, powder coating, or anodizing to obtain the desired finish.

Applying organic powder through electrostatic attraction to metal is referred to as powder coating. Powder coating has the following benefits over traditional wet painting: it is more economical since there is not a loss of material due to overspray, its application is safer as it is less likely to be inhaled due to its solid and inert form unlike wet paint that is sprayed on, and it is better for the environment since it does not contain harmful solvents or VOCs as paint may. Furthermore it can be applied quicker than wet paint since it typically only needs one coat to finish, and its application generally produces a thicker more flexible coating that is tougher than conventional paint. (Sparta Engineering, 2015) While wet paint has the benefit of being available in more finish colors and if desired a thinner layer of paint can be applied; these factors do not impact this project. The number of available powder coat options are still extensive, for example Prismatic Powders offers six thousand five hundred options (Prismatic Powders, 2015). Therefore, the color limitation will not be an issue. Also, for this project a thicker layer of paint is desired since screens will be exposed to exterior weather conditions. (Midwest Metal Products, 2015)

A protective coating for metal can also be achieved through an electrochemical process called anodizing. The coating is integral with the metal and therefore will not peel or flake off. It can also be colored by using dyes. Generally this process is less expensive 
than wet painting or powder coating and in high traffic areas the coating can take more physical abuse. Anodized metal such as aluminum also is unaffected by sunlight, which degrades the other two organic coatings in consideration. The biggest drawback to anodizing over wet painting and powder coating is the fact that it is difficult to control color variation in treated metal. (Southern Aluminum Finish Companies, 2015) Since controlling the finish color is an important element of the design, powder coating appears to be the best finish option for this project. A smooth finish can also be achieved by powder coating the surface which will aid in increasing the ability of the screen walls to reflect sunlight and its associated heat gain. 


\section{Texture}

It is important to determine a suitable perforated pattern for the screen walls that are to be introduced including guardrails for slab openings and interconnecting stairs. Ideally the pattern should function to allow sufficient light into the space while helping reduce the heat gain within the space. More importantly the pattern should create a more enjoyable space for the occupants and visitors to the local area.

Lenclos demonstrates the power that a simple perforated pattern has when struck by the evening's sunlight (Figure 6.1). Even though the building's façade and exterior fire escape are painted the sample light blue color, the movement of light over the stair's perforated form creates a beautiful dynamic space.

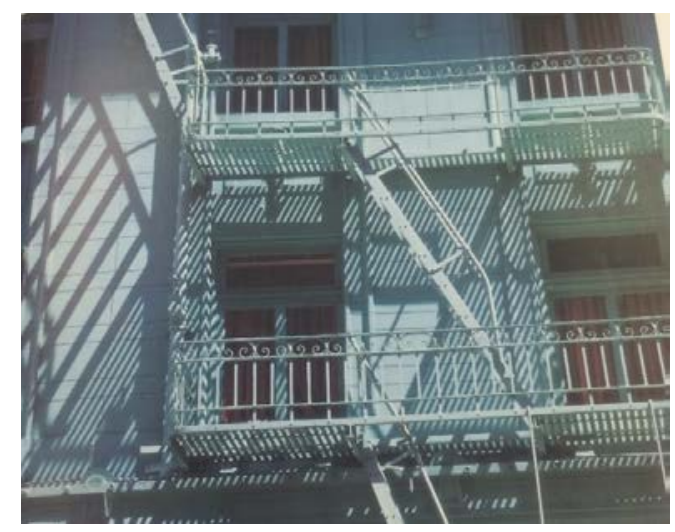

Figure 6.1: Iron Fire Escape in San Francisco (Lenclos, 77)

Modern day advances in fabrication have allowed for greater degrees of customization in perforated forms to take place at lower cost. Design Blitz has taken advantage of these developments as displayed by their walkway design at One Workplace Headquarters in Santa Clara (Figure 6.2). While at $35511^{\text {th }}$ in San Francisco a tighter knitted set of tiny holes were made in a corrugated metal screen to allow light and air in while maintaining the original exterior appearance due to the building's historical status as seen on Figure 6.3 and Figure 6.4. 


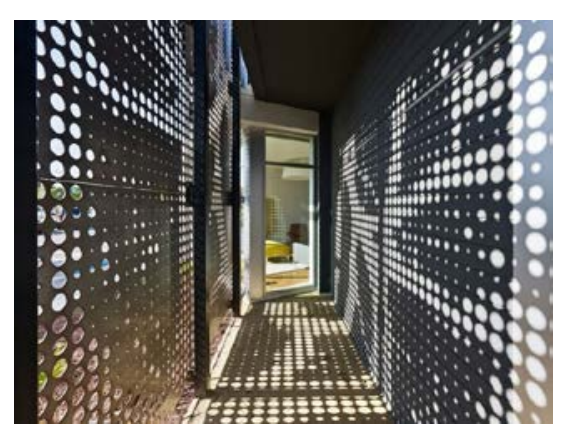

Figure 6.2: Walkway at One Workplace Headquarters (Comtemporist, 2015)

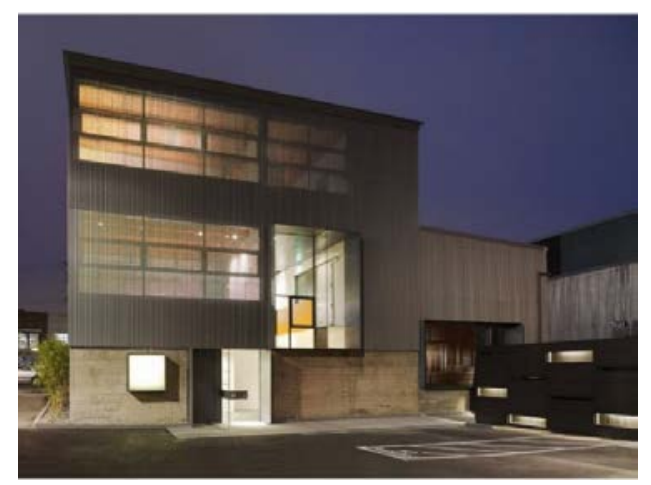

Figure 6.3: $35511^{\text {th }}$ Street Perforation (ArchDaily, 2015)

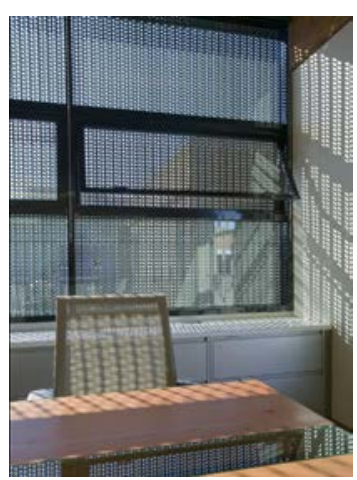

Figure 6.4: Converted 355 11th Street, San Francisco (ArchDaily, 2015)

Figure 6.5 shows the original elevation and the proposed façade modifications to this historic warehouse. The warehouse's new perforate wall acts as a second skin, aiding in mitigating solar heat gain while helping maintain the buildings original industry character. Peering In's design can similarly take advantage of limiting heat gain through the introduction of the proposed screen walls. 




Figure 6.5: Proposed 355 11th Street Conversion, San Francisco (ArchDaily, 2015) Another approach to a perforated wall is reflected by Dutch architect Erick van Egeraat's award winning design of the Roskilde Incinerator located in Denmark. A perforated umber-colored aluminum façade encloses the plant's functional core. Circular holes that were laser cut increase in density as the structure reaches up around the spire. The façade is backlit at night to glow as a symbol of the plant's energy production as seen on Figure 6.6.

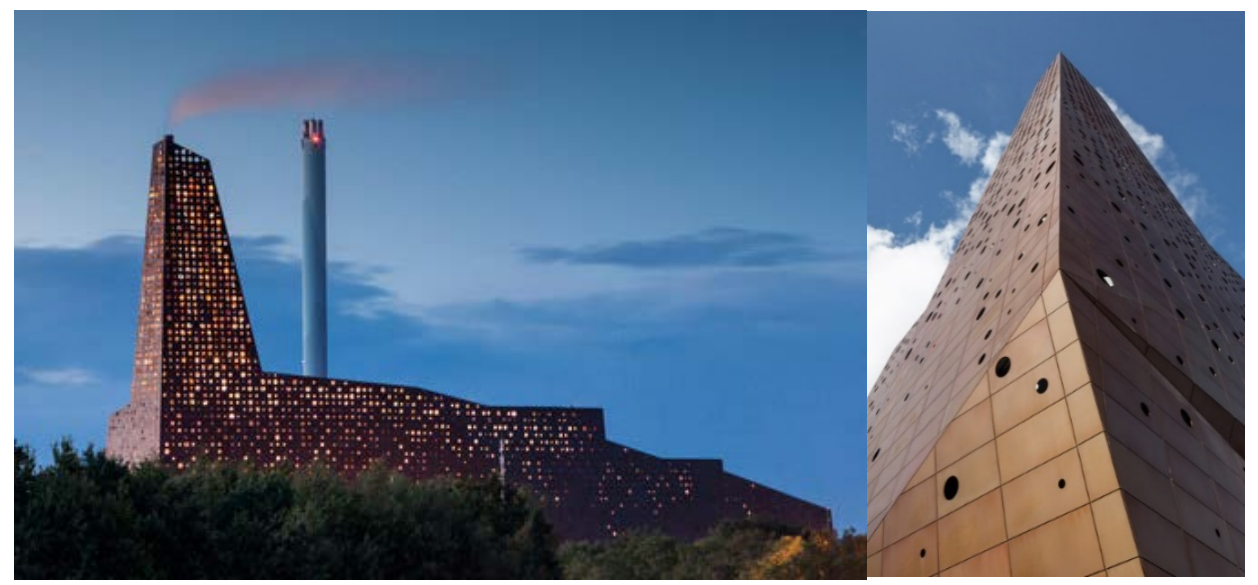

Figure 6.6: Roskilde Incinerator Perforated Aluminum Façade (Dezeen Magazine, 2015) 


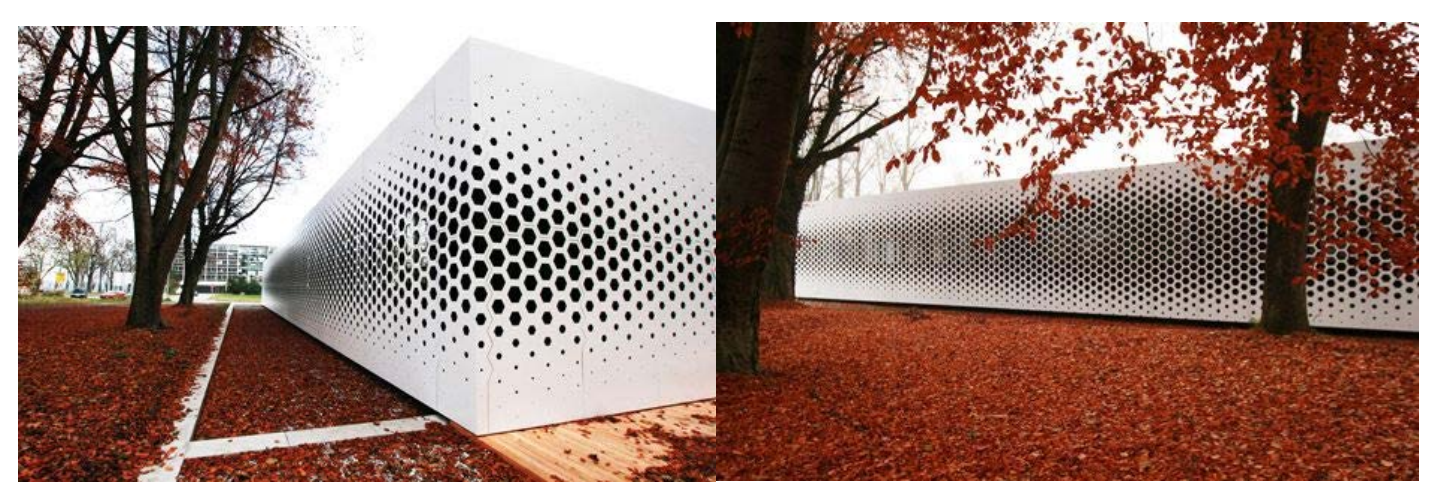

Figure 6.7: Campus Netwerk Exterior Façade (Dezeen Magazine, 2015)

The development of parametric software has allowed Format Elf Architekten to concentrate a pattern of hexagonal holes in areas that required more sunlight due to existing shading from surrounding trees for the Campus Netwerk (Figure 6.7). This Germany office building's aluminum hexagon façade was added to control daylight entering the interior.

Experiments in porosity continue to push the boundaries of perforated patterns as displayed by Figure 6.8. These experiences were carried out by Steven Holl Architects. Design projects that takes advantage of CNC driven digital fabrication have a variety of available perforation options.

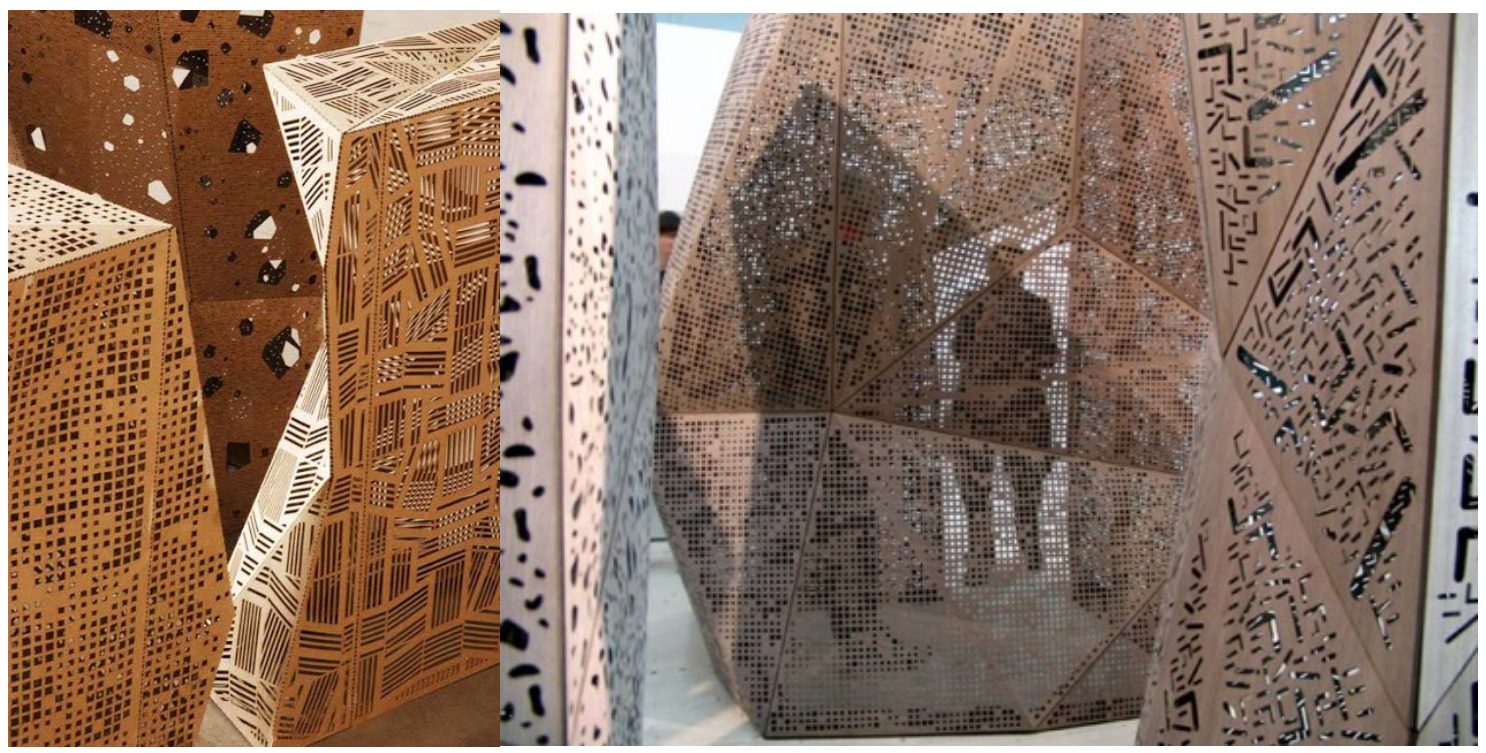

Figure 6.8: Experiments in Porosity (Ponoko, 2015) 
The Vanke City Center Sales Gallery project's perforated exterior skin offers the greatest degree of promise for the Peering In project (Figure 6.9). This project uses a highly porous screen wall that is made up of a double layered panel system that uses two contrasting colors.

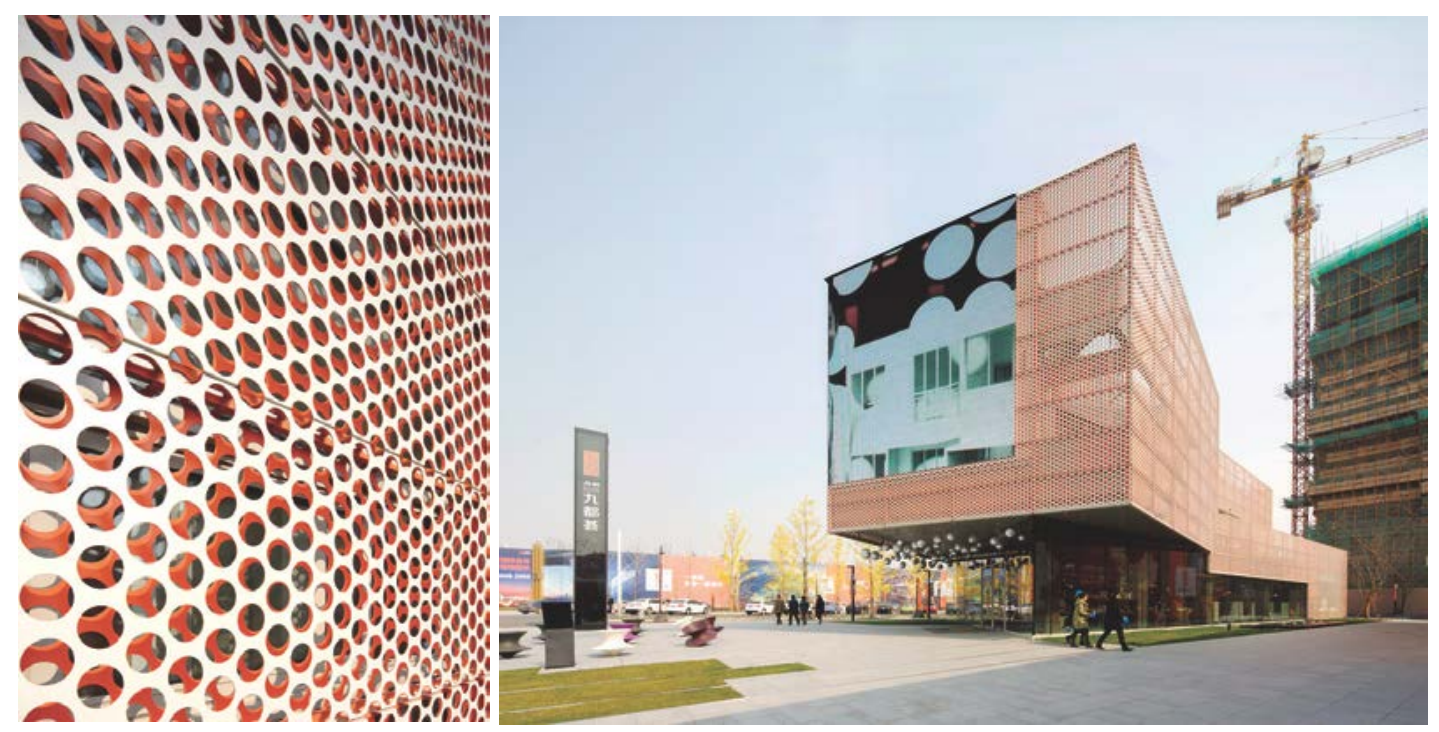

Figure 6.9: Vanke City Center Sales Gallery Project (ArchDaily, 2015)

The Peering In screen walls are to be incorporated into the building as portion of its exterior skin. These architectural element while add texture to the Union Bank Plaza's building inside and out. These screen can help limit glare and heat gain during the day while allowing for those to view the outside world in a new manner. At night, artificial light that shines through the screen walls will highlight the building’s new texture. 


\section{Design}

The project's goal of providing affordable incremental improvements can be achieved by introducing perforated screen walls between exterior columns of the Union Bank Plaza which sit proud of the exterior glazing system. This undertaken can be reinforced with the addition of slab openings and interconnecting stairs between stacked floors. These slab openings and interconnection stairs have been outlined on the building models Appendix A but have not been described in depth since the primary focus of the project is the design of the exterior screen wall system. The screens will function to diffuse natural light and reduce building heat gain, while its color and form will provide visional appeal for occupants and passersby. Slab openings and interconnecting stairs will allow for vertical mobility of occupants. These elements will provide variety amongst floors not experienced by occupants of a traditional office space.

\subsection{Integrated Building Envelopes}

The design for this project is focused primary on the screen wall systems but also touches on interconnecting stairs and slab openings. Correcting performance problems, projecting a more desirable image, and addressing the needs of new occupants are the three primary drives of most facade retrofits including this project (Gonchar, 2013). Assigned weights to these three drivers differ for every project but at the same time these elements are closely intertwined. For this project the addition of visually appealing screens promotes the health and well-being of the building's occupants while attracting outsiders into a once

muted office environment. This system also helps improve the building's performance by reducing heat gain and glare through the existing glazed building envelop that was updated in the nineties. 
There is not a perfect solution that works for the upgrade of every building envelop application and unlike many others the proposed modification adds to the existing envelop it does not replace it. The upgrade of 185 Post as outlined in Chapter 2 similarly adds to the building with the addition of a second glass skin. Finding the right balance between the form and function for the proposed application was a complex challenge that needed to consider an array of parameters including the user requirements, environmental impacts and climatic factors such as humidity, wind, sun, moisture, and temperature. The new screen system that is to be integrated into the building will aid in reducing the solar gain by reflecting some of sun's rays away from the building's interior. This reflection is increased through the use of bright colors that have a higher Solar Reflective Index. Higher concentrations of brighter colors have been incorporated into the design on the two southeast and southwest facing elevations since the sun's intensity is greatest on these two sides of the building.

The design of the façade system needed to consider the needs of multiple disciplines especially those of the structural engineer and architecture. The structural engineer's primary consideration will be providing a solid connection between the screens and the building. Making sure the screens stay intact without compromising the existing structure is paramount. The screens will not only have to resist the load of their own weight, but will need to resist climatic and seismic forces.

The architect on the other hand will need to consider a much larger array of functions that a façade system aims to provide. These function include life safety, security, insulation from the hot and the cold, noise protection, solar gain, visual protection, views and waterproofing (Figure 7.1). Since the proposed screen section is an added layer to the 
existing façade system it does not need or aim to address each of these function noted but it can assist the existing weather tight glazing system.

Significant historic events can help provide guidance to a complex system like the modern day façade. The energy crisis in the 1970s and the rise in public awareness in the 1960s highlighted environmental issues to architects. Mike Davies’s and Richard Rogers's critical assessment of modern architects' love affair with glass and transparency in A Wall for All Seasons highlights the importance of energy usage to an architectural design.

By considering sustainability when making each major design decision, a more robust energy efficient design can be created. Selecting durable materials with life cycles that are not detrimental to the environment is one strategy that has be employed into this design by selecting aluminum as the primary material. Combining this practice of sustainable material selection with other passive strategies will not only help create a healthier environment but it will help push down energy used to maintain daily operations.

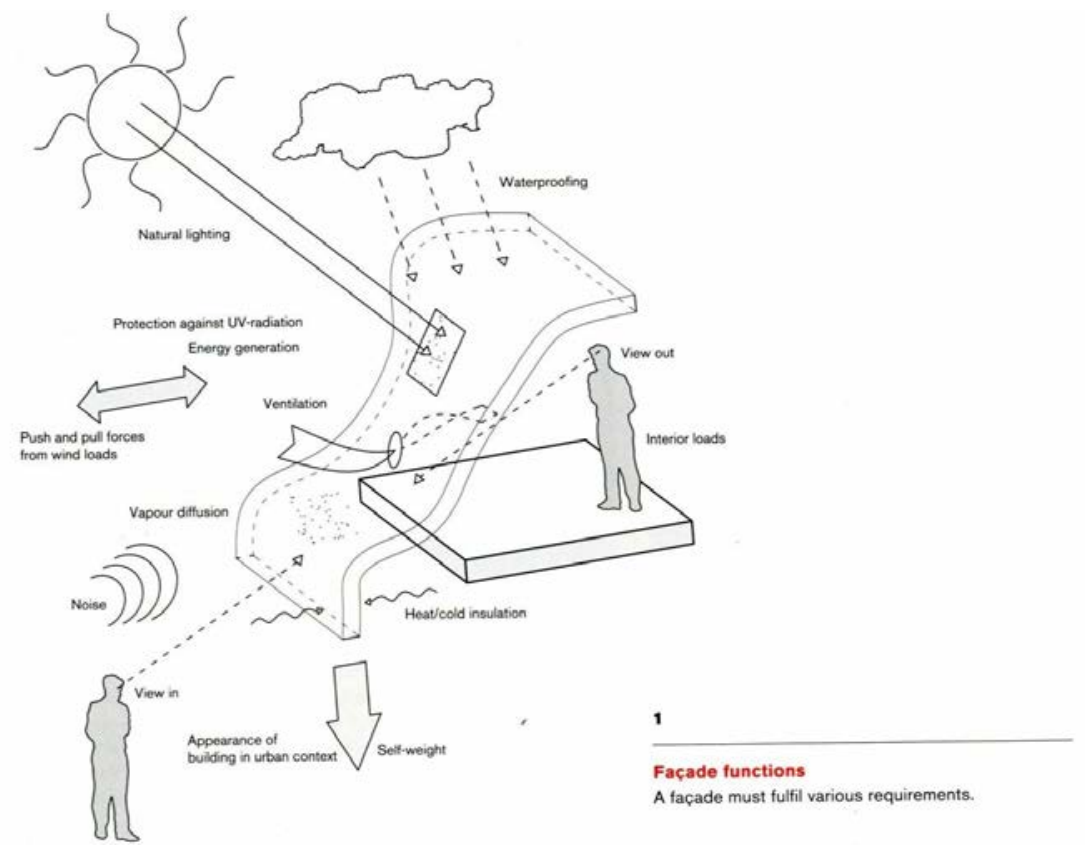

Figure 7.1: Integrated Façade (Knaack et al 36) 
These screens take advantage of passive architectural strategies, which will aid in reducing the energy demanded to create a comfortable space. They will help create a cooler interior space by acting as barriers to the sun that currently beats upon the glazing system. These screens also diffuse light through their perforated panels, which limits glare. By painting the screens that face the exterior brighter colors like orange and yellow, higher levels of the sun's heat will be reflected as opposed to darker more heat absorbing colors as outlined on Figure 7.2.

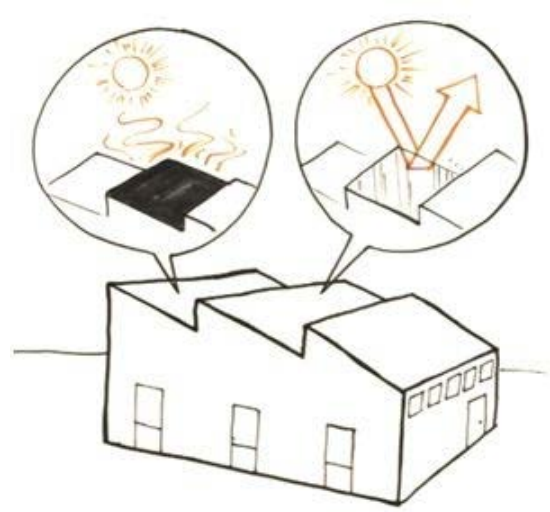

Figure 7.2: Hot Black Roof versus Cool White Roof (AutoDesk, 2015)

As displayed by Figure 4.19, window shades similar to those produced by MechoSystems are incorporated into commercial tenant improvement projects to help limit glare and solar gain. The incorporation of such a shade system is another passive strategy that will complement the screen walls by limiting glare and solar gain, as well as aiding in controlling the degree of color saturation occupants will be exposed when a calmer environment is needed. 


\subsection{Design Details}

Designing a system that meets the goals outlined by the problem statement in Chapter 1 was a huge challenge. Research into dozens of precedents, a site visit, exploration of the site's local area, as well as research into numerous physical characteristics of an architectural system including color, material, and texture were all important steps in the design process. The creation of a design that not only will be durable and affordable but will tie in with the surrounding cultural context was the outcome.

Peering In’s prescribed colorful screen wall system covers the exterior of the Union Bank Plaza building from Level 2 to Level 40 as shown by Appendix A Sheet A9. The colorful building rendering stands alongside a rendering of the existing monotone building. The selected colorful palette of these screens match the palette of colors displayed by Figure 4.13. While Appendix A Sheet A9 shows how colorful screens layout on a whole building scale, it is extremely important to note that each screen displayed on this rendering is made up of a two panel system that is perforated. While the panel facing the exterior is that of the color shown on Sheet A9, it is backed by a second panel of contrasting color. This second panel of contrasting color can be seen through perforations as shown by Appendix A Sheet A11. This drawing provides a more detailed view of the interaction between both interior facing and exterior facing panels.

The color palette and perforation of these screens offers further opportunities to liberate occupants from a monotone interior through the incorporation of these design elements into interconnecting stairs between three different sections of Union Bank Plaza. The first through third levels, fourteenth through fifteen levels and eighteenth through twenty-third levels make up the three different sections showcased by Appendix A Sheet 
3 to Sheet 7. Not only do these three building cuts reflect the potential vertical integration interconnecting stairs can add to the design, they outline how the screen elements and interconnecting stairs can be unified by sharing the same colorful palette of colors and perforated patterns for stair elements. These renderings on Sheet 3 to Sheet 7 show a demo plan, complete plan, new stair and rail plan, and new façade plan. The demo plan outlines in dark blue the slab openings and exterior sunshades that are to be removed prior to install of new stairs, rails and exterior screens.

While the bold palette of colors used for Appendix A's design may delight when installed, occupants may grow tired of the colors selected. The versatility of the system will allow installed screens to be easily removed and powder coated with newly desired colors without the need for demolition. Appendix B and Appendix C offer two of thousands of available palettes that these screens could be recolored to meet new tastes.

\subsection{Construction}

Over time the design was refined to cut down on variations in the screen wall and stair systems. This will save on element customization costs during fabrication and will help simplify installation. Appendix Sheet 10 provides construction details for the screen wall assembly.

While fashion treads in the apparel industry are short-live but are easily changed and customized to meet the needs of individuals. Architecture has struggled to be as dynamic when it comes to meeting the needs of those that it serves. Creating a set of architectural elements that are less invasive to the building's core elements that can be changed out to meet changing treads was an important design element. The proposed screen wall system has been designed with a high level of consideration for the versatility 
of the system. Screen walls can be installed, disassembled and modified with ease as outlined by Appendix C Sheet A10. Sheet A10 reflects details that show how panels can be hung on posts and secured with a metal top plate that can be easily remove to allow panels to be swooped out or taken back to the shop for modifications. The construction sequence and the estimated timeline of the screen wall project is outlined by the schedule per Appendix D. If desired another phase can be added to the project to add the interconnecting stairs between floors. 


\section{Conclusion}

The project's design has evolved from a narrow vague focus of connecting a prefabricated façade system to one or more unspecified existing buildings. The final design not only outlines the connection of a new screen wall system to the face of the existing Union Bank Plaza building, but it includes the design of this system, construction details and insight into how this design can continue to evolve by adding interconnecting stairs and openings between floors.

The author took a holistic approach to this project of not focusing purely on the development of the aesthetics of the design, which is the downfall of many architectural design projects. Creating pretty pictures of a design that can never be built since the stakeholders' needs are given little consideration is a shortsighted design approach. Bloszies outlines a methodology in Chapter 4 Project Execution of his book Old Buildings, New Designs that consider a range of parameters that impact the success of adding new architectural elements to an existing building including: stakeholders, expectations, design difficulties, building in the already built environment and successful execution (p49).

\subsection{Stakeholders}

First the needs of the typical stakeholders, which are often conflicting, must be considered for successful execution of the project. These stakeholders include the owner,

the design team, the local planning department, special regional commissions, the local building department and special interest groups (Bloszies, 49). 
The owner's desire to get the greatest economy for the investment made is factored into the design. With a strengthening commercial market as outlined in Chapter 1, offering a more desirable work environment will help command higher rents. The main design element is the screen wall system which has a low design and construction cost due to the limited impact on the existing building, simple architectural design and ease of installation. Also the design has versatility that allows the system to be removed or updated easily, a short implementation duration allowing for the investment to be capitalized upon, limited risk since the added architectural elements can be phased in construction allowing for assessment of the benefits with low costs, and the ability to incorporate interconnecting stairs and openings that use architectural elements that reinforce the perforated metal screen palettes.

The architect's and their broader design team's desire is to create a quality integrative design that links the new and old. While modernists fought to eliminate ornamentation from architectural design, arguing the fact that these elements are unnecessary and quickly go out of style, this view is rarely supported by the populace (Bloszies, 16). Since the Union Bank Plaza building employees the modernist architectural system the integration of the proposed new architectural elements into the existing design considers the modernist architectures' viewpoint along with the views of the present day populace and designer. Modern digital tools and manufacturing equipment will allow the design to incorporate colorful perforated aluminum screens that are far removed from the classical style that modernist architects rebelled against. In addition, the design has factored in the rapidly evolving twenty-first century culture by designing a screen wall system that can be easily updated to meet changing needs. 
The Department of City Planning's greatest priority is to serve the common good of the city's community. The Union Bank Plaza is an important Los Angeles landmark since it set the milestone as the tallest building in the region in 1968 and was one of the first skyscrapers in Bunker Hill, which underwent a huge redevelopment to become Los Angeles's business center. This building stands as a testament to the financial stability of this banking institution since the Union Bank is the building’s main tenant. As a banking center, the International Style the architect employed complements the bank's goal to reflect purity through its form and a degree of sophistication. As outlined in Chapter 3, the surrounding community has grown into a center for the Arts. The building can adapt to meet the needs of its surrounding community and its occupants who live in this expressive land through the integration of the proposed colorful screen walls and complementary interior communicating elements.

The Department of Building and Safety's priority is safety. The addition of the screen walls will not impact the structural integrity of the existing building. Careful planning has gone into the plan that will lead to safe installation of these screen wall sections with minimal disruption to the building's occupants and passersby. The addition of the interconnecting stairs and other slab openings will require added structural support, but these supports will be limited to two sides of each new opening. Each opening lines up with two beams to limit the structural upgrade required if it is decided to add openings and interconnecting stairs.

The needs for any potential special interest advocates that may speak up when the project is submitted to planning for approval will be narrow in focus to meet their specific agenda. It will become evident during planning if there are any special interest advocates 
that raise issue with the current design. Prior to submitting the design for planning it is recommended that steps are taken to contact local art organizations including the Museum of Contemporary Art (MOCA) Los Angeles, the Los Angeles County Arts Commission, and City of Los Angeles Department of Cultural Affairs Public Art Division. These local bodies could provide valuable feedback on artistic desires of the local people and visitors to the region. Their inclusion in the process will be a positive reflection to special interest advocates and the planning department who will weigh in on appearance of the new screens that will be visible from the surrounding public space. Numerous art bodies also provide financial incentives for a number of publicly accessible art installations including the Los Angeles County Arts Commission which allocates one percent of the design and construction costs of new county capital projects to the Civic Art Special Fund since 2004.

\subsection{Expectations}

The second consideration is determining how many jurisdictions will be involved in the approval process, the type of approvals that are needed and how long it will take to receive approval. There are three categories that should be considered: environmental impact, planning and zoning compliance, and building code conformance. (Bloszies 52)

The environmental impact of all construction projects in California fall underneath the California Environmental Quality Act of 1970. Due to the small scale upgrade to the existing building, constructing the proposed design is exempt from the act's requirements per Article 15301. Existing Facilities.

Complying with planning and zoning requirements is the second category that needs to be considered. Since the exterior of the building will require small modifications 
due to the fact that the screens are being added the planning department will need to review the design. Large cities like Los Angeles have a historic preservation office within their planning department. Department of City Planning’s Office of Historic Resources has a list of buildings and structures designated as Historic-Cultural Monuments. The Union Bank Plaza is not on this list and therefore, will not be restricted from making sufficient modifications to its façade. Since the building's use will have little to no change, zoning will not be change.

The third and final category to be considered is compliance with the building codes. Since the building improvements proposed are small in scale, especially with respect to the screen walls, building officials more than likely will only request these new elements meet current codes and will not to request that whole building floors are brought up to current code. The incremental improvements proposed will allow the building owners to take advantage of grandfather policies that allow the existing building elements to remain as is, especially since the proposed upgrades do not tie into the existing electrical system and window envelope, which are subject to new Title 24 regulations.

The screen wall system's addition can easily meet new code requirements. They will be inaccessible to the public, therefore upgrades to meet the Americans with Disability Act will not be required. The screens' supporting frame system can be tied securely into the existing perimeter slab with minimal distribution to the structure by using concrete anchors.

In accordance with Section 706 of the California Building Code the interconnecting stairs and slab openings proposed will not require a fire-resistance rated enclosure since no more than two floors are connected. Additional fire sprinklers can be added underneath 
stairs when each floor space is modified to meet the needs of the new space. The new stairs and guardrails around openings can also be designed to meet current code dimensions for these elements.

\subsection{Design Difficulties}

Working new elements into an existing building can pose a range of technical challenges not faced when constructing a new building. Existing conditions need to be reviewed and documented for an accurate design to be created. In addition, original construction documents need to be obtained to allow for a review of hidden elements and to develop an understanding of the materials used to allow for compatibility of the new design with the existing building. An example of the hidden elements that need review are those above the exterior soffit, which will need to be opened up to connect the supporting screen elements to the slab above, while avoiding perimeter beams. If construction documentation is lacking, investigation into the existing conditions is promoted to reduce the potential unknowns that may impact the design’s successful implementation.

It is recommended that the strength of the existing concrete slab is tested since this factor will drive the selection of the concrete anchor that is to be used for the screen connections. The fireproofing that covers the pan deck that the concrete anchor will penetrate should also be tested to determine what compatible material can be added to patch the fireproofing removed to install the connections for the screen posts.

If the position of the project that involves creating openings in the slab is pursued a shoring plan will need to be created to support the slab when cut back prior to new beams being added on two sides of each opening. 


\subsection{Building in an Already Built Environment}

If a crane was to be used to hoist materials up to the higher floors it would need to be large enough to hoist materials over the raise plaza and up to the twenty-sixth floor. The site is located in the busy downtown district, which would require the pick to occur during non-business hours resulting in overtime needing to be paid to workers picking and securing the material. Overall the cost of a crane would be too expensive. The design has factored this limitation in and the screen wall sections at higher floors can be installed safely without the need for a crane, scaffolding or any other special hoisting equipment.

\subsection{Successful Execution}

A number of varying parameters including changes in costs of materials and labor, as well as overcoming any unforeseen not evident during the design of the project should be accounted for by agreeing with the owner to set aside a contingency for these items and other potential cost increases. If such a step is not implemented cost pressures that arise could potentially comprising the integrity of the project. 


\section{BIBLIOGRAPHY}

AC Martin. “Union Bank Plaza.” AC Martin. Web. 06 Dec. 2015.

$<$ http://www.acmartin.com/portfolio/union-bank-plaza>

AutoDesk Sustainability Workshop. "Surface Color and Cool Roofs.” AutoDesk. Web. 08 Dec. 2015. <http://sustainabilityworkshop.autodesk.com/buildings/direct-solargain>

Band + Allen, “185 Post” Brand + Allen. Web 15 Nov. 2015. $<$ http://www.brandallen.com/185post/index.html\#>

Barahona, Cristián. “Nestlé Social Block / GH+A Guillermo Hevia.” ArchDaily. Web. 08 Nov. 2015. <http://www.archdaily.com/52763/nestle-social-block-gha-guillermohevia/>

Beckmann, Poul, and Robert Bowles. Structural Aspects of Building Conservation. Oxford: Elsevier Butterworth-Heinemann, 2004. Print.

Bloszies, Charles F. and Allie Roberson. Personal interview. 29 May 2015.

Bloszies, Charles F. Old Buildings, New Designs: Architectural Transformations. New York: Princeton Architectural Press, 2012. Print.

Boswell, Keith and Yoko Takada. Personal interview. 02 May 2014.

Brookes, Alan J., and Maarten Meijs. Cladding of Buildings. New York: Taylor \& Francis, 2008. Print.

Brown, Eliot. “Office Market is on a Slow Roll.” JLL. Web. 06 July 2015. <http://www.joneslanglasalleblog.com/investor/office-market-is-on-a-slow-roll/>

Canizaro, Vincent. Architectural Regionalism: Collected Writings on Place, Identity, Modernity, and Tradition. New York: Princeton Architectural Press, 2007. Print.

Castro, Douglas, et al. 420 Boyd St. LA. Do Art Foundation. Web. 2 Nov. 2015. $<$ http://doartfoundation.org/public_art/420-boyd-building-mural/>

Ceramic Architects. “ARCHEA Nembro Library Nembro, Italy 2007.” Ceramic Architects. Web. 08 Dec. 2015.

$<$ http://www.ceramicarchitectures.com/obras/nembro-library/>

Charles F. Bloszies Architects. “690 Folsom.” Arch Engine. Web. 06 Nov. 2015. $<$ http://www.archengine.com/690-folsom-1/>

Diamonstein, Barbaralee. Remaking America: New Uses, Old Places. New York, NY: 
Crown Publishers, Inc., 1986. Print.

“Erick van Egeraat’s Roskilde power plant has a glowing perforated façade.” Dezeen Magazine. Web. 08 Dec. 2015.

<http://www.dezeen.com/2014/09/02/incineration-line-roskilde-erick-vanegeraat-power-plant-perforated-facade/>

Erin Ashley Art. “Jewel Box.” Esty. Web. 08 Dec. 2015.

$<$ https://www.etsy.com/listing/200467852/large-painting-abstract

painting?ref=shop_home_active_9>

“Fire and police station berlin.” Sauerbuch Hutton. Web. 08 Dec. 2015.

$<$ http://sauerbruchhutton.de/images/FPR_fire_and_policestation_en.pdf >

Foulks, William G. Historic Building Facades: The Manual for Maintenance and Rehabilitation / New York Landmarks Conservancy. New York: Wiley, 1997. Print.

Franck, Karen A. Nancy Wolf: Hidden Cities, Hidden Longings. London: Academy Editions, 1996. Print.

Gensler. "NAIOP '12 Ideas Competition - Office Building of the Future." Vimeo. 2012. Web. 08 Dec. 2013. <http://vimeo.com/51982951>.

He, Shu. "Vanke New City Center Sales Gallery / Spark Architects” ArchDaily. Web. 08 Dec. 2015. <http://www.archdaily.com/500160/vanke-new-city-center-sales-galleryspark-architects $>$

"Honeycomb perforations speckle façade of Campus Netwerk office by Format Elf Architekten.” Dezeen Magazine. Web. 08 Dec. 2015. $<$ http://www.dezeen.com/2014/08/29/campus-netzwerk-office-format-elfarchitekten-perforated-aluminium/>

Hopper, Cody. “Sold Archives.” Cody Hooper Art. Web. 08 Nov. 2015.

<http://www.codyhooperart.com/sold-archives.html>

“100 Van Ness (Progression Photos).” Architect Magazine. Web. 08 Dec. 2015. $<$ http://www.architectmagazine.com/project-gallery/100-van-ness-progressionphotos>

Jessica. Design Seeds: For all who love color. Web. 08 Dec. 2015. <http://designseeds.com/>

Jelinek, Adam. "Powder Coating vs. Wet Paint and Plating." Midwest Metal Products. Web. 08 Dec. 2015. <http://www.mwestmp.com/blog/powder-coating-vs-wetpaint-and-plating/>

Jones Lange LaSalle. “Office Property Clock.” JLL. Web. 6 Dec. 2015. 
$<$ http://www.us.jll.com/united-states/en-us/research/property-clocks/officeproperty-clock>

Kieran, Stephen, and James Timberlake. Refabricating Architecture: How Manufacturing Methodologies Are Poised To Transform Building Construction. New York: McGraw-Hill Companies, Inc., 2004. Print.

Knaack, Ulrich, et al. Façades: Principles of Construction. Basel; Boston, MA:

Birkhäuser Publishers for Architecture, 2007.

Knauff, Barry. Abstract Artist. Web. 08 Dec. 2015. $<$ http://www.abstractartist.com/\#/barryknauff/>

Lancaster, Michael. Colorscape. Wiley, 1996. Print.

LA Tourism \& Convention Board. “Things to Do in Venice, California.” Discover Los Angeles. Web. 08 Dec. 2015. <http://www.discoverlosangeles.com/blog/thingsto-do-venice california>

Leibowitz, Bonny. The Bonny Studio. Web. 08 Dec. 2015. $<$ http://www.thebonnystudio.com/>

Lenclos, Jean-Philippe and Dominique, Color of the World, W. W. Norton \& Company, 2004. Print. MacGregor, Miles. Joli. 2011. LA. El Mac. Web. 11/2/15. $<$ http://elmac.net/gallery/spraypaint/page/9/>

McClatchey, Penn. "How to decide between anodizing, paint and powder coating." Southern Aluminum Finish Companies. Web. 08 Dec. 2015. $<$ https://www.saf.com/how-to-specify/how-to-decide-between-anodizingpainting-and-powder-coating/>

McLachlan, Fiona. Architectural Colour in the Professional Palette, London: Routledge, 2012. Print.

MechoSystems. MechoShade. Web. 08 Dec. 2015. < http://mechoshade.com/>

Millman, Matthew. "355 11th Street / Aidlin Darling Design.” ArchDaily. Web. 08 Dec. 2015. <http://www.archdaily.com/468061/355-11th-street-aidlin-darling-design>

Moeller, Christian. “Hands.” Christian Moeller. Web. 08 Dec. 2015. $<$ http://christianmoeller.com/Hands-1>

Moeller, Christian. “Spectators.” Christian Moeller. Web. 08 Dec. 2015. $<$ http://christianmoeller.com/Spectators $>$

Monet, Claude. “Sunrise.” Painting. Art Factory. 2 Nov. 2015. 
$<$ http://www.artyfactory.com/art_appreciation/art_movements/impressionism.htm $>$

“One Workplace Headquarters by Design Blitz.” Comtemporist. Web. 08 Dec. 2015. $<$ http://www.contemporist.com/2013/07/18/one-workplace-headquarters-bydesign-blitz/ow_170713_12/>

Prismatic Powders. Web. 08 Dec. 2015. <http://www.prismaticpowders.com/>

Reed, Mariko. "Preservation: Post Street” Architectural Record. Web. 06 Nov. 2015. $<$ http://archrecord.construction.com/tech/preservation/post_street/default.asp>

"Renovation of 680/690 Folsom Slated To Get Going this November.” Socketsite, Web. 06 Dec.2015 <http://www.socketsite.com/archives/2011/09/renovation_of_680690_folsom_sla ted_to_finally_begin.html>

Rostron, R. Michael. Light Cladding of Buildings. London: Architectural Press, 1964. Print.

“San Jose International Airport Art + Technology Program.” SEGD. Web. 08 Dec. 2015. $<$ https://segd.org/san-jose-international-airport-art-technology-program>

Schiada, Amber. “San Francisco Office Insight - Q3 2014.” JLL. 2014. Web. 11 Dec. 2013 $<$ http://www.jll.com/san-francisco/en-us/research>

Schwanke, Dean. “ULI Case Studies 680 Folsom Street San Francisco.” ULI. Web. 06 Dec. 2015. <http://uli.org/case-study/uli-case-studies-680-folsom-street-sanfrancisco/>

Shadow Monster Bear. Smile South Central. LA. Shadow Monster Bear. Web. 2 Nov. 2015. <http://www.shadowmonsterbear.com/>

Steven Holl Architects. "Experiments in Porosity.” Ponoko. Web. 08 Dec. 2015. $<$ http://blog.ponoko.com/2009/12/13/experiments-in-porosity/>

Steven Holl Architects. "Flashback: Sarphatistraat Offices / Steven Holl Architects." ArchDaily. Web. 08 Nov. 2015. <http://www.archdaily.com/201033/flashbacksarphatistraat-offices-steven-holl-architects/>

Steven Holl Architects. "Nelson-Atkins Museum of Art.” Steven Holl Architects. Web. 08 Nov. 2015. <http://www.stevenholl.com/project-detail.php?id=19>

Sykes, A. Krista (Editor). The Architecture Reader: Essential Writings from Vitruvius to the Present. New York: George Braziller Publishers, 2007. Print. 
The Aluminum Association. “Aluminum Recycling.” The Aluminum Assoication. Web. 08 Nov. 2015.<http://www.aluminum.org/sustainability/aluminum-r ecycling\#sthash.84pHOuzX.dpuf>

“The Best Places For Business And Careers.” Forbes. Web. 08 Dec. 2015. $<$ http://www.forbes.com/places/ca/los-angeles/>

“The Creative Economy.” Los Angeles Works: Mayor's Office of Economic and Workforce Development. Web. 08 Dec. 2015

$<$ http://www.losangelesworks.org/whylaworks/creative-economy.cfm>

The Editors of Encyclopedia Britannica. “International Style Architecture.” Encyclopedia Britannica. Web. 06 Dec. 2015. <http://www.britannica.com/art/InternationalStyle-architecture>

Thompson, Jason. "Powder Coating Vs Paint - What you need to know.” Sparta Engineering.

Web. 08 Nov. 2015. <http://www.spartaengineering.com/powder-coating/>

“Union Bank Plaza.” Hertz Investment Group. Web. 08 Dec. 2015. $<$ http://www.hertzgroup.com/unionbankplaza.html>

UNStudio. “La Defense Offices.” UNStudio. Web. 08 Dec. 2015. $<$ http://www.unstudio.com/projects/la-defense-offices $>$

Upton, Scott. Hidell Brooks Galley. Web. 08 Nov. 2015. <http://www.hidellbrooks.com/index/\#/artists/scott-upton/>

Weston, Richard. 100 Ideas That Changed Architecture. London: Laurence King Publishing, 2011. Print.

Wright, Angela and Chris Bailey. "The exact color to paint your office to become more productive.” A Life of Productivity. Web. 08 Dec. 2015.

$<$ http://alifeofproductivity.com/angela-wright-interview/> 


\section{APPENDICES}

Appendix A - Peering In Drawings - Sheet 1 to Sheet 11 


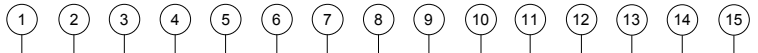

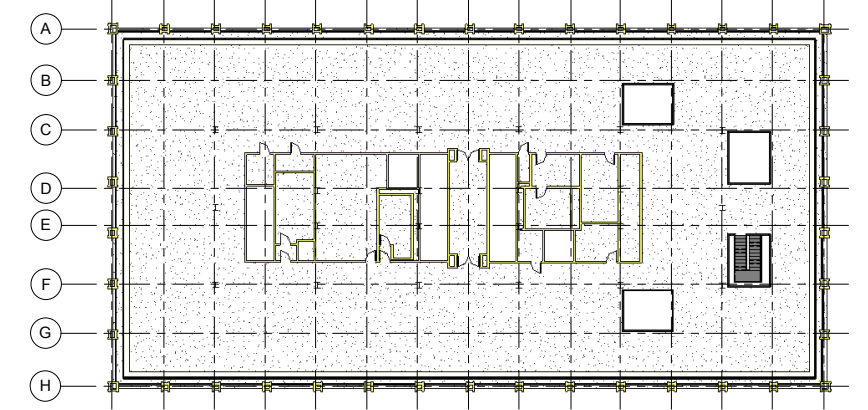

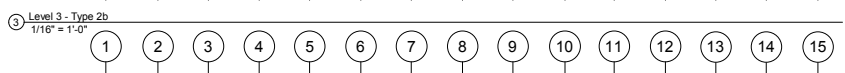

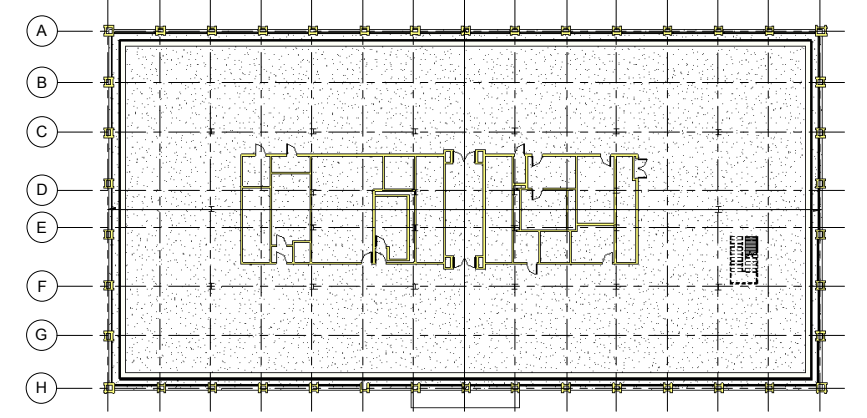

\begin{tabular}{|l|}
\hline$\infty$ \\
3
\end{tabular}

(1) (2) (3) (4) (5) (6) (7) (8) (9) (10) (11) (12) (13) (14) (15)

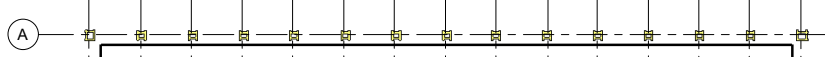
(B) - $\frac{1}{1}-1-1-1-1-1-1-1-1-1-\frac{1}{1}-\frac{1}{1}-\frac{1}{1}-\frac{1}{1}-\frac{1}{1}$ (C) - t t - t - - $-1-1-1-1-1-1-1-1-1$ (D) -

(5)

(F) -

(G) -

(1) - $\frac{1}{1} \frac{1}{1} \frac{1}{1} \frac{1}{1}$

(1) Leve1 1 - Trpoe
(1) (2) (3) (4) (5) (6) 7 (7) (8) (9) (10) (11) (12) (13) (14)

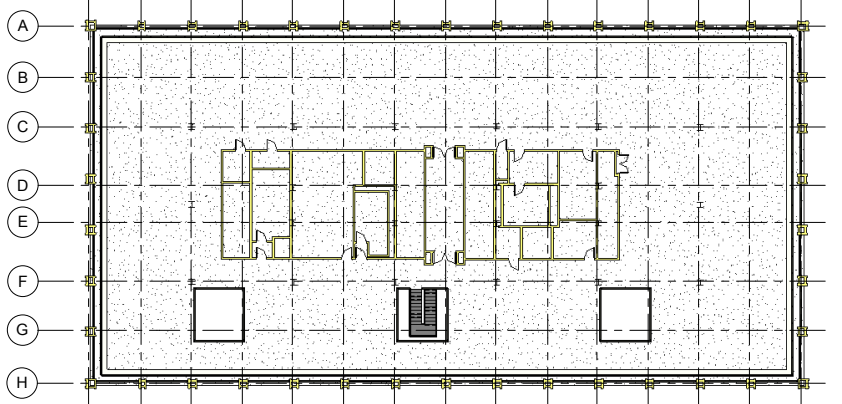

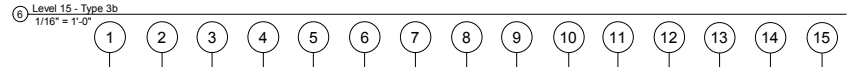

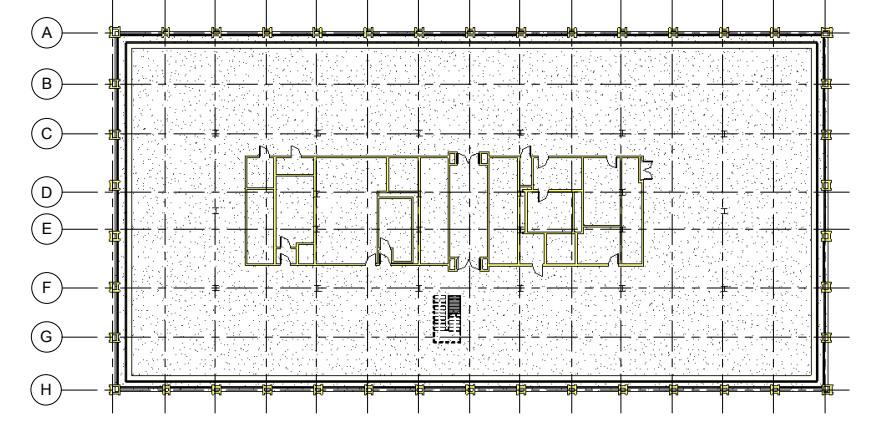

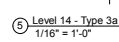

\section{(1) (2) (3) (4) (5) (6) (7) (8) (9) (10) (11) (12) (13) (14)}

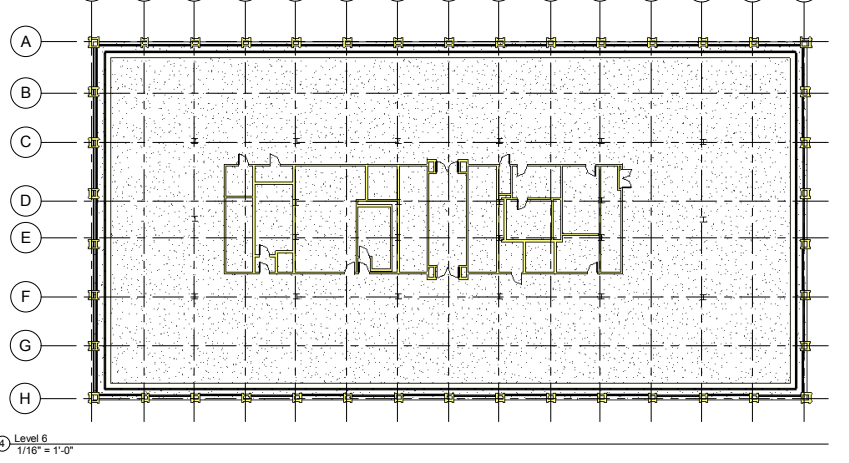

\begin{tabular}{|c|c|c|}
\hline $\begin{array}{c}\text { Version } \\
3\end{array}$ & Final Design & $12-3-15$ \\
\hline \multicolumn{3}{|c|}{ Daire Heneghan } \\
\hline \multicolumn{3}{|c|}{ Peering In } \\
\hline \multicolumn{3}{|c|}{ Floor Plans Lower } \\
\hline 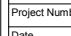 & & eering In \\
\hline Date & & $12 / 03 / 15$ \\
\hline cheoded By & $\frac{D}{c}$ & $\begin{array}{l}\text { eleghan } \\
\text { yFaculty }\end{array}$ \\
\hline
\end{tabular}


(1) (2) (3) (4) (5) (6) 7 (7) 8 ( 9 (9) (10) (11) (12) (13) (14) 15

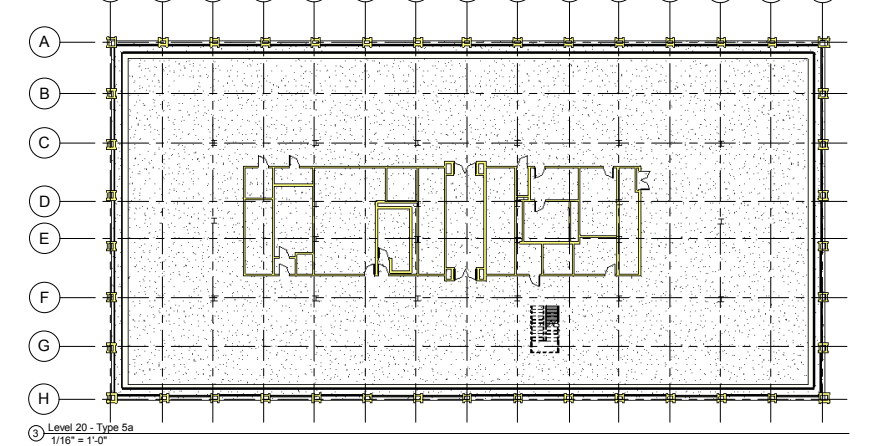

(1) (2) (3) (4) (5) (6) 7 (7) 8 ( ) 9 (9) 110 (11) (12) (13) (14)

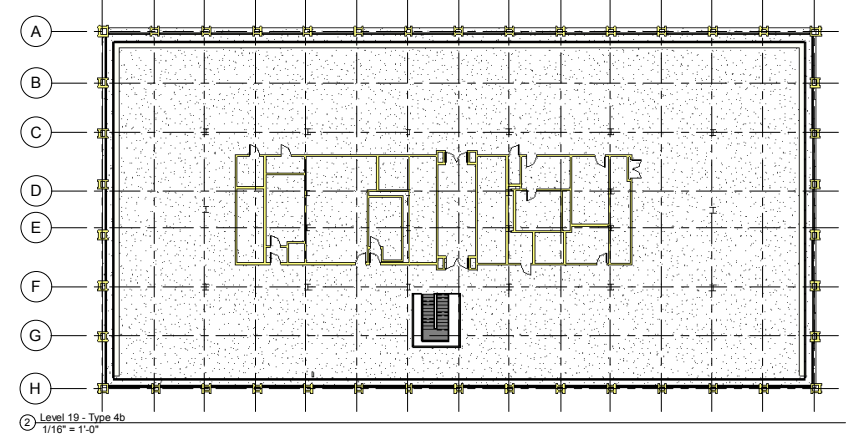

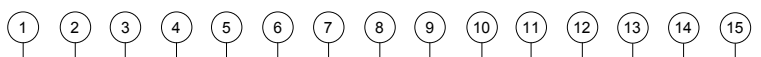

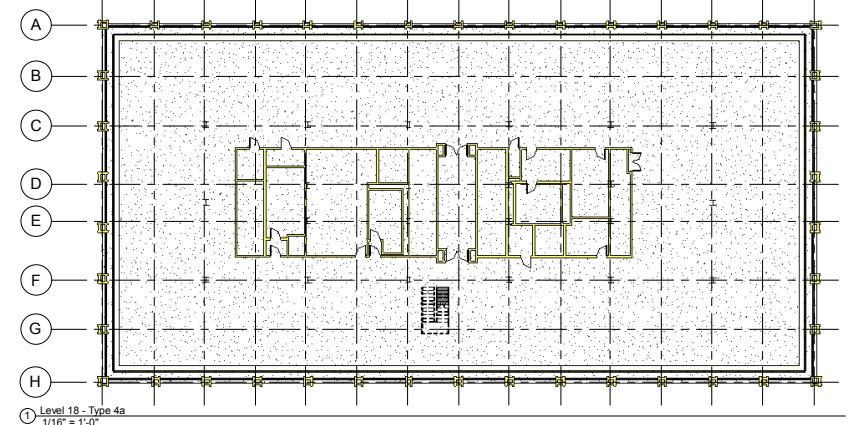

(1) (2) (3) (4) (5) (6) (7) (8) (9) (10) (11) (12) (13) (14) (15)

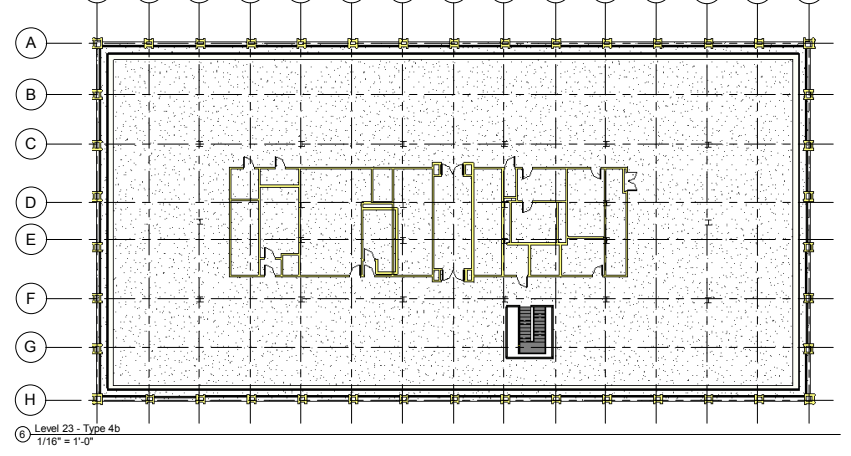

(1) (2) (3) (4) (5) (6) 7 (7) 8 (8) 9 (9) 10 (11) (12) (13) (14)

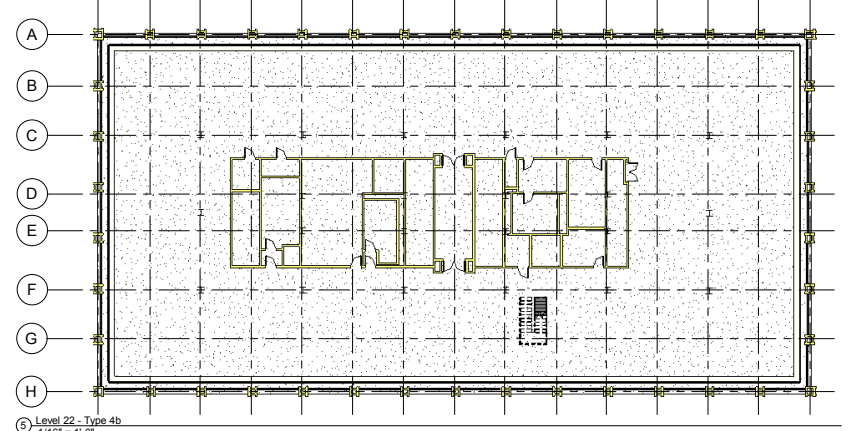

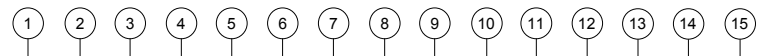

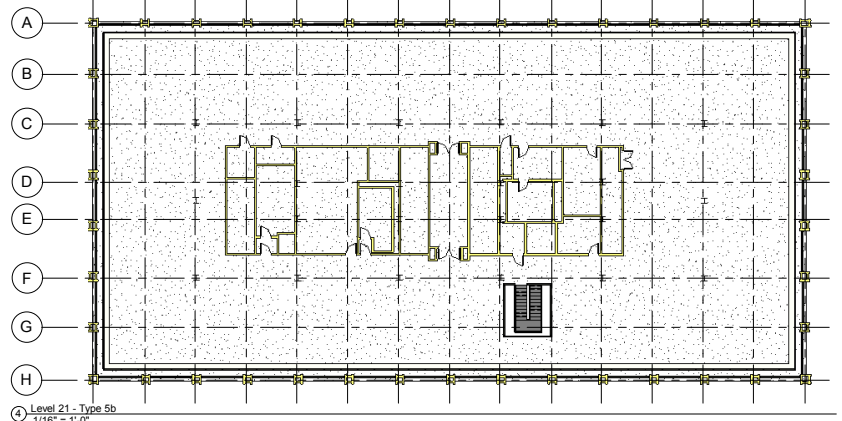




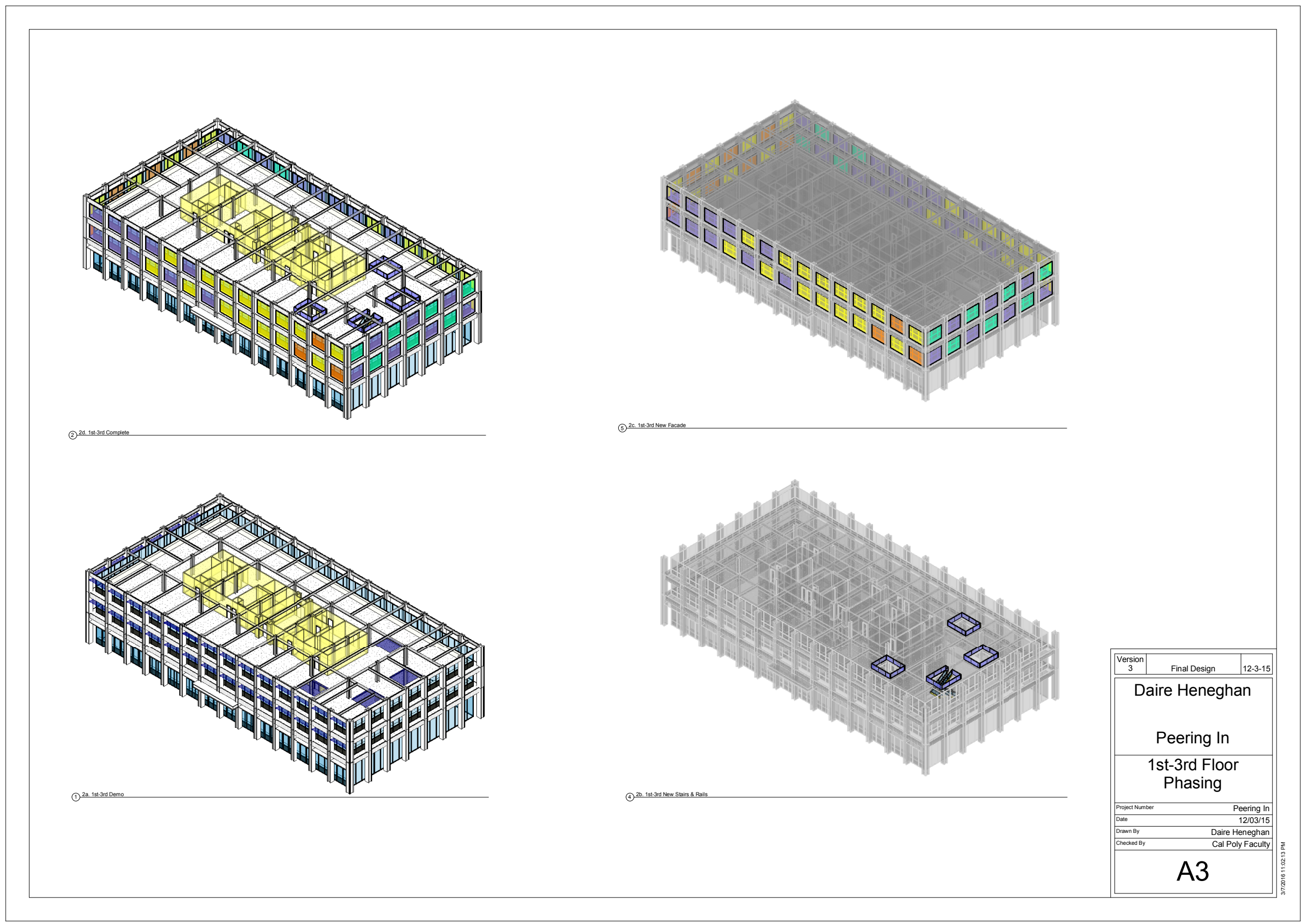




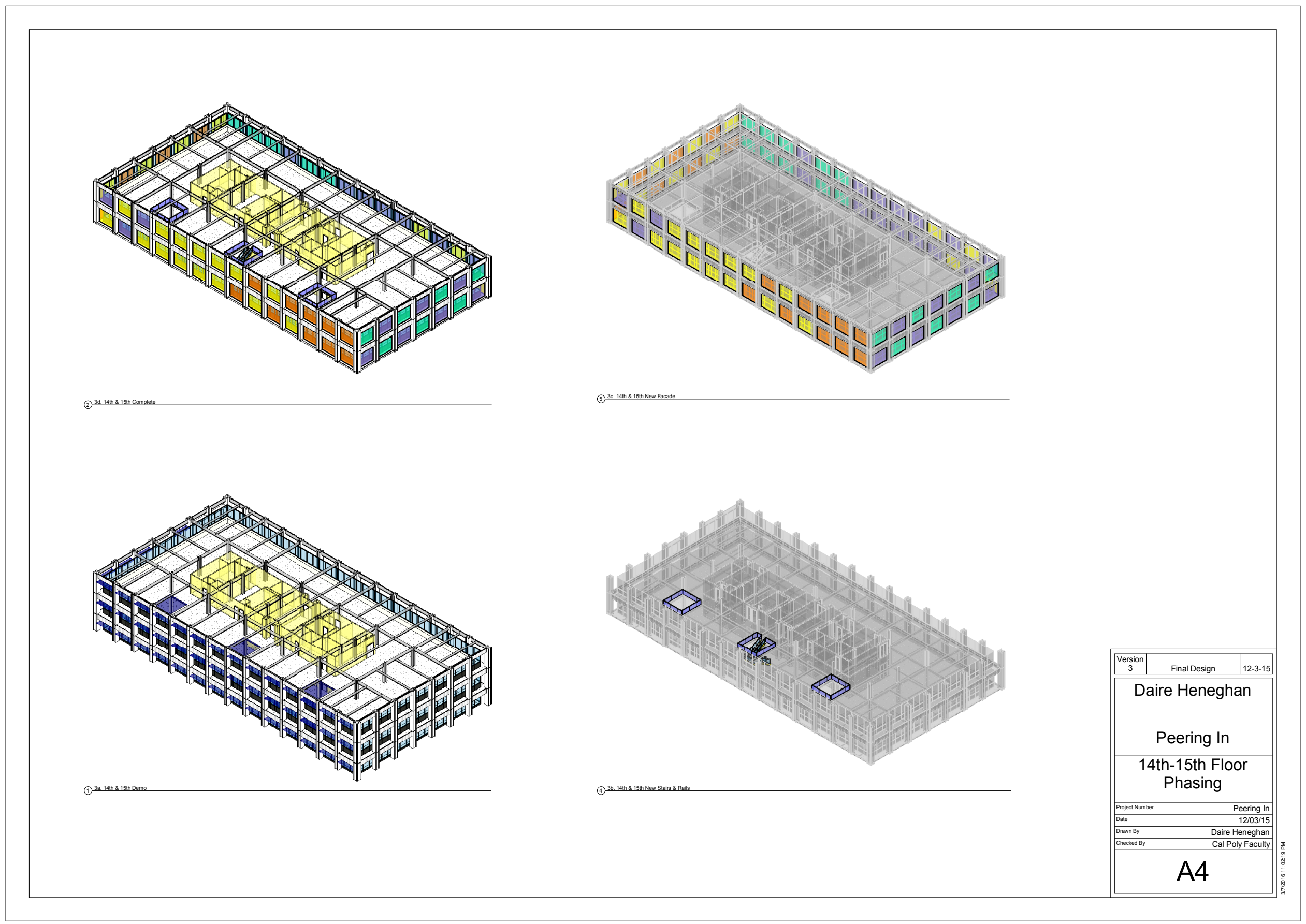




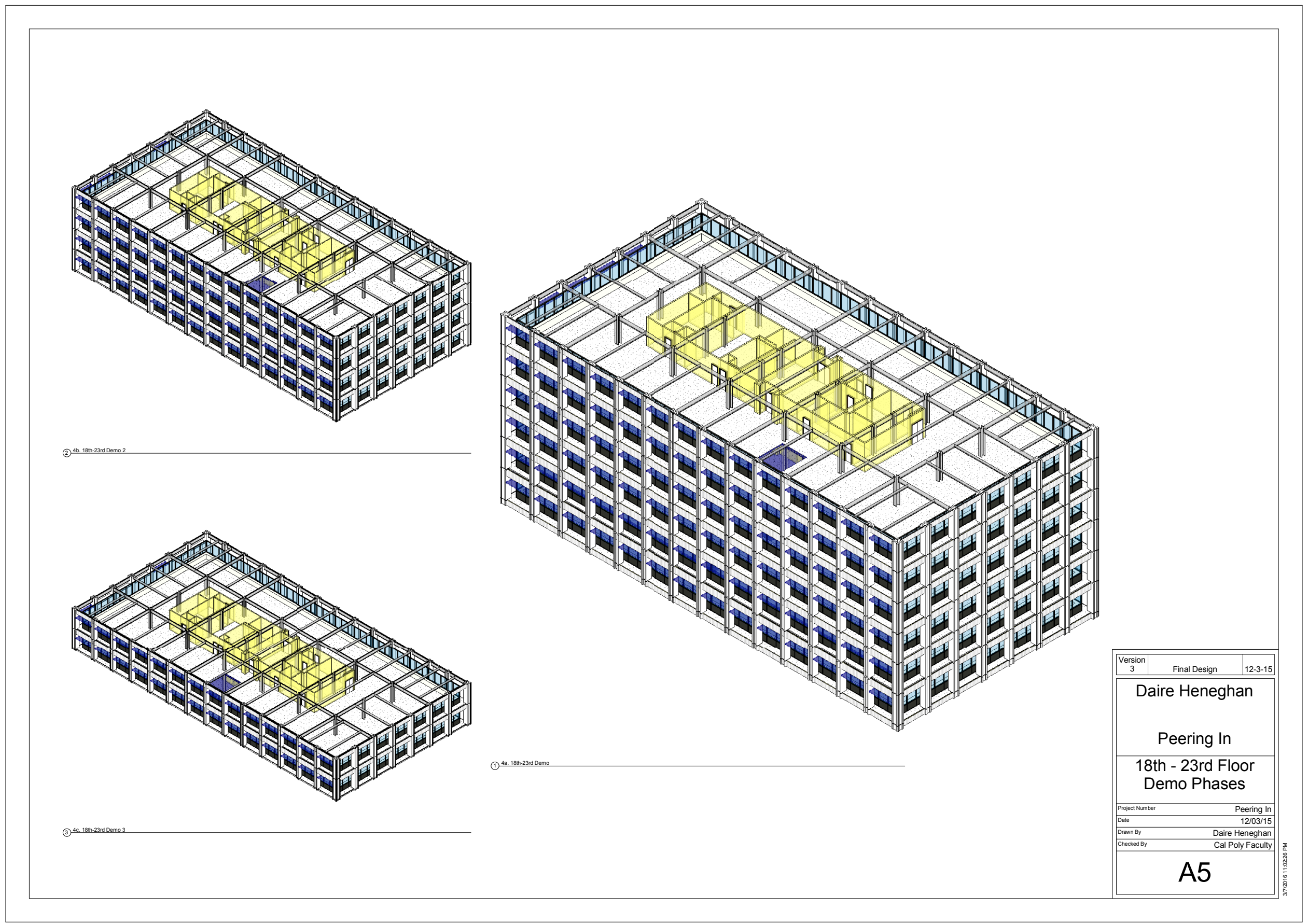




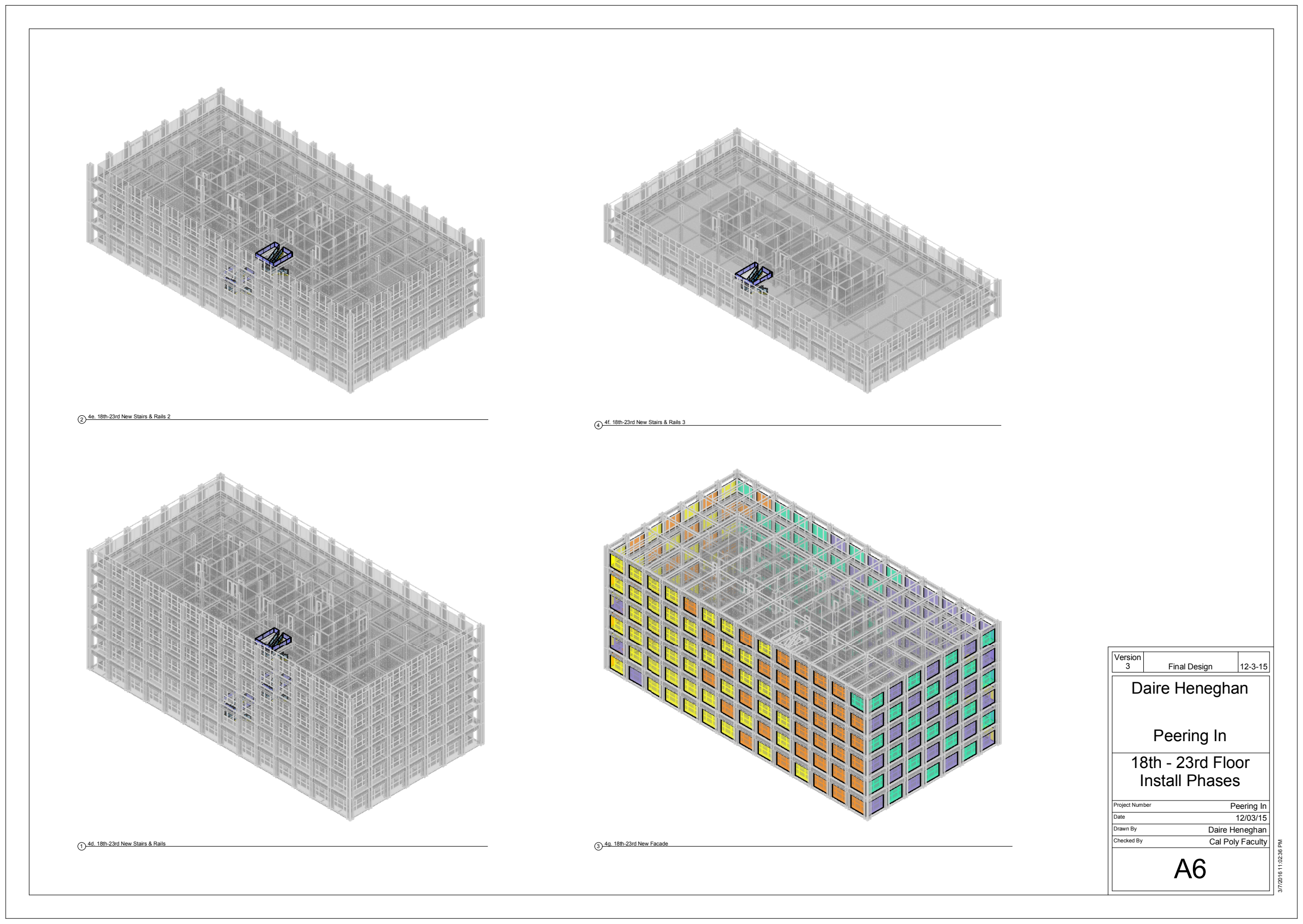




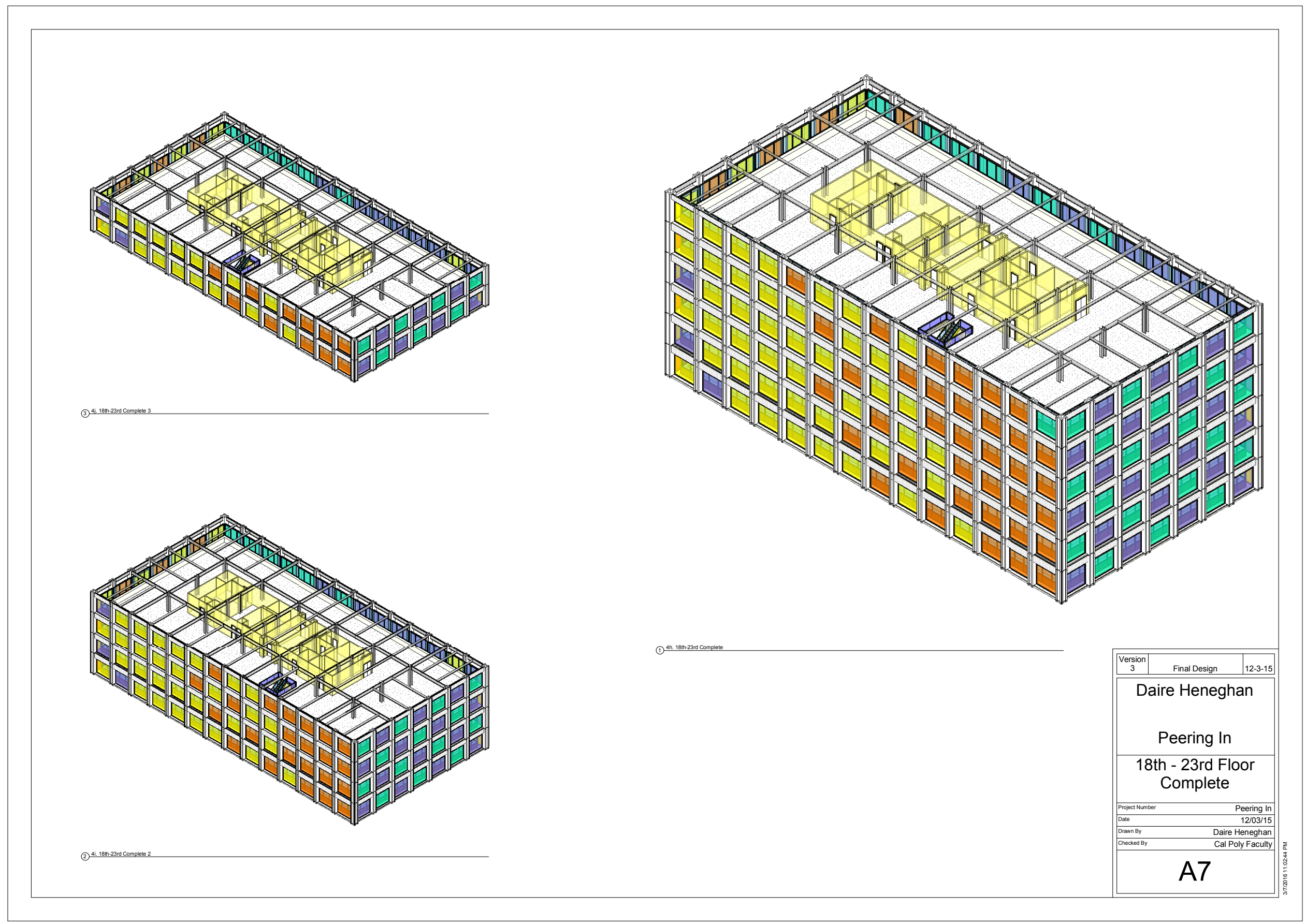




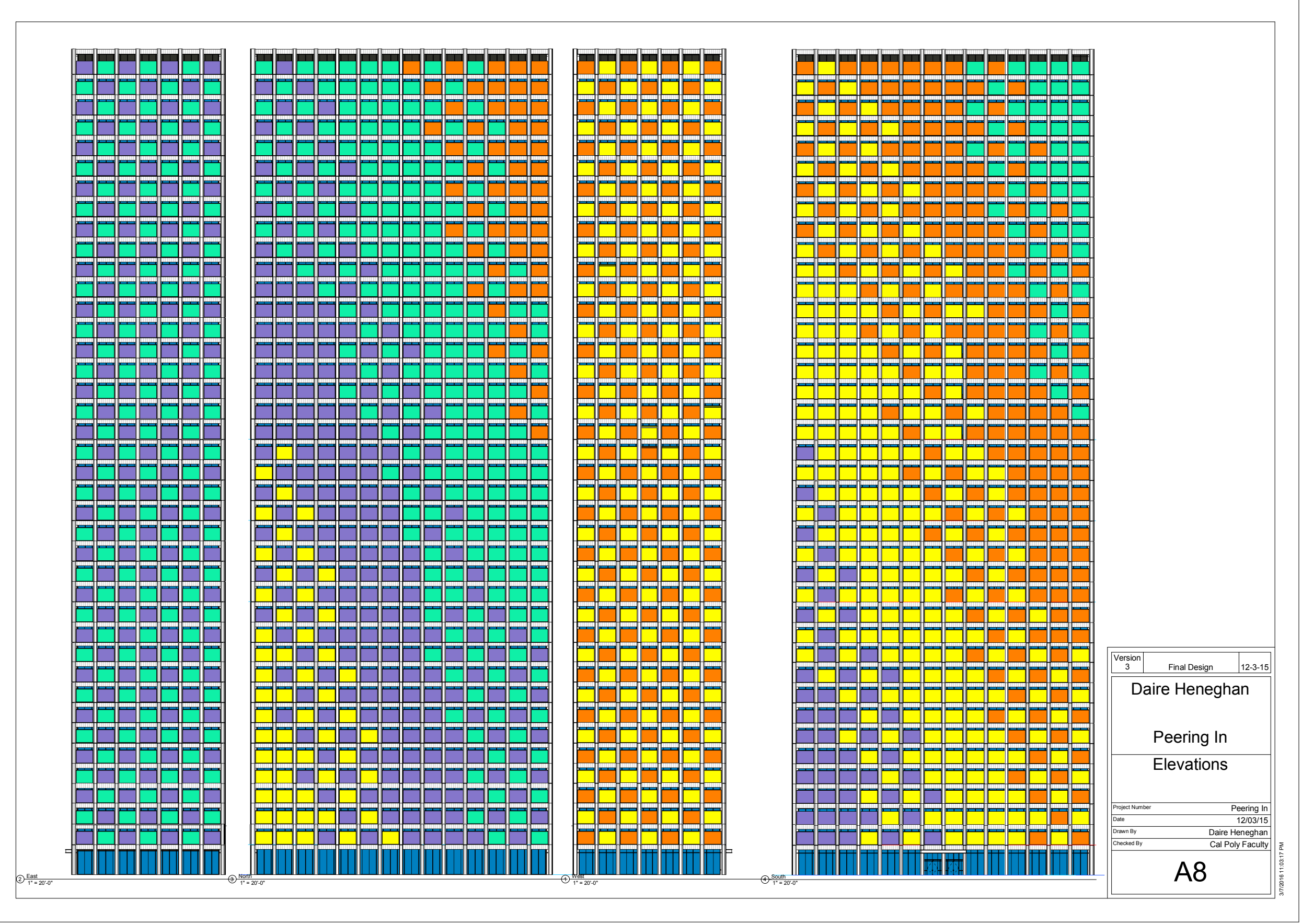




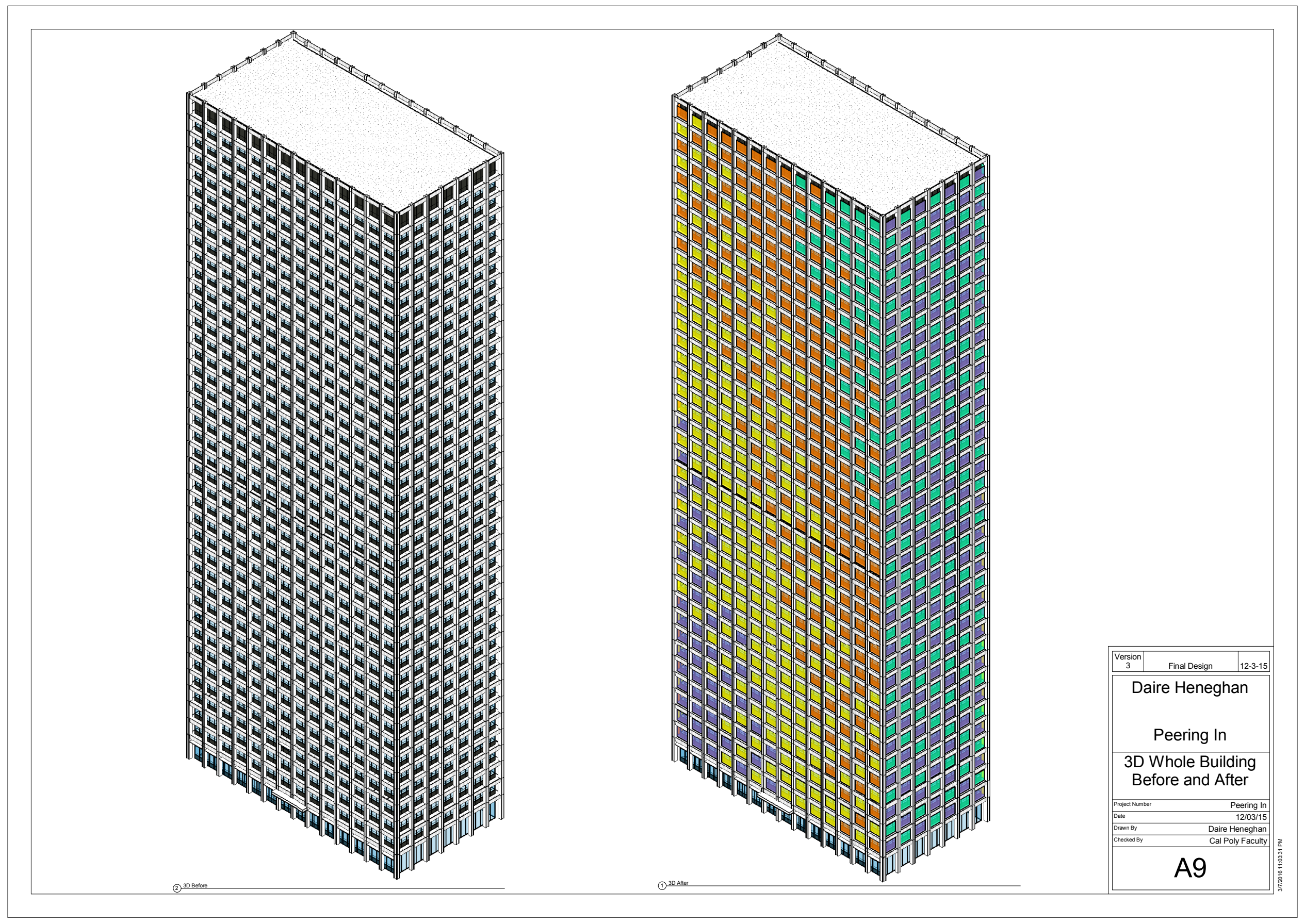




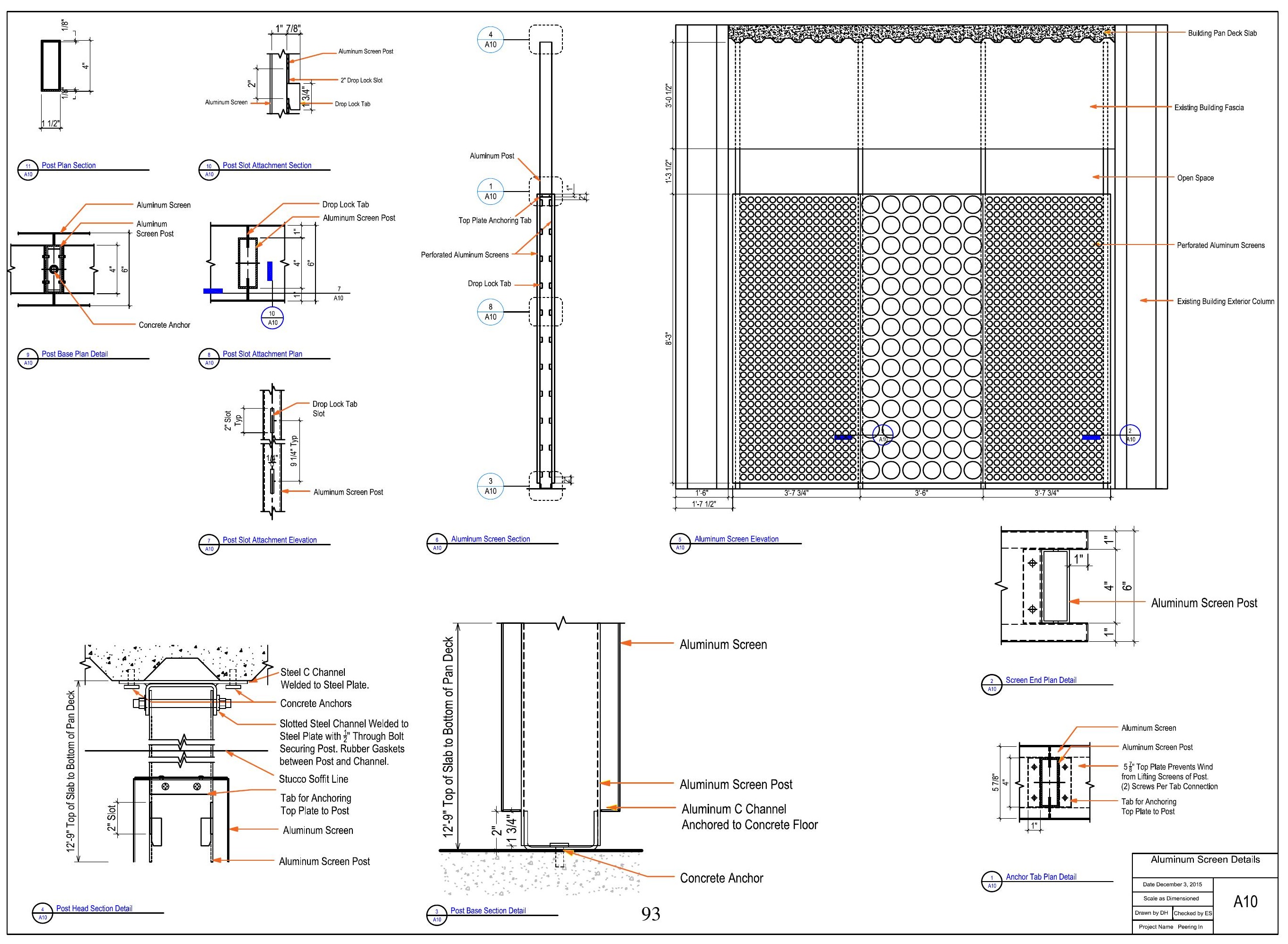







Peering In Drawings - Beach House - Sheet 8 to Sheet 9 


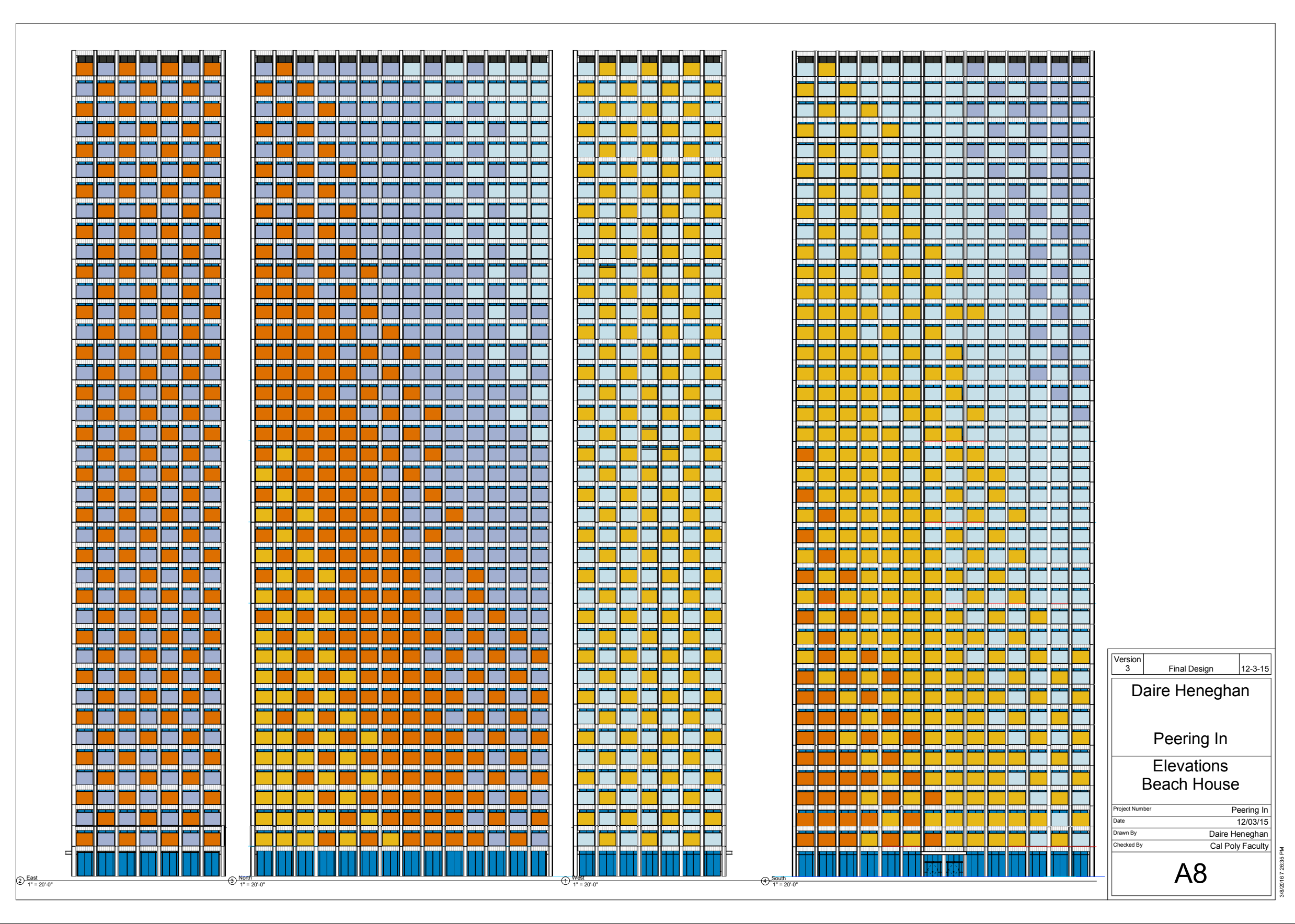




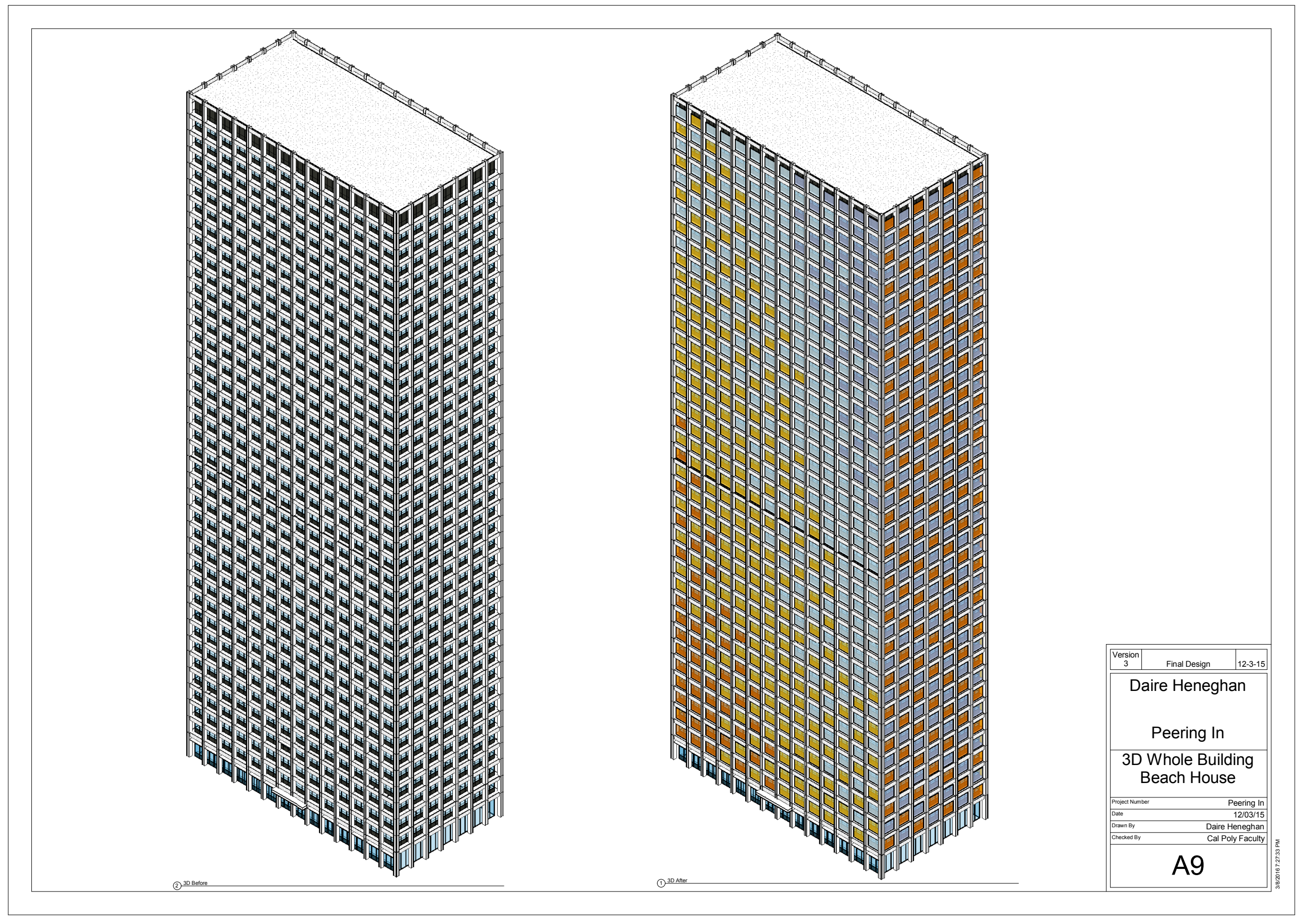


Peering In Drawings - Decor - Sheet 8 to Sheet 9 


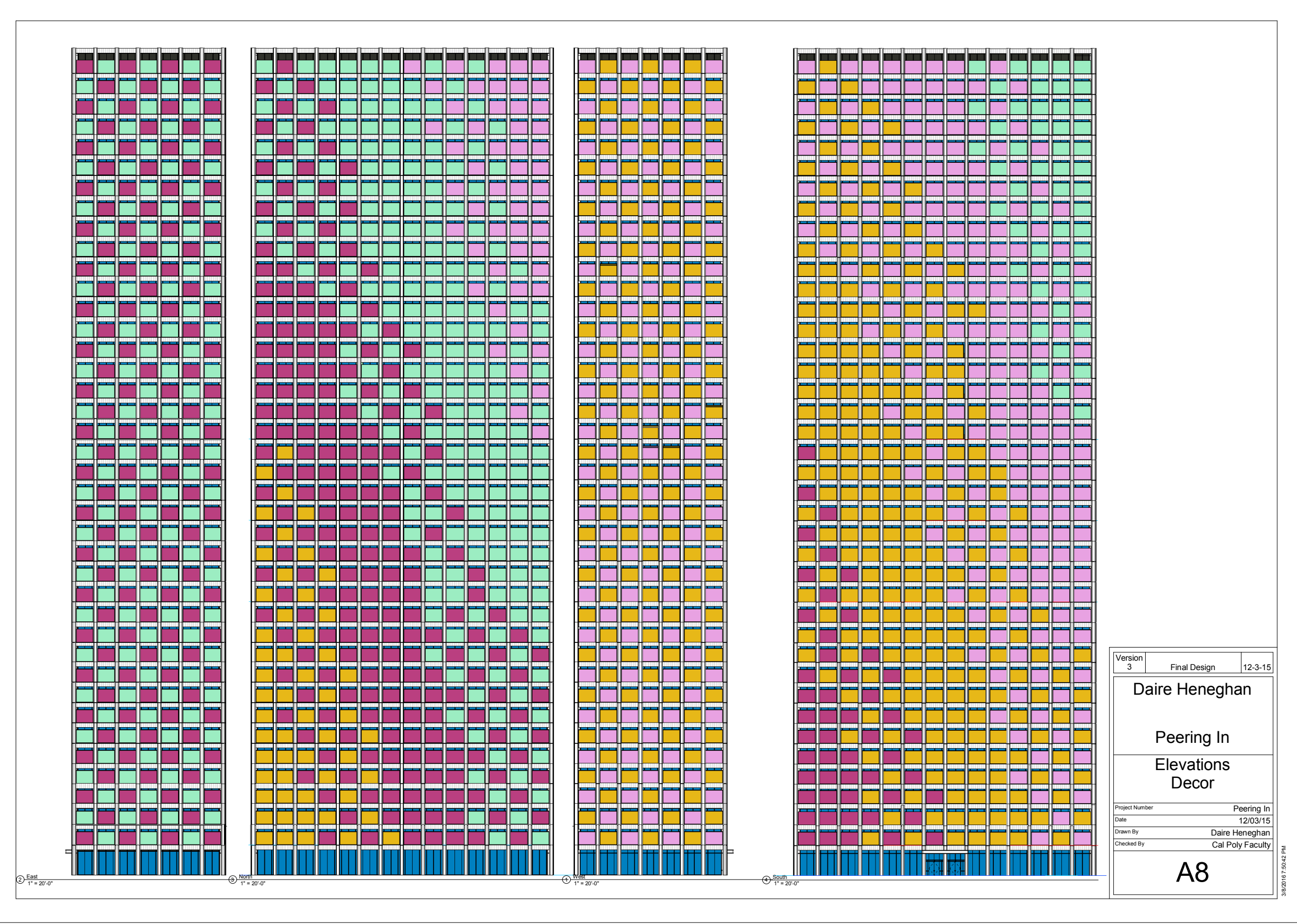




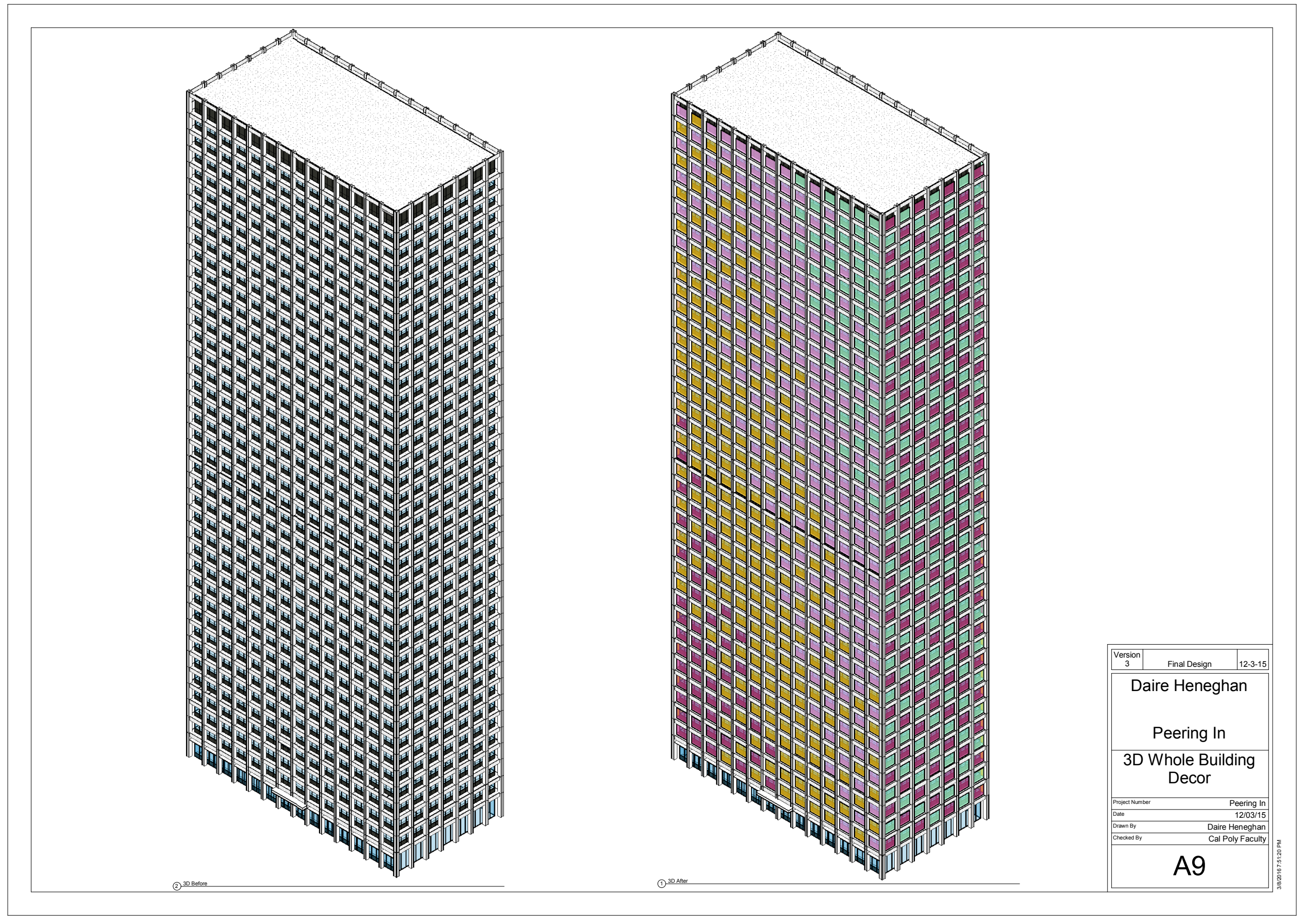


Appendix D - Peering In Construction Schedule 


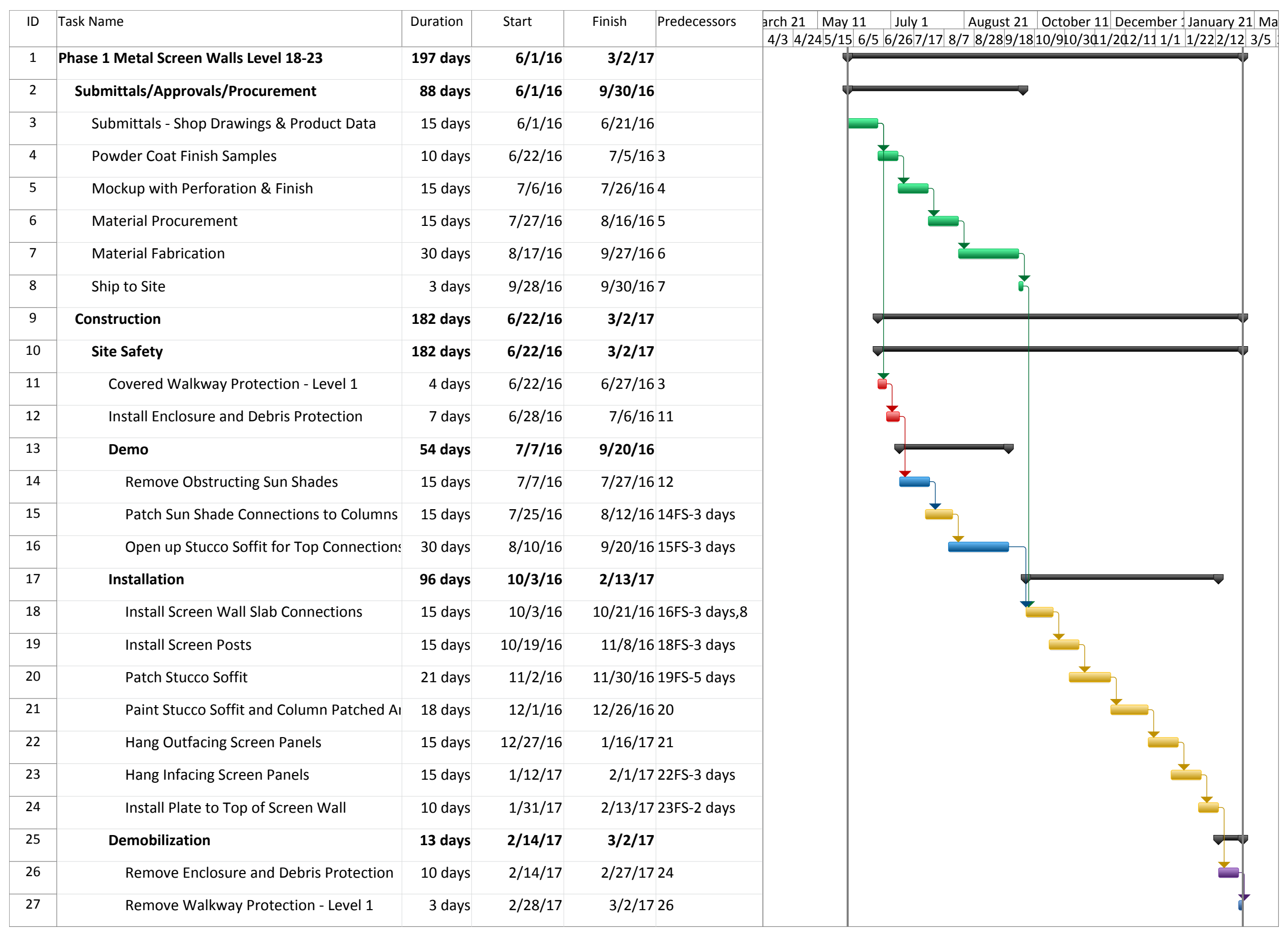

